\title{
Regeneration of Fe(II) from Fenton-derived ferric sludge using a novel biocathode
}

\author{
Wang, Guan; Tang, Kai; Jiang, Yufeng; Andersen, Henrik Rasmus; Zhang, Yifeng
}

Published in:

15th DWF Water Research Conference - Technical abstracts

Publication date:

2021

Document Version

Publisher's PDF, also known as Version of record

Link back to DTU Orbit

Citation (APA):

Wang, G., Tang, K., Jiang, Y., Andersen, H. R., \& Zhang, Y. (2021). Regeneration of Fe(II) from Fenton-derived ferric sludge using a novel biocathode. In 15th DWF Water Research Conference - Technical abstracts (pp. 3535). Danish Water Forum.

\section{General rights}

Copyright and moral rights for the publications made accessible in the public portal are retained by the authors and/or other copyright owners and it is a condition of accessing publications that users recognise and abide by the legal requirements associated with these rights.

- Users may download and print one copy of any publication from the public portal for the purpose of private study or research.

- You may not further distribute the material or use it for any profit-making activity or commercial gain

- You may freely distribute the URL identifying the publication in the public portal 


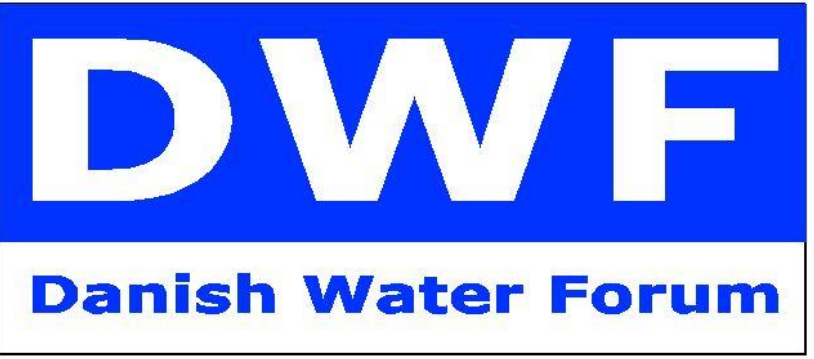

\section{$15^{\text {th }}$ DWF WATER RESEARCH CONFERENCE} 2nd February to $18^{\text {th }}$ March 2021 ONLINE

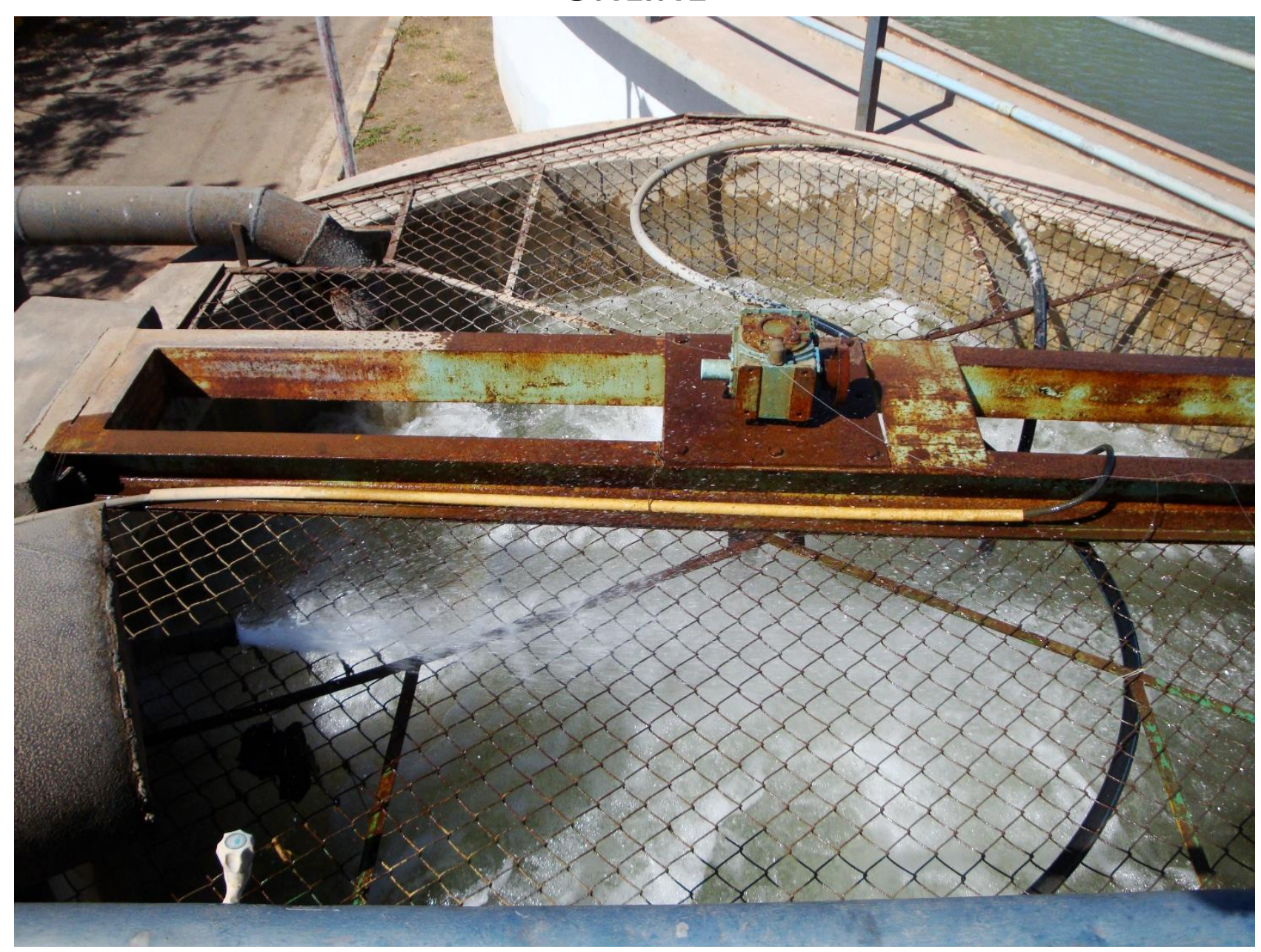

\section{Technical Abstracts}




\section{Table of Contents}

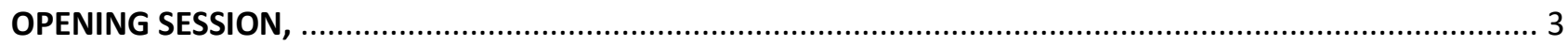

Session 1: Water supply and treatment technologies........................................................................ 4

Session 2: Præsentation af små- og mellemstore vandvirksomheder - Samarbejde mellem SMV'er og

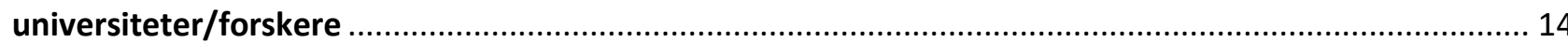

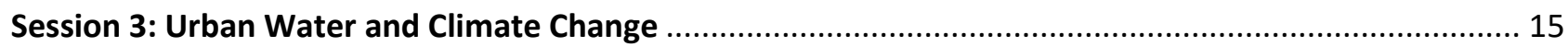

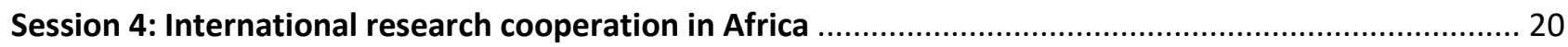

Session 5A: Advances in wastewater treatment technologies Part A .................................................. 30

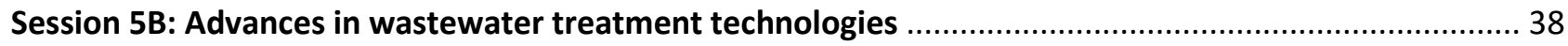

Session 6: Taking a moment - Bridging Seniors and Young Water Professionals..................................... 48

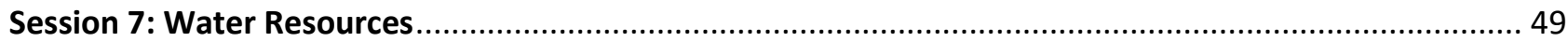

\section{1}

Danish Water Forum

Agern Alle 5, 2970 Hørsholm, Denmark.

www.danishwaterforum.dk, dwf@danishwaterforum.dk 
OPENING SESSION,

Tuesday $2^{\text {nd }}$ February 09:45-12:15

THEME: Water in EU and beyond

Moderator and Chair: Bjørn K. Jensen, Vice chairman, Danish Water Forum

09:45 Welcome, by Hans-Martin Friis Møller, Chairman, Danish Water Forum

09:55 Logistics, by Jesper Dannisøe, Director, Danish Water Forum

10:00 Focus on Water in the EU Parliament, by MP Pernille Weiss, Chairwoman of the Water Group in the EU Parliament

10:15 Horizon Europe. Opportunities for Danish Research and Innovation in the Water Sector, by Stefanie Bondy Jørgensen, Ministry of Higher Education and Science

10:35 Water4All. A Water Partnership within Horizon Europe, by Olivier Bouc, Agence Nationale de La Recherche, France

10:50 Q\&A

11:00 A New Research Membership in European Water Association, by Bjørn Kaare Jensen, European Water Association

11:10 Water Europe - a Gateway to Research in EU and Beyond, by Durk Krol, Water Europe

11:25 Danida and water resources research in developing countries, by Mike Speirs, Ministry of Foreign Affairs of Denmark

11:40 International Cooperation in IFD Grand Solution Projects, by NN, InnovationFund Denmark

11:55 Q\&A

12:05 Wrap up, by Jesper Dannisøe, Director, Danish Water Forum

12:10 Lunch break (on your own!!)

NO ABSTRACTS FOR THIS SESSION 


\section{Session 1: Water supply and treatment technologies}

\section{February 13:00 - 16:00, Teams}

\section{Chair: Hans-Jørgen Albrechtsen, DTU Envir. Co-chair: Torben Lund Skovhus, VIA University College}

13:00 Hans-Jørgen Albrechtsen: Welcome

13:05 Jesper Dannisøe: Logistics

13:10 Occurrence of toxic pyrrolizidine alkaloids from butterbur in surface water and seepage water: Vaidotas Kisielius, Jawameer R. Hama, Bjarne W. Strobel, Hans Chr. Bruun Hansen, Lars Holm Rasmussen

13:25 Spatial analysis of water quality and income in Europe: Erik Brockwella, Katarina Elofsson, George Marbuah, and Sandra Nordmark

13:40 Membrane technology for removal of pesticide residues BAM, MCPA and MCPP in groundwater-based drinking water treatment: Mahdi Nikbakht Fini, Henrik Tækker Madsen, and Jens Muff

13:55 Preconcentration by reverse osmosis allows for prolonged biodegradation of pesticide residue BAM in pilot scale sand filters: Morten Dencher Schostag, A. Gobbi,, M.N. Fini, L. Ellegaard-Jensen, N. Badawi,, L.H. Hansen, J. Muff, A.C. Koch, J. Aamand, and C.N. Albers

14:10 Break

14:25 The synergistic integration of advanced oxidation and nanofiltration - effect on fouling and rejection of Bisphenol A: Katarzyna Janowska, Xianzheng Ma, Vittorio Boffa, Mads Koustrup Jørgensen, Victor M. Candelari

14:40 A Novel Dual-reaction Centre Catalyst for Effective Degradation of Persistent Organic Pollutants (POPs): Zhiqun Xie, Zongsu Wei

14:55 InnoFlot: Resource-efficient process optimization by applying flotation technology with food grade flocculants: Emil Holm, L.E. Jensen, L.M. Agneessens, C. Kragelund Rickers, J. Rasmussen, E.J. Jurgensen:

15:10 Surface disinfection using ozonated water - effects on food quality: Lars Holm Rasmussen, D.N. Lindqvist, M. Rosenfjeld:

15:25 Measured and calculated Calcium Carbonate Precipitation Potential: S. V. Afshar, HJ. Albrechtsen, Martin Rygaard

15:40 Hans-Jørgen Albrechtsen: Closing remarks 


\title{
Occurrence of toxic pyrrolizidine alkaloids from butterbur in surface water and seepage water
}

\author{
Vaidotas Kisielius*, Jawameer R. Hama**, Bjarne W. Strobel, Hans Chr. Bruun Hansen, Lars Holm \\ Rasmussen***
}

\begin{abstract}
Introduction: Many plant species produce highly toxic compounds as a part of their specific mechanism of defence. It is estimated that among the most common toxic plant secondary metabolites are pyrrolizidine alkaloids (PAs) (e.g. from Asteraceae, Boraginaceae, Fabaceae). The PAs are well-documented mutagenic, carcinogenic and hepatotoxic compounds. Health authorities recommend minimizing human exposure to PAs via food, medicinal products and natural remedies to ensure consumer health and safety. Though these compounds often occur in plant biomass in large quantities, their environmental fate is largely unknown. The aim of our research was to create necessary analytical methods and to investigate the compounds in water resources.
\end{abstract}

Methods and data: A site with a channelized surface water stream and a system of groundwater abstraction wells was selected in eastern Denmark (Humleore forest). The shores of the stream and the land surface surrounding several wells were infested with the invasive PA-producing butterbur plant (Petasites hybridus (Asteraceae)) (Rød hestehov). The wells consist of a vertical pipe providing access to deep groundwater ( $\sim 60 \mathrm{~m}$ depth) and a surrounding casing supported by concrete rings that naturally fill with seepage water from the soil (2.2-3.0 $\mathrm{m}$ depth). We sampled the stream, the wells infested with Petasites and the control wells with no Petasites around them, and analysed the results in the University of Copenhagen with a recently developed LC-MS/MS-based method ${ }^{1}$.

Results: We measured a base flow PA concentration of $\sim 70 \mathrm{ng} / \mathrm{L}$ in the stream water. After intense rain the PA concentration increased 10 fold. In addition, we measured up to $230 \mathrm{ng} / \mathrm{L}$ of the PAs in seepage water from groundwater wells. The dominant PAs in both water types corresponded to the most abundant PAs in the butterbur plant (senkirkine, senecionine, senecionine $\mathrm{N}$-oxide). No PAs were measured in the deep groundwater ( $60 \mathrm{~m}$ depth) in the particular case study, but their presence in the seepage water point to risk of groundwater contamination if the wells become unhermetic ${ }^{2}$.

Discussion and take-home message: The study presents discovery of persistent plant toxins in well water and their associated risks. The study is part of an European research network demonstrating that natural toxins often occur as important emerging water contaminants https://natoxaq.ku.dk/publications/.

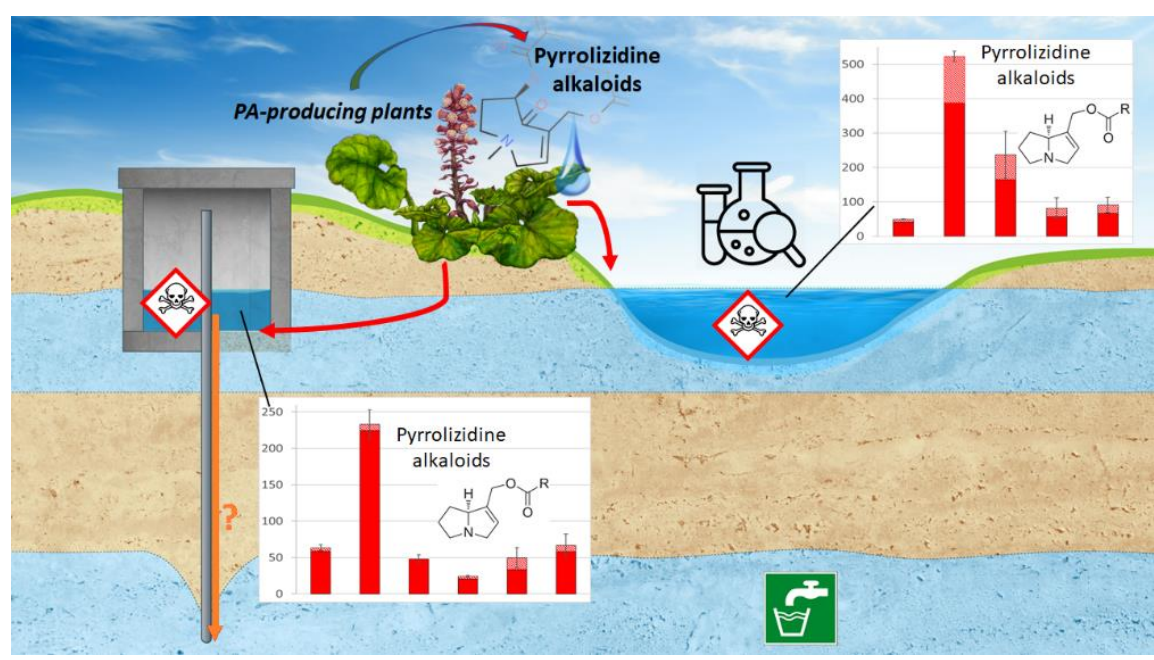

*vaidotas.kisielius@gmail.com: University College Copenhagen, Sigurdsgade 26, 2200 Copenhagen N

**jawameer@plen.ku.dk: University of Copenhagen, Thorvaldsensvej 40, 1871 Frederiksberg C

***Ihra@kp.dk: University College Copenhagen, Sigurdsgade 26, 2200 Copenhagen N

${ }^{1}$ Hama J.R. \& Strobel B.W. Pyrrolizidine alkaloids quantified in soil and water using UPLC-MS/MS. RSC Adv. 9, 3035030357 (2019).

${ }^{2}$ Kisielius V., Hama J.R., Skrbic N., Strobel B.W., Hansen H.C.B., Rasmussen L.H. The invasive butterbur contaminates stream and seepage water in groundwater wells with toxic pyrrolizidine alkaloids. Sci Rep 10, 19784 (2020). 


\title{
Spatial analysis of water quality and income in Europe
}

\author{
Erik Brockwella, Katarina Elofssona,b,c* George Marbuahc, and Sandra Nordmarkc
}

Introduction: The European Union (EU) adopted the so-called Water Framework Directive (WFD) in the year 2000 to ensure that the Member States achieve good ecological status in all surface water bodies. Despite progress, only $40 \%$ of surface water bodies currently meet this requirement. This raises a concern regarding the potential of policy changes to counteract the increasing scale of production and consumption, with respect to the impact on water quality. The purpose of this study is to empirically investigate the relationship between water quality and income within the European Union, considering spatial interdependences across countries.

Methods and data: We apply a spatial econometrics framework using panel data, at the national level, for twenty EU countries across seventeen years, 1998 to 2014. Furthermore, we account for the role of human and livestock population size, institutional quality and economic openness for water quality.

Results: Results show that a significant EKC relationship is seen with an inverted N-shaped relationship between income and water quality degradation. Water quality is decreasing in income for low income levels, increasing in income when GDP per capita is between 13,323 and 37,507 USD, and deteriorating for high income levels. Eight out of twenty countries have income levels associated with a declining water quality. Spatial spillovers between countries are significant and positive. Higher livestock density levels are associated with lower levels of water quality, while institutional quality and openness to trade are positively associated with water quality.

Discussion and take-home message: A possible interpretation of the results is that moderate increases in income lead to increased pollution abatement efforts, benefitting water quality. For further increases in income, available technologies might not be sufficient to sustain low pollution levels. Positive spillovers between countries indicate the existence of institutional spillovers and learning. Technological innovations and institutional cooperation and learning may help to counteract decreasing water quality for higher income levels.

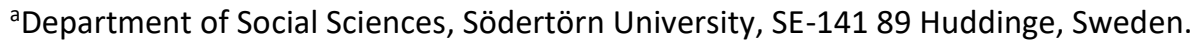

${ }^{b}$ Department of Environmental Sciences, Aarhus University, Frederiksbergsvej 399, DK-4000 Roskilde, Denmark. 'Department of Economics, Swedish University of Agricultural Sciences, Box 7013, SE-750 07 Uppsala, Sweden.

*Presenter.

\section{Membrane technology for removal of pesticide residues BAM, MCPA and MCPP in groundwater-based drinking water treatment}

\author{
M. Nikbakht Fini ${ }^{*}, A A U-B I O$, Henrik Tækker Madsen ${ }^{* *}$, SaltPower, and Jens Muff ${ }^{* * *}, A A U-B I O$
}

\begin{abstract}
Introduction
Groundwater is the main resource of drinking water in Denmark, but it is threatened by pesticide pollution. The pesticide metabolite, 2,6-dichlorobenzamide (BAM), as well as phenoxy acid herbicides, MCPA and MCPP, are frequently found in Danish groundwater. Sand filtration of aerated groundwater is often used at Danish waterworks to remove iron, manganese, ammonium and organic matter which is ineffective towards removal of most pesticides leading to an increased consumer health risks if the contaminated abstraction wells are not abandoned. Therefore, new treatment concepts are required to meet the drinking water quality guidelines. Membrane separation may be an effective choice of treatment technology towards the pesticides. The presented results in the current study show that commercially available nanofiltration (NF) and reverse osmosis (RO) membranes are efficient in the rejection of MCPA, MCPP, and BAM. The study also presents results on forward osmosis (FO) separation of pesticides using Aquaporin membranes, a new and interesting approach to membrane filtration in water prone to scaling. FO is demonstrated to be less impacted by high concentrations of scalants. In conclusion, the paper shows that membrane separation is an efficient technology for treatment of pesticides in groundwater-based drinking water production
\end{abstract}




\title{
Results and discussion
}

In NF/RO studies, four commercial membranes were tested to treat groundwater polluted by targeted pesticides. It was found that NF membranes were not applicable for removal of pesticides while RO and LPRO membranes both could reject pesticides $>92 \%$ (Figure 1). However, it was observed that NF membranes might be effective in micropollutant-level concentration for phenoxy acid herbicides, MCPA and MCPP, as they hold negative charges and could be repelled by negatively charged NF membranes. Therefore, the concentration of pollutants might influence differently the membrane filtration depending on the properties of both membranes and pesticides and consequently, the separation mechanism of pesticide removal. Studies were also completed on FO process. The use of aquaporin FO membranes in different FO systems from a very tiny setup and a prevalent lab-scale system to a hollow fiber pilot-scale setup revealed that the obtained results from the tiny equipment could be translated to pilot-scale rejection values. This can promote the use of FO process in different applications with a simple, quick, and inexpensive method. The aquaporin FO membrane demonstrated an excellent rejection of $>98 \%$ for all the pesticides while having a superior permeation flux compared to other few commercial FO membranes.

In scaling propensity studies between RO and FO processes, the threshold concentration of a model scalant in the feed water, calcium sulfate (gypsum), was found to be higher for FO process when the same membrane was used in a similar setup to record flux decline as a result of scaling. Therefore, it can be concluded that FO is less prone to scaling and can be an alternative solution where water has high ionic strength.

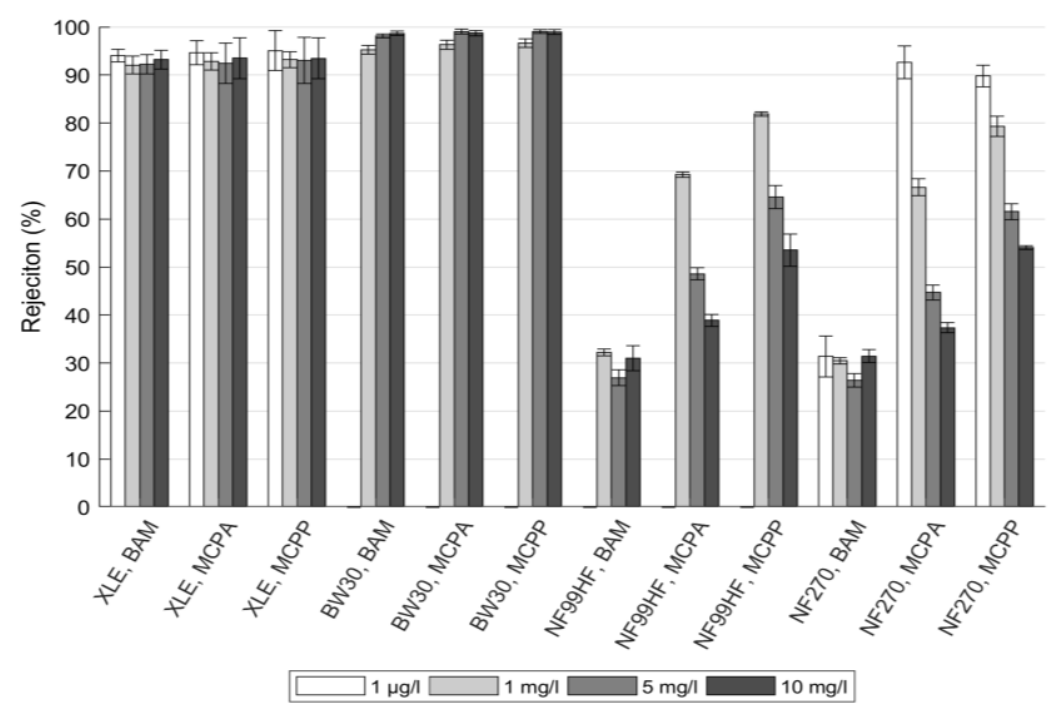

Figure 1. Rejection values at different pesticide concentrations in Milli-Q water using different commercial membranes.

\section{Preconcentration by reverse osmosis allows for prolonged biodegradation of pesticide residue BAM in pilot scale sand filters}

\author{
Morten Dencher Schostag, GEUS, A. Gobbi, KU-PLEN, M.N. Fini, AAU-BIO, L. Ellegaard-Jensen, AU-ENVS, N. \\ Badawi, GEUS, L.H. Hansen, KU-PLEN, J. Muff, AAU-BIO, A.C. Koch, Silhorko-Eurowater, J. Aamand, GEUS, \\ and C.N. Albers, GEUS.
}

\section{Introduction:}

Groundwater contamination by pesticide residues poses a great threat to the quality of drinking water. With new nontarget screening methods, it can be expected that more compounds will be added to the list of groundwater contaminants exceeding the EU legal limit for pesticides in drinking water of $0.1 \mu \mathrm{g} / \mathrm{l}$. Therefore, there is an urgent need for solutions to remediate pesticide polluted drinking water. One way to remediate pesticide polluted drinking water is to bioaugment sand filters with specific pesticide degrading bacteria. We have previously bioaugmented sand filters with the 2.6- 
dichlorobenzamide (BAM) degrading Aminobacter sp. MSH1 bacterium to remediate BAM-polluted drinking water. This resulted in complete degradation of BAM, but the efficiency decreased due to leaching of degrader bacteria.

\section{Method and data:}

In this study, we used reverse osmosis (RO) membrane filters to purify BAM polluted groundwater. This produces ultrapure water, but also a retentate with higher BAM and nutrients concentrations. The concentrate was then treated in sand filters added MSH1. The volume of retentate water was app. 10 times lower than that of the total starting volume. This decreased the volume of water, which was treated in the sand filters, while the inlet water contained higher concentrations of BAM and nutrients beneficial for the BAM-degrading process. First, we investigated the influence of the MSH1 density and water residence time on the period of efficient BAM-degradation, using small laboratory columns. Later, the combined RO-sand filter approach was up-scaled to a mobile pilot plant facility with a XLE RO membrane unit and two bioaugmented biofilters. The pilot plant was connected to abandoned drinking water well in Esbjerg, Denmark (BAM conc. $0.3 \mu \mathrm{g} / \mathrm{l})$. First, the pilot plant was used to compare the efficiency of the MSH1 bioaugmented biofilters to treat either groundwater directly from the well or the concentrate of the RO filtration (10x concentrated groundwater) at a residence time of $30 \mathrm{~min}$. Later, both biofilters were fed membrane retentate, with residence times of 30 and 132 min.

\section{Results:}

The small laboratory column experiments showed that MSH1 density had an impact on the length of the period BAM

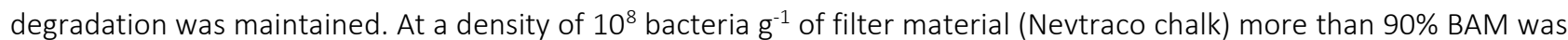
removed for 70 days. Longer resistance times also showed to increase the period of efficient degradation and at a residence time of 132 min. efficient degradation was maintained for 70 days.

Pilot plant results showed no effect with or without membrane retentate and showed significant BAM removal for less than 7 days. The loss of BAM degradation efficiency could be correlated to the loss of MSH1. In the second pilot plant attempt, difference in retention time showed to increase the length for $>85 \%$ BAM removal from 2 days to more than 64 days (Figure 2).

\section{Discussion and take-home message:}

Here we have shown that cell density and residence time both have an impact on the removal of BAM in a biofilter at both lab scale and pilot scale, giving best conditions for degradation by using $10^{8}$ cells $\mathrm{g}^{-1}$ filter material with long residence time of $132 \mathrm{~min}$. This combined approach using RO membrane techniques combined with bioaugmented biofilters is a novel promising solution to remediate pesticide polluted drinking water. This study can be seen as a proof of concept for bioaugmentation combined with membrane techniques, which may be used with other xenobiotic degrading bacteria.

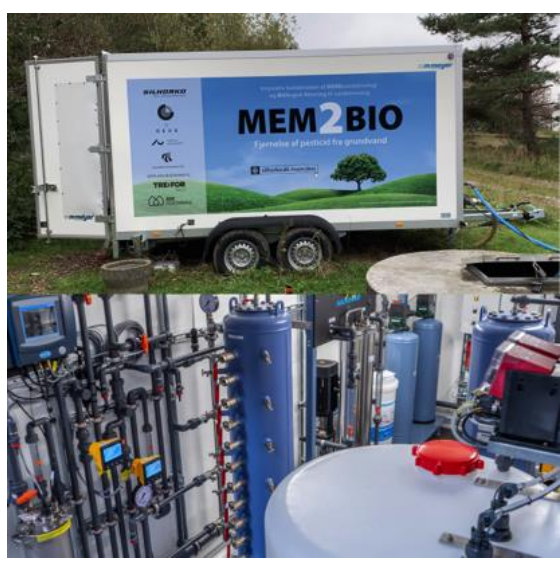

Figure 1: Pilot plant at the site in Esbjerg

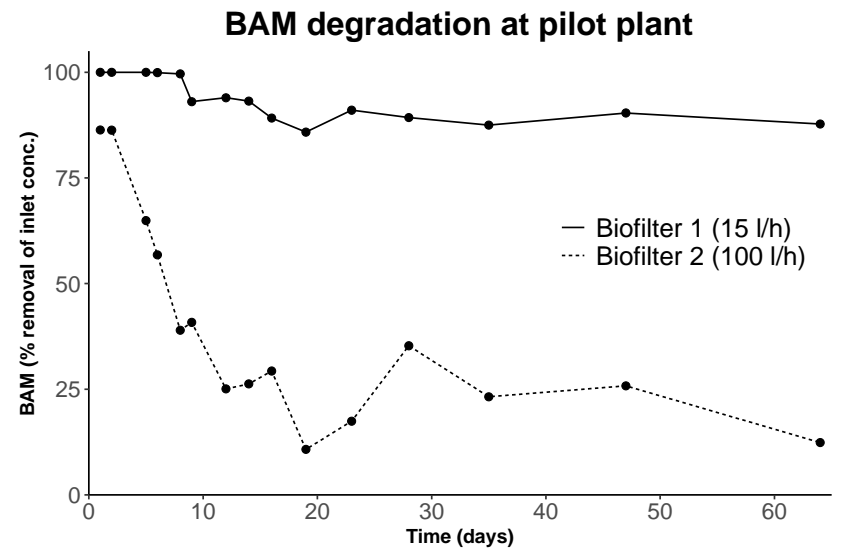

Figure 2: BAM removal efficiency as \% of inlet concentration in the outlet water of the two biofilters with different residence times at the pilot plant. 


\title{
The synergistic integration of advanced oxidation and nanofiltration - effect on fouling and rejection of Bisphenol A
}

\author{
Katarzyna Janowska ${ }^{1 *}$, Xianzheng $\mathrm{Ma}^{1 * *}$, Vittorio Boffa ${ }^{1 * * *}$, Mads Koustrup Jørgensen ${ }^{1 * * *}$, Victor M. Candelario $^{2 * * * *}$
}

Due to limitation of usable water resources and increasing global water crisis it is relevant to improve water and wastewater treatment efficiency focusing on elimination of contaminants of emerging concern. These contaminants are present in very low concentrations and are difficult to remove by the conventional physiochemical and biological treatments. However, among the available methods, membrane filtration and advanced oxidation processes are gaining increasing attention due to their high efficiency in removing organic pollutants from water systems. In the treatment of municipal WWTP effluent the development of ceramic membranes is rapidly growing and may be used as a possible alternative to the polymeric membranes due to their higher stability, larger permeability and lower tendency for fouling. Moreover, inorganic NF membranes show great potential for water desalination and detoxification because they are easy to clean and have long lifespan. At the same time, the thermocatalytic perovskites demonstrate advantages over other advanced oxidation processes as they have no need for addition of chemicals or light sources, hence low energy consumption and simplicity of operation.

Therefore, we propose an integrated process of pressure-driven inorganic nanofiltration membrane and advanced oxidation based on the generation of reactive oxygen species by a thermocatalytic perovskite, namely Ce-doped strontium ferrate. $5 \%$ mol $\mathrm{Al}_{2} \mathrm{O}_{3}$-doped amorphous silica membrane used for nanofiltration tests was prepared via the sol-gel method. The perovskite-type cerium-doped strontium ferrite $\mathrm{Sr}_{.85} \mathrm{Ce}_{0.15} \mathrm{FeO}_{3-\delta}$ (SCF) was synthesized by solution combustion method from citric acid. Effluent from Aalborg Wastewater Plant West (WWTP) was heated and filtered for few hours in experiments with $(1 \mathrm{mg} / \mathrm{mL})$ and without addition of thermocatalyst. The filtrations were carried out at a temperature of $50^{\circ} \mathrm{C}$ and the effluent was spiked with BPA to reach a concentration of $10 \mathrm{mg} / \mathrm{L}$. The cross flow was set up to $0.2 \mathrm{~L} / \mathrm{s}$ and the feed was pressurized to 6 Bars. The BPA rejection was monitored in the feed and the permeate by high-performance liquid chromatography (HPLC). Results showed that the BPA rejection for tests without catalyst was $98.6 \%$, while for test with catalyst it reached $99.4 \%$. The water permeability of effluent samples without catalyst was higher than for samples with catalyst in the first 40 minutes of experiment (Figure 1). However, after 40 minutes it was lower than real wastewater sample with catalyst, as was expected for whole process. The $80 \%$ flux decline can be explained by membrane fouling by organic matter. The flux decline for filtrations with catalyst was only $20 \%$, which is an effect of the degradation of organic foulants.

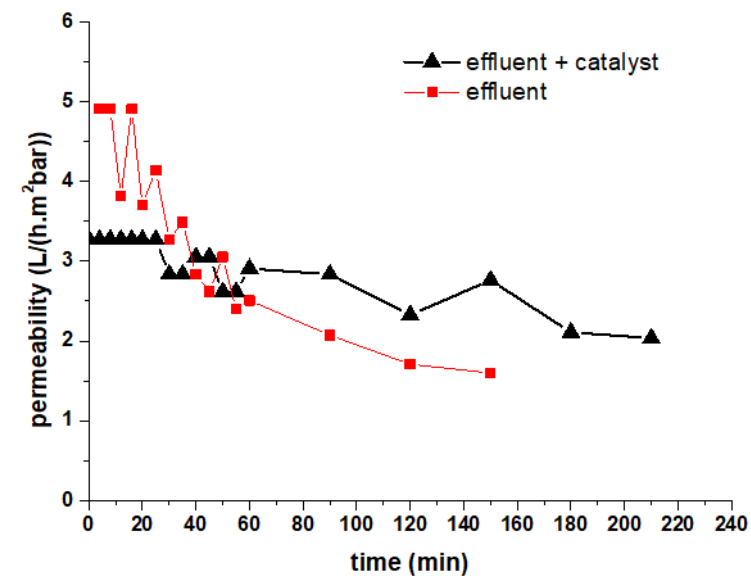

Figure 1

Comparison of water permeability of membrane used for NF of effluent with (black line) and without catalyst (red line)

The present study reveals that this ceramic catalyst combined with ceramic membrane nanofiltration can enhance production of cleaner water by decreasing fouling and improving the degradation of pollutants in wastewater treatment.

${ }^{1}$ Center for Membrane Technology, Department of Chemistry and Bioscience, Aalborg University, Fredrik Bajers Vej $7 H$, DK-9220 Aalborg East, Denmark; ${ }^{2}$ LiqTech International A/S, Industriparken 22C, 2750 Ballerup, Denmark.

*kaj@bio.aau.dk, **xm@bio.aau.dk,***vb@bio.aau.dk,**** mkj@bio.aau.dk, ***** vcl@liatech.com 


\title{
A Novel Dual-reaction Centre Catalyst for Effective Degradation of Persistent Organic Pollutants (POPs)
}

Zhiqun Xie*, Zongsu Wei**, Centre for Water Technology (WATEC), Department of Engineering, Aarhus University

\begin{abstract}
Introduction: To foster an effective degradation of persistent organic pollutants (e.g., phenolic compounds, pesticides, etc.) in waters, ultrafine nano-scale $\mathrm{Mn}_{2} \mathrm{O}_{3}$ as a promising Fenton-like catalyst was tailor designed, due to the variation of its complicated valence changes (II, III, IV) and high specific areas.

Methods and data: In order to improve the stability of ultrafine nano-scale $\mathrm{Mn}_{2} \mathrm{O}_{3}$, we used metal-organic frameworks (MOFs) with porous structure and tunable chemical composition as precursors to fabricate stable nano-scale heterogeneous catalysts. Moreover, we used cation- $\pi$ interaction, and metal- $\mathrm{N}$ complexation to induce the formation of dual reaction center which is effective in overcoming the limitations of the classical Fenton oxidation reactions. Therefore, we can construct MOFs with these two binding forces by selecting the appropriate ligands to induce a large polarization difference on the catalyst surface. Ultrafine- $\mathrm{Mn}_{2} \mathrm{O}_{3} @ \mathrm{~N}$-doped porous carbon hybrids $\left[\mathrm{Mn}(\mathrm{Ta})_{0.9}(\mathrm{Bd})_{1.2}\right]$ derived from Mn-MOFs was constructed with non-radial $\left({ }^{1} \mathrm{O}_{2}\right)$ Fenton-like reaction.
\end{abstract}

Results: We used XRD, XPS, FTIR, RAMAN, TPR, EPR, EIS, SEM and TEM to characterize the structure and therefore explain reaction mechanism of the catalyst. Cation- $\pi$ bonds and $\mathrm{Mn}-\mathrm{N}$ complexation induced the formation of electronrich $\mathrm{Mn}$ center which provided electrons for peroxymonosulfate (PMS) activation to produce radicals, accompanying with generation of ${ }^{1} \mathrm{O}_{2}$ via chain reaction. $20 \mathrm{mg} / \mathrm{L}$ of Bisphenol A could be completely degraded by the $\mathrm{Mn}(\mathrm{Ta})_{0.9}(\mathrm{Bd})_{1.2}$ within $16 \mathrm{~min}(\mathrm{PMS}=0.033 \mathrm{~g} / \mathrm{L})$ and the TOC removal rate can reach $80 \%$.

Discussion and take-home message: The porous structure of $\mathrm{N}$-doped carbon shell could not only facilitate recombination of free radicals for generation of ${ }^{1} \mathrm{O}_{2}$ but also provide adsorption sites for organics. On the other hand, $\mathrm{N}$-doped carbon shell could improve the electrons transfer from organic intermediate radicals to electron-rich $\mathrm{Mn}$ center via C-O-Mn and C-N-Mn bonds, which promote the redox of Mn to avoid PMS invalid decomposition. Being attributed to synergistic effects of dual-reaction center, our new catalyst of $\mathrm{Mn}(\mathrm{Ta})_{0.9}(\mathrm{Bd})_{1.2}$ shows promising potential for mineralization of persistent organic pollutants such as phenolic compounds, pharmaceuticals, pesticides, etc.

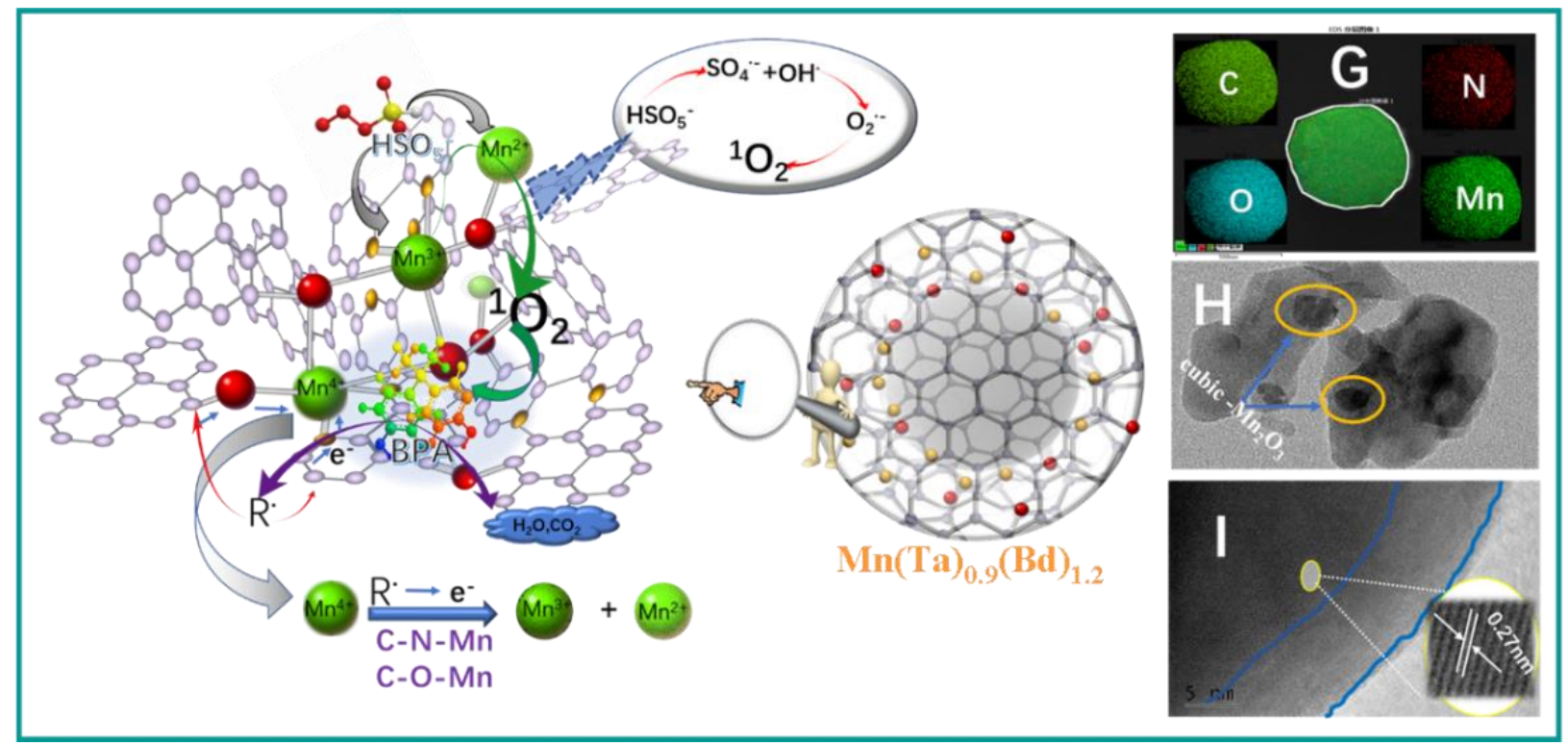

*au681447@uni.au.dk: Nørrebrogade 44, Building 18, 8000 Aarhus C, Denmark

**zwei@eng.au.dk: Nørrebrogade 44, Building 18, 8000 Aarhus C, Denmark 


\title{
InnoFlot: Resource-efficient process optimization by applying flotation technology with food grade flocculants
}

\author{
E. Holm, L.E. Jensen, L.M. Agneessens, C. Kragelund Rickers, Danish Technological Institute*, \\ J. Rasmussen, TripleNine**, E.J. Jurgensen, BIO-AQUA***
}

\section{Introduction}

A new lighthouse project develops and implements an innovative flotation technology concept at the fishmeal and oil producer TripleNine in Thyborøn in close collaboration with Danish Technological Institute, Lemvig Vand and BIO-AQUA. The new technology solution takes conventional flotation to a new level and allows using the foam produced after treatment of landing water to enter the fish meal production. Direct use of the foam for fish meal production is possible as the landing water is treated using food grade flocculants. The InnoFlot concept consists of 3 flotation units that can be operated in different ways; the first two units can be operated in series and in parallel depending on the landing water to be treated. The last flotation unit is solely operated as conditioning for discharge to the local wastewater treatment.

The project will optimize and deliver resource-efficient flotation of the landing water to:

- Remove dry matter from the landing water, enabling further reuse of the water, reducing the overall water consumption

- Increase dry matter concentration in the flotation foam using food grade flocculants and the MC Higgins method to determine dosage.

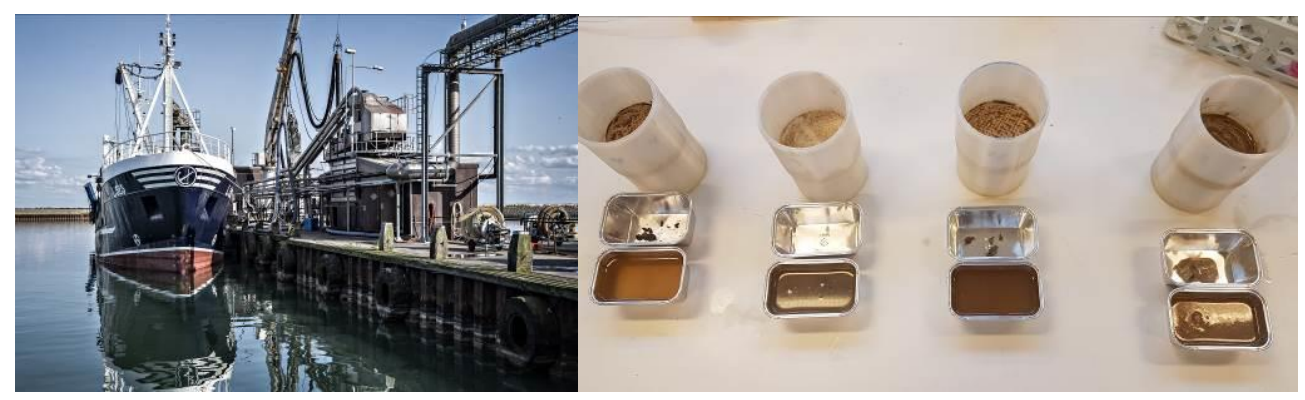

Figure 2: Landing of fish at TripleNine at Thyborøn (left) and evaluation flocculant efficiency and dosage using MC Higgins' test (right).

Methods and data

Food grade flocculants were therefore identified based on literature review and previous projects. Screening of optimal dosage concentrations was done using jar tests, while flocculation efficiency was quantified by modified Higgins' centrifugal tests and measurement of capillary suction time. The effect and correlation between flocculant dosage, landing water $\mathrm{pH}$ and chloride concentration has been determined for the two most promising flocculants using factorial design experiments. In addition, initial pilot scale experiments were performed investigating different scenarios; namely a combination of flotation using air alone or in combination with food grade flocculants.

\section{Results}

The lab experiments identified two promising food grade flocculants, and a quantitative evaluation of optimal flocculant dosage is ongoing. The pilot scale experiments documented a reduction of dry matter between $70-90 \%$ of the landing water, enabling a significantly longer recycling of the landing water.

\section{Discussion and take-home message}

The initial results underline the strength of the flotation technology and shows that it is possible to reduce the consumption of fresh water significantly during fish landing. This process water treatment using multiple steps of flotation and the potential resource recovery solution will be the first of its kind and has the potential to be applied within food and feed industries worldwide.

\footnotetext{
*cakr@teknologisk.dk: lagn@teknologisk.dk: 201406139@post.au.dk ; emilfholm@gmail.com: Kongsvang Allé 29, 8000 Aarhus C

**jra@999.dk: Sydhavevej 14, 7680 Thyborøn

***ejj@bio-aqua.dk: Strøbjergvej 29, DK-3600 Frederikssund
} 


\title{
Surface disinfection using ozonated water - effects on food quality \\ Lars Holm Rasmussen*, D.N. Lindqvist**, M. Rosenfjeld ${ }^{* * *}$, University College Copenhagen
}

\begin{abstract}
Introduction: Fresh and semi-processed fruits, vegetables, sprouts and herbs can be delicious, but can cause health issues due to contamination with bacteria and other microorganisms. Recently, ozonation of food products has been promoted as a solution to these problems. At industrial scale as well as in private kitchens. Ozonators are promoted commercially as solution to microbiological contaminations, but also as tool to remove surface deposited pesticides. Ozonation can be an effective, cheap and environmentally friendly tool for surface disinfection and decontamination. But only relevant for those food commodities unaffected by the treatment in relation to food quality parameters such as nutritional status, texture, taste and smell. Essential oils are important for our perception of food. This group of volatile and hydrophobic substances have significant influence on taste and smell. An illustrative example is the essential oil of citrus fruits such as oranges which is dominated by the terpene limonene. Limonene is partially responsible for the characteristic smell of the orange. Hence, preservation of the essential oils is important for food storage and treatment. Essential oils are found in most if not all fruit and vegetable-based food products.
\end{abstract}

Methods and data: Here, we report the effect of surface disinfection procedures using different concentrations of ozonated water and treatment times on sage leaves and lemons. The following essential oil fragrance compounds were studied using GC-FID: $\beta$-pinene, $\alpha$-thujone, $\beta$-thujone, sabinene and limonene (all terpenes/terpenoids). In addition, the effect on the total amount of essential oil in the lemon-peel was established.

Results: Our results show that ozone treatment of sage cause significant degradation of sabinene and $\beta$-pinene compared to the terpenoids $\alpha / \beta$-thujone which were more ozone resistant. The same was the case for limonene in lemons. The total amount of essential oil in both products significantly decreased (50-90+ \%).

Discussion and take-home message: The fast degradation of the terpenes $\beta$-pinene, limonene and sabinene is likely to follow the Criegee-mechanism, involving double bond-breaks during ozonolysis while single-bond breaks of the terpenoids are slower. In conclusion, use of ozonated water has severe impact on the composition as well as the amount of essential oils present in sage and lemon. Hence, application of ozonated water for surface disinfection should be targeted fruits and vegetables where the essential oil has limited effect on the food quality perception.

The study was a part of the project WASHO3 financed by the Green Development and Demonstration Programme (GUDP) in Denmark (J.no.: 34009-18-1366).

*LHRA@KP.DK: Sigurdsgade 26, 2200 Copenhagen N.

**DALI@KP.DK: Sigurdsgade 26, 2200 Copenhagen N.

*** MROS@KP.DK : Sigurdsgade 26, 2200 Copenhagen N. 


\title{
Measured and calculated Calcium Carbonate Precipitation Potential
}

S. V. Afshar*, HJ. Albrechtsen**, M. Rygaard***, DTU Environment

\begin{abstract}
Water hardness is caused by the presence of dissolved calcium and magnesium minerals that are naturally present in the water. Consumers of drinking water, living in areas with hard water, are often troubled with calcium carbonate scale deposits. Scale deposits stain surfaces may lead to reduced lifetime of equipment, reduced efficiency of heat transfer, and clogging of water pipes. We have measured and calculated the calcium carbonate precipitation potential for varying water types and surfaces, using a combination of conventional and newly developed techniques

Introduction: Earlier studies have shown that the potential for $\mathrm{CaCO}_{3}$ scaling in water does not only depend on water hardness, but also $\mathrm{pH}$, alkalinity and other ions - mainly sodium, potassium, chloride, phosphate, sulphate, and nitrate. While $\mathrm{CaCO}_{3}$ scaling potential can be calculated as the Calcium Carbonate Precipitation Potential (CCPP), it is not a measure of the actual scaling taking place. Our project compared theoretical and measured calcium carbonate precipitation potentials with actual measured scaling on tiles and in water heaters. The project is relevant for prediction of consumer satisfaction, e.g. in considerations of water softening initiatives.

Methods and data: We modified and evaluated a method for measured calcium carbonate precipitation potential (MCCP). We developed a simple, yet robust measure of Observed Scaling Deposits based on image analysis that provide a measure of actual deposits on bathroom tiles. Our study evaluated the OSD test method and compared results directly to calculated CCPP and water hardness values for water with hardness between 0 and $22 \mathrm{dH}$. Scaling in water heaters was observed for four water types.

Results and conclusions: CCPP is easily calculated but it is uncertain what information it provides in open systems with atmospheric exchange compared to hardness alone. This may be different for closed systems such as water heaters and piping systems. Measuring scaling potentials (MCCP) was challenging and we did not succeed in generating robust results across sample replicas. On the other hand, image analysis of scaling on tiles turned out to provide a robust and direct measure of scaling potentials across different water types. Surprisingly, there is a marked scaling of tiles even at low to medium water hardness. Scaling of tiles did not vary markedly from 11 to $22 \mathrm{dH}$. Our results are important to consider in the alignment of consumer expectations: A reduction of hardness from 22 to $11 \mathrm{dH}$ and marked reduction in calculated calcium carbonate precipitation potential will markedly reduce scaling in e.g. water heaters, but may not change observed scaling on bathroom tiles.
\end{abstract}

*sevaf@env.dtu.dk, **hana@env.dtu.dk,***mryg@env.dtu.dk, Bygningstorvet, Bygning 115, 2800 Lyngby 


\section{Session 2: Præsentation af små- og mellemstore vandvirksomheder - Samarbejde mellem SMV'er og universiteter/forskere 3 February 9:00 - 12:00, Teams}

The session will present Danish small and medium-sized water companies, including tales on the road from researcher and start-up to become a water company, concrete cases on cooperation between SMEs and universities/researchers, opportunities for future cooperation between SMEs and researchers, and lessons learned to share with future entrepreneurs.

The presentations will be given in Danish or English.

Chair: Jesper Dannisøe, Co-chair: Bjørn Kaare Jensen

\section{Draft program}

9:00 Jesper Dannisøe, Director, DWF: Welcome og logistics

9:10 Mikkel Holmen Andersen, CTO: Unisense - The pathway for development of new sensors for $\mathrm{N}_{2} \mathrm{O}$

9:20 Søren Porsgaard, CEO: SulfiLogger - Reliable $\mathrm{H}_{2} \mathrm{~S}$ measurements - anywhere in the sewers or at treatment plants

9:30 Christian Wieth, CCO: AquaGreen - Innovative solution for wastewater sludge treatment

9:40 Krzysztof (Chris) Kowalski, Civil Engineer: Danwatec - Experience with pilot plants and modelling

9:50 Per Skougaard Kaspersen, Senior Specialist: LNH Water - Strategisk planlægning af afløbssystemer

10:00 Follow up questions and answers

10:10 Thomas Munch-Laursen, CEO: Aguardio

10:20 Søren Robenhagen, Sales Director: Aquaporin - Water made by nature

10:30 Jørgen Bo Nielsen, Director: CBMC - Digital climate adaptation tools

10:40 Peter Rasch, CEO: DRYP - Data and collaboration - bridging boundaries; scientific, geographical and organisational

10:50: $\quad$ Vibe Gro, Co-owner: PileByg

11:00: $\quad$ Follow up questions and answers

11:10 Karl Haxthausen, PhD: NIHAX IvS - PhD projekt leder (snart) til spinoff: bio-elektroder - nyt virkemiddel til sørestaurering

11:20 Lasse Boehm, Product manager: Cembrane

11:30 Mads Nedergaard, CEO: VIABLE- Produkt intro MODULE1 og udviklingssamarbejde med DTU

11:40 David N. Ø.-Munck, Process Engineer: LiqTech - Sustainable water treatment

11:50 Rune Kirt, CEO: Kirt x Thomsen

12:00 Follow up questions and answers

12:10 Bjørn Jensen: Closing remarks 


\section{Session 3: Urban Water and Climate Change}

3 February 2021, 13:00 - 14:45, Teams

Chair: Ole Mark, Krüger. Co-chair: Peter E. Holm, KU, PLEN.

13:00 Ole Mark: Welcome

13:05 Jesper Dannisøe: Logistics

13:10 Surface permeability for permeable asphalt and effects of maintenance. J. Støvring, L. S. Meyer.

13:25 Risk of reactivating existing contamination in establishment of SUDS in urban environments. Anna Bondo Medhus, S.E. Poulsen, T.R. Andersen, M. Bak, N.K. Christensen, P. Thomsen, J.O. Andreasen, T.B. Hansen.

13:40 Water Smart Planning. Mette Ryom Nielsen, P. Thomsen.

13:55 A detailed, adaptable, country-wide rainfall-runoff model - application in Denmark: Alexandra M. Murray, G.H. Jørgensen, N. Balbarini.

14:10 Vacant

14:25 Ole Mark, Peter E. Holm: Closing remarks 


\section{Surface permeability for permeable asphalt and effects of maintenance}

Jan Støuring, University of Copenhagen*, L. S. Meyer, Frederiksberg Municipality**

Introduction: Streets and urban plazas paved with permeable pavements are one means to help mitigate and adapt the urban landscape to effects of climate change. Infiltration through the surface of the pavement is crucial for obtaining the kind of environmental benefits for which permeable pavement systems have been design and planned. While pavement design and application techniques are vital factors for ensuring high permeability from day of construction, long-run permeability can be ensured only by controlling on-site factors such as sedimentation input and by using the appropriate maintenance techniques. With the aim of enhancing our understanding of the kinds of sedimentation processes and appropriate maintenance techniques this abstract report results from an on-going study of surface permeability on three streets paved with permeable asphalt.

Methods and data: The surface permeability of the streets, all in the municipality of Frederiksberg, Denmark (Figure 1) constructed in December 2016 and onwards was assessed using the test method: ASTM C1781/C1781M-13 (ASTM, 2013). The test method returns the Surface Infiltration Rate (SIR). In order to follow the longitudinal development in SIR, tests have been conducted two-four times a year, in the period from January 2017 to April 2020. The tests include pre- and post-tests in relation to the use of two types of cleaning techniques: A street sweeper (Holder C250) and a specialized vacuum truck (Beam S9000). Each site's unique history of sedimentation and compaction was recorded in line with earlier study by Støvring et al. (Støvring et al., 2018).

Results: So far, a total of 381 individual infiltration tests at 44 designated test spots have been conducted on the three streets in the period. The test results show considerable variation in surface permeability across the three streets within the very first months after construction. Over time, however, the surface permeability rates tend to homogenize. Testing the effect on SIR by use of a street sweeper showed no effect of two-time passing and a diminutive effect of five-time passing. Using a specialized vacuum truck overpassing test locations two times showed an increase in surface permeability at all test spots and a mean increase of SIR from $1230 \mathrm{~mm} / \mathrm{h}$ to $2585 \mathrm{~mm} / \mathrm{h}$. Out of the total number of tests, 113 test results returned SIR below a 10 -year level of service. However, all except five, improved after cleaning regardless the technique.

\section{Discussion and take-home message:}

- Considerable variation of SIR within and across streets during the first months of service that, however, tend to homogenize reflecting each site's unique history of sedimentation and compaction.

- The few areas with a stable high SIR indicate that permeable asphalt not located in heavily trafficked areas and at a safe distance from construction, sites and other sedimentation inputs can maintain high surface permeability.

- The cleaning effect of using a specialized vacuum truck is most pronounced when the SIR is within the range 50$500 \mathrm{~mm} / \mathrm{h}$ highlighting the necessity to address sediments before the permeability becomes too low $(<50 \mathrm{~mm} / \mathrm{h})$.
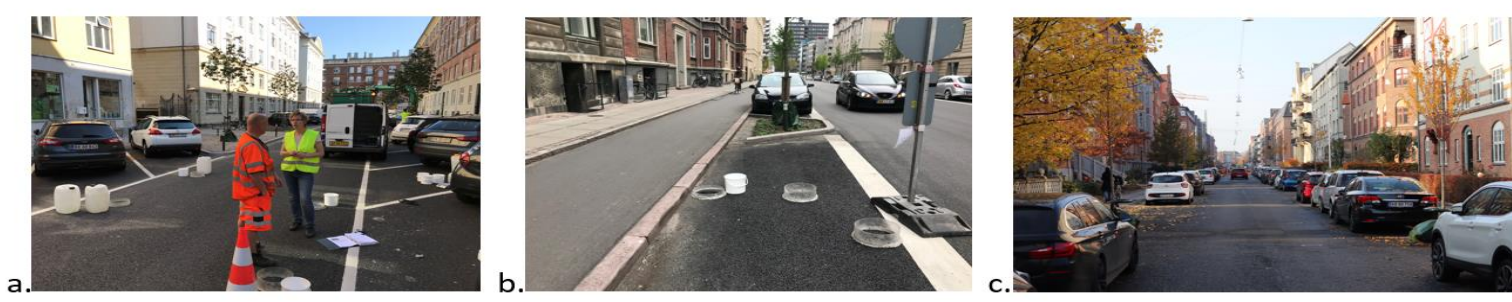

Figure 1: Photo of streets subjected to tests; a) ÆErøvej, b) Madvigs Allé, c) Mariendalsvej

Støvring, J., Dam, T., Bergen Jensen, M., 2018. Surface sedimentation at permeable pavement systems: implications for planning and design. Urban Water J. 15, 124-131.

* jls@ign.ku.dk: Rolighedsvej 23, 1958 Frederiksberg C

**leme03@frederiksberg.dk: Smallegade 1, 2000 Frederiksberg C 


\section{Risk of reactivating existing contamination in establishment of SUDS in urban environments}

Anna Bondo Medhus, Via University College*, S.E. Poulsen, Via University College*, T.R. Andersen, Via University College*, M. Bak, Aarhus Municipality**, N.K. Christensen, Aarhus Municipality**, P. Thomsen, Rambøll***, J.-O. Andreasen, Aarhus Water****, T.B. Hansen, Central Region Denmark*****

\section{Abstract}

We suggest a workflow for pre-investigations when considering infiltration based SUDS (Sustainable Urban Drainage Systems) - The purpose of the workflow is to address the potential risk of reactivating existing buried contamination in the near vicinity of the SUDS. The decision-making process is illustrated by case examples representing different paths in the workflow diagram.

\section{Introduction:}

The present and near future climate changes in Denmark challenge urban planners because traditional urban sewer systems have typically been designed for the climate at the time of construction. An easy and economically feasible way to mitigate this is to introduce SUDS. Infiltration elevates groundwater levels and potentially mobilize existing immobile soil contamination. This may affect contamination originally considered less critical and immobile due to a location above the groundwater table. We present an approach for assessing risk of reactivation of such contaminations prior to establishment of infiltration based SUDS.

\section{Methods and data:}

We conducted a desk study in order to summarize recommendations and rules as well as the current practice. Based on that, the experience of project participants and a stakeholder group a provisional workflow was drafted. The workflow was tested for two case examples in Aarhus. Hydrogeological models were constructed based on geophysical measurements and borehole information. Hydrological modelling was conducted in order to evaluate the risk of reactivation of nearby contaminations. Based on the experience from the case areas the workflow was updated to become more suitable for decision making.

\section{Results:}

A best practice including a suggested workflow was produced. In the best practice, examples are provided illustrating the different possible paths available in the workflow.

\section{Discussion and take-home message:}

VIA University College, Aarhus municipality, Rambøll, Aarhus Water and the Central Region Denmark has created a "Best practice" which can be applied prior to establishment of infiltration based SUDS. It will guide the reader though steps to assess the risk of reactivating existing contamination.

*anbm@via.dk: Chr. M. Østergaardsvej 8700 Horsens, Denmark 


\title{
Water Smart Planning \\ Mette. Ryom, Ramboll Water*, P. Thomsen, Ramboll Water
}

\begin{abstract}
Introduction: Understanding and management of the water cycle is no longer only a necessity in relation to vulnerable protected nature. Climate changes and ambitions of sustainable urban development has introduced an increased need for in depth knowledge about the water cycle when developing structural planning and urban design.
\end{abstract}

Methods and data: To obtain a sustainable urban development and to address $\mathrm{CO}_{2}$ reduction, the energy consumption and use of resources must be reduced. The goal is total utilization of local resources and reduced need for the external water supply, wastewater and electricity supply.

To some extend knowledge about the water cycle can be found through borehole databases, piezometric maps, soil type maps, stream stations etc. But when the understanding of the water cycle is needed on a detailed level and not on a regional scale, more dense data and more detailed models are needed. This is obtained by adding data on project level. These data include real time hydrological monitoring data, data driven analysis and predictive evaluation of the water cycle balance.

\section{Results:}

With Water Smart Planning we are aiming at sustainable structural planning and urban design. As illustrated in the figure below, this can be obtained through different mechanisms. In the cross-field between climate change and wastewater treatment is the separation of rainwater from the wastewater network that will reduce load and save energy at the WWTP. The result of the monitoring, analysis and predictive analysis of the water cycle will be the basis of designing resilient solutions for handling the decoupled rainwater. The rain and surface water are planned to be led into canals, corridors and basins, which can both constitute as cloudburst protection, secondary quality water supply and a scenic recreational excursion destination. The use of rainwater as secondary quality water supply will reduce the need for district water supply and can be achieved by simple treatment at local mini treatment plan and used for washing, toilet flushing and garden watering. This is especially applicable in new development but can also be considered when redeveloping existing urban areas. Considering reduction of the extend of district energy supply, a multi-source heat pump can be established at the mini treatment plan for co-production of cooling and lowtemperature district heating. Development of solutions must satisfy natural protection, like maintenance of biological system in streams and wetlands, and protection of potential vulnerable groundwater resources.

Discussion and take-home message: To account for water in structural planning and urban design is not an "add on" in the final phase of a development plan. The options for including sustainable water planning must be considered in the very first stages and be part of the basis for the entire strategy of the structural planning or urban design.

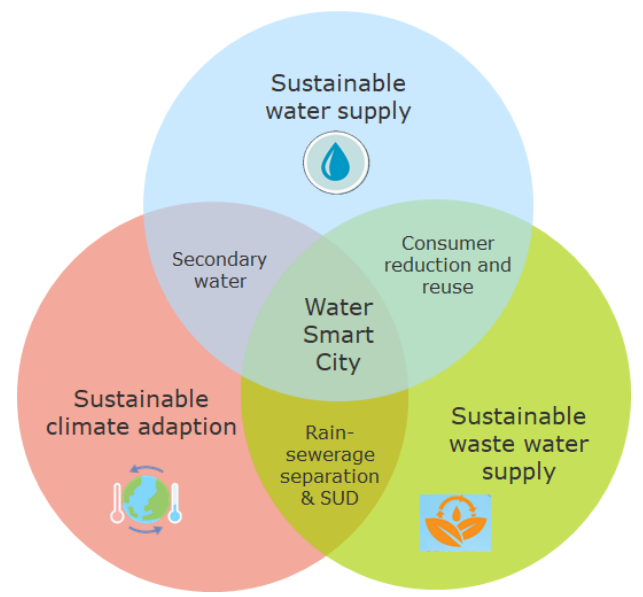

*mrn@ramboll.dk: Olof Palmes Allé 22, 8200 Aarhus N, Denmark

** prt@ramboll.dk: Olof Palmes Allé 22, 8200 Aarhus N, Denmark 


\title{
A detailed, adaptable, country-wide rainfall-runoff model - application in Denmark
} A.M. Murray, DHI*, G.H. Jørgensen**, DHI, N. Balbarini, DHI***

\begin{abstract}
Rainfall-runoff models (NAM models) are reputable and widely used in hydrological applications. Paired with current and forecast data, they can be run quickly and produce accurate real-time information, such as river discharge. There are many NAM models built at the city or basin scale in Denmark, and a Global Hydrological Model (GHM) is in development that applies this concept to the world's major rivers, but no model currently encompasses the entire country of Denmark and provides hydrological information at a suitable scale for areas outside of the detailed, basinscale models. Weather data, such as rainfall and temperature, are available from DMI in historical datasets and as real-time and forecast data, and broadly span the whole country. Using this weather data, a NAM model that operates in the same framework as the GHM has been applied to Danish catchments to provide simulated historical and forecasted discharge in all rivers and most streams.
\end{abstract}

A $40 \mathrm{~cm}$ DEM from Kortforsyningen was aggregated to $4 \mathrm{~m}^{2}$, hydrologically corrected, and used to create catchments. Catchments were delineated at each confluence, measurement station, or at approximately each $1 \mathrm{~km}$ of stream length, such that all catchments are approximately $1 \mathrm{~km}^{2}$ in area. The model is flexible, in that as new measurement stations are established, new catchment pour points can easily be added to the model. 48,885 hydrological catchments cover the $42,933 \mathrm{~km} 2$ of Denmark. A NAM model is executed for each catchment, and water is routed kinematically from one catchment to the next.

NAM model inputs consist of daily rainfall, temperature, and evaporation data. Historical rainfall and temperature data from 1989-2011 produced by DMI were combined with historical data from DMI's weather archive (vejrarkiv) from 2011-present. Historical daily evaporation data from 1989-2011 produced by DMI were combined with a calculated Penman-Monteith evaporation (FAO) based on data from DMI's vejrarkiv from 2011-present. Observed discharge values from 260 measurement stations (Miljøstyrelsen) evenly distributed throughout the country and on all major rivers were used for calibration over the period with available data, 2007-2019.

Good fits $\left(R^{2}>0.8\right)$ have been obtained for major rivers (Gudenå, Skjernå, Suså). Calibration for the model has incorporated methods for ascertaining NAM model parameters from global datasets, an approach also used in the GHM calibration, such as calculation of overland flow time constants (CK 1,2$)$ using the FAO's SCS-CN method based on soil type and land use. Calibration will continue into 2021. The model is already set to function in real-time using hourly rainfall and temperature data from vejrarkiv.

Visualisation of the model displays simulated discharge for each kilometer of the stream network and allows for easy identification of upstream catchment area at each routing point. Further outputs from the model could include hydrological variables described by the NAM model, and applications can include calculation of freshwater discharge from Danish coasts to the marine environment. With forecast inputs, the model can give a hydrological or runoff forecast, as a complement the weather forecasts, that would be particularly useful to areas not already covered by detailed, basin-scaled models. The model produced in this work is comprehensive in its coverage, yet light in its operation, and is able to provide current and forecasted hydrological pictures of all Danish streams.

*almm@dhigroup.com : Agern Allé 5, DK-2970 Hørsholm, Denmark

** ghj@dhigroup.com : Agern Allé 5, DK-2970 Hørsholm, Denmark

*** niba@dhigroup.com : Agern Allé 5, DK-2970 Hørsholm, Denmark 


\section{Session 4: International research cooperation in Africa}

4 February 13:00 - 16:00, Teams

\section{Chair: Bjørn Kaare Jensen, Co-chair: Lars Skov Andersen}

13:00 Peter E. Holm: Welcome

13:10 Jesper Dannisøe: Logistics

13:15 Delineating groundwater potential zones of the Nasia Basin, Northern Ghana using geostatistics, GIS/RS: Abdul-Samed Aliou, Sandow Mark Yidana, Yvonne Sena Akosua Loh, Larry Pax Chegbeleh:

13:30 Groundwater recharge controlled by ephemeral rivers and climate in the semi-arid Limpopo Province of South Africa: John Lindle, Karen Villholth, Richard Taylor, Karsten Høgh Jensen

13:45 Holistic groundwater resource characterisation and assessment model for the Nasia Basin, Northern Ghana: Millicent Obeng Addai, Sandow Mark Yidana, Peter Engesgaard, Larry-Pax Chebeleh, Lars Troldborg, Clement Alo

14:00 Integrated groundwater management in a semi-arid diverse stakeholder catchment in Limpopo Province, South Africa: Karen G. Villholth, Girma Y. Ebrahim, Manuel Magombeyi, Karsten H. Jensen, Jaqui Goldin, Resego Mokomela:

14:15 Break

14:25 North - South Groundwater Partnership: Lars Skov Andersen, James Sauramba:

14:40 New geophysical tools applied for siting of groundwater wells in SADC Member States: Denys Grombacher, P. Maurya, R. Kraghede, J. Pedersen, J. Lind and E. Auken

14:55 Testing Danish groundwater mapping methodologies in South Africa, Case Ladysmith, South Africa: Jan Kürstein, T.M Madsen, P.G. Pedersen, M. S. Linneberg, F. Fourie, M. Awodwa, N. Vermaak, G. Metcalf:

15:10 Flowing rivers and full stomachs? Socio-economic benefits of ecological infrastructure in South Africa: Maya Pasgaard, Niels Fold, Rasmus Skov Olesen, Laura Vang Rasmussen:

15:25 Pathways to Water Resilient South African Cities (PaWS): Lise Herslund, Patience Mguni, Marina Bergen Jensen, Kirsty Carden, Neil Armitage:

15:40 Assessment of new sludge management strategies in the Cape Flats wastewater treatment works, South Africa: X. Flores-Alsina, E. Ramin, K.V. Gernaey, T. Harding, D. Ikumi, C. Brouckaert, D. J. Batstone, S. Sötemann:

15:55 Peter Holm: Closing remarks 


\title{
Delineating groundwater potential zones of the Nasia Basin, Northern Ghana using geostatistics, GIS/RS
}

\author{
Abdul-Samed Aliou, Sandow Mark Yidana, Yvonne Sena Akosua Loh, Larry Pax Chegbeleh
}

\section{Introduction}

The development of groundwater resources across the Voltaian Supergroup of the Nasia Basin in Northern Ghana is constrained by the lack of knowledge of suitable locations for groundwater exploration. Groundwater practitioners over the years have recorded low success rate of drilling boreholes partly because of the absence of a guiding document in their operation. As a contribution to the Danida-funded Development Research Project "Groundwater Development and Sustainable Agriculture", DFC File No. 14P02-GHA, this study seeks to develop a groundwater potential map that will delineate possible suitable zones to aid in groundwater exploration.

\section{Methods and data}

An integrated method involving hydrogeological investigations, geostatistics, remote sensing and geographical information system was used to achieve this objective. Due to limited pumping test data in the study area, cokriging, a geostatistical technique was employed to calculate aquifer transmissivity because it considers the spatial auto correlation of transmissivity and specific capacity which is in abundance. Kriging was used to develop interpolation images for static water level, regolith thickness, well depth and recharge. Remote sensing techniques (using ASTER DEM data) were used to determine slope, drainage density and lineament map of the study area. Spatial layers were prepared for transmissivity, well depth, recharge, static water level, regolith thickness, slope, drainage density and lineament using GIS techniques. Multi-criteria evaluation techniques were used to integrate all the thematic layers. Individual themes and their corresponding categories were assigned a knowledge base ranking from 1 to 5 , depending on their importance for groundwater potential. Using the Raster calculator tool in ArcGIS 10.6 software, all thematic maps were integrated to produce a composite groundwater potential map of the study area

\section{Results}

The identified groundwater potential zones were classified into five zones, from very good to very poor. The generated potential zones were validated using borehole yield data and it showed consistency with the observations. The results from the hydrogeological investigation indicate that cokriging gives better estimates of spatial aquifer transmissivity and therefore is a better approach in estimating transmissivity in the area considering the paucity of pumping test data. Variographic analysis conducted indicate that groundwater within the study area is structurally controlled. The groundwater potential map showed that $2 \%$ of the study area was classified as very good while $18 \%$ is of good potential. These are areas within the Kodjari formation southwest of the Panabako sandstone formation of the study area. About $38 \%$ of the study area was classified as moderate potential and it is sparsely distributed across the study area. About $41 \%$ represent poor potential for groundwater mainly within the Bimbilla formation. Less than $1 \%$ of the study area was classified as very low potential areas and also concentrated in southwest of the study area.

\section{Discussion and take-home message}

The groundwater potential map will serve as baseline information for groundwater practitioners and this has the high possibility of increasing the success rate of boreholes since it will serve as a guide for groundwater investigation. The groundwater potential map further shows that the potential for high yielding boreholes is limited to about $20 \%$ of the study area. Therefore, for irrigational purposes, other strategies such as tapping water from the weathered zone should be considered. 


\title{
Groundwater recharge controlled by ephemeral rivers and climate in the semi-arid Limpopo Province of South Africa
}

\author{
John Lindle, Institute of Geosciences and Natural Resource Management, University of Copenhagen \\ Karen Villholth, International Water Management Institute (IWM) \\ Richard Taylor, University College London \\ Karsten Høgh Jensen, Institute of Geosciences and Natural Resource Management, University of Copenhagen
}

\begin{abstract}
In arid and semi-arid regions, recharge is subject to a significant spatial as well as seasonal and inter-annual variation, further subjected to uncertainty and temporal shifts due to climate change. Spatially, replenishment of an aquifer may occur as either diffuse or focused recharge. Diffuse recharge is the process, which takes place in the landscape in a distributed manner when precipitation infiltrates the soil surface and subsequently leaves the root zone and percolates to the water table. Spatially, this component is dependent on land use and topographic, soil and geological controls, and temporally it depends on the distribution of precipitation on timescales from daily events through seasonal and inter-annual variability to long-term climate-driven patterns. The inter-annual variability is often an important factor as several years of little recharge may be followed by an extreme precipitation event leading to significant recharge and associated abrupt increase in groundwater levels. Such process is referred to as diffusive episodic recharge. Focused recharge occurs beneath ephemeral river beds in response to water build-up in the river courses from heavy precipitation and surface runoff. This recharge component depends on precipitation intensity and duration as well as the hydraulic properties of the river system. Recharge from this process is also of episodic nature, may be very high and exceed the recharge caused by diffuse recharge.
\end{abstract}

We have analyzed the occurrences of the two recharge processes and their relative importance in the Limpopo Province in South Africa based on collected data on precipitation, groundwater levels from monitoring wells, soil, land use and geology. Two methods were used for estimating recharge: (1) the water fluctuation method where the recharge is estimated on event-based increases in groundwater level and (2) the Hydrus 1D numerical model that computes the fluxes at the water table based on specified meteorological drivers and soil characteristics.

Our analysis document that episodic events, as observed in the groundwater table records, are disproportionately critical for aquifer replenishment and groundwater sustainability in the region. Further, focused recharge enhances the groundwater availability in areas in proximity to these normally dry water bodies. Overall, the high inter-annual climate variability is responsible for the recurring episodic groundwater recharge events that punctuate longer-term trends. 


\section{Holistic Groundwater resource characterization and assessment model}

Millicent Obeng Addai(1) Sandow Mark Yidana(1) Peter Engesgaard (2) Larry-Pax Chebeleh (1) Lars Trodborg (3) Clement Alo (4)

For the first time, a holistic groundwater resource characterisation and assessment model has been developed for the Nasia Basin, a sub-basin of the White Volta Basin in the northern part of Ghana. The model is 3-dimensional, and is highly integrated such that it is capable of analysing several potential water management scenarios in one fell swoop. The model is useful for policymakers in the planning and sustainable management of the groundwater resource in the basin. The calibrated 3-D numerical transient model that was developed from the hydrogeological conceptual framework of the Nasia basin was used to perform four possible scenarios: (1) increase in population, (2) climate variations, (3) increased abstraction for irrigation, and (4) worst-case scenario which is a combination of all three scenarios (1), (2), and (3). These scenarios were performed to ascertain the sustainability of the groundwater resources in the wake of climate change and increased abstractions for both domestic and irrigational needs. This simulation indicated that there was a reduction in the groundwater discharge into streams under these stress conditions. This reduction can affect the stream levels in the basin and subsequently, the ecosystem.

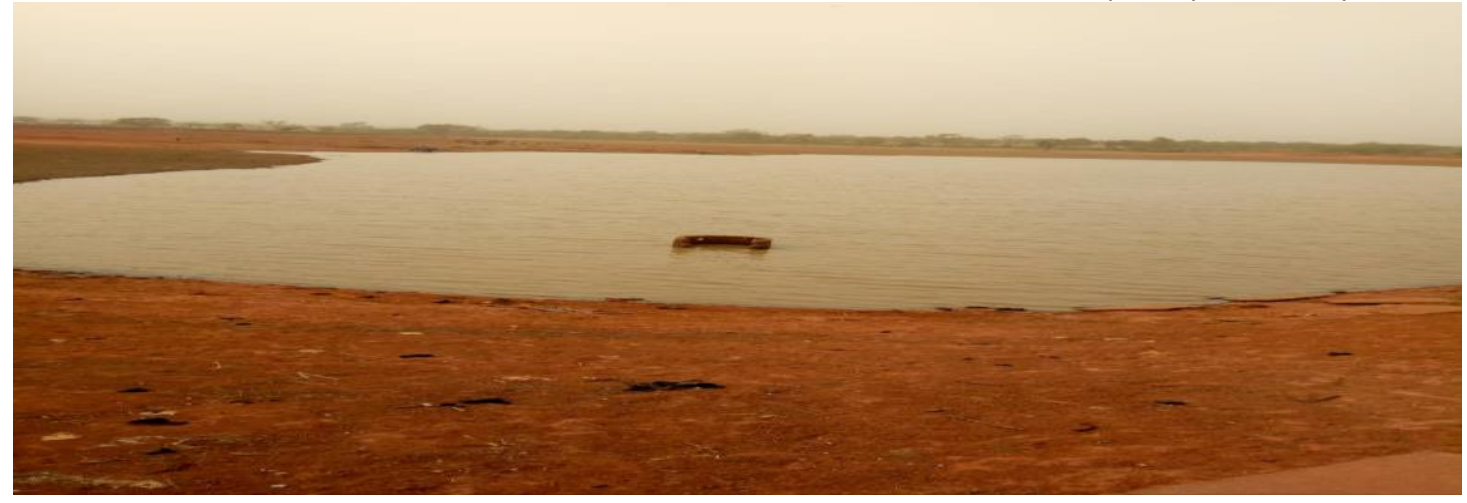

This project was sponsored by DANIDA with project number (14-P02-GHA).

1University of Ghana; 2University of Copenhagen; 3Geological Survey of Denmark and Greenland (GEUS); 4Montclair State University 


\title{
Integrated groundwater management in a semi-arid diverse stakeholder catchment in Limpopo Province, South Africa
}

Karen G. Villholth, Girma Y. Ebrahim and Manuel Magombey, International Water Management Institute (IWM), South Afric, Karsten H. Jensen, Institute of Geosciences and Natural Resource Management, University of Copenhagen Jaqui Goldin and Resego Mokomela, University of Western Cape, South Africa

\begin{abstract}
Improving groundwater management in the highly stressed middle Limpopo River Basin requires integrated approaches in order to achieve long-term socially as well as environmental sustainability. This paper describes prolonged research and engagement in the Hout Catchment in the Limpopo Province of South Africa, which is known for its excellent potato production to a large part of the country. Low rainfall ( $400 \mathrm{~mm} / \mathrm{yr}$ ), high groundwater dependence for intensive agriculture and relatively shallow aquifers subjected to only decadal events of significant replenishment, exacerbated by climate change, means that innovative, informed and participatory processes are required to sustain the critical dependence on groundwater. The study included long-term (> 6 years) recurrent engagement with stakeholders to understand their issues, originally focusing on large-scale irrigators who are the main consumers of the resource, but gradually also small communities with inadequate access to basic water supply services. A key tool to inform the engagement was a catchment-level dynamic integrated hydrogeological model, which clearly highlighted the episodic nature of recharge governed by intense rainfall events, allowing focused recharge along ephemeral river to dominate and concentrate the recharge process. Farmers have coped with variability, uncertainty and risk of exhaustion of the resource for generations through various social and customary agreements as well as some technological solutions, such as water harvesting - both in rural areas, but increasingly also in urban areas through recycling of wastewater via managed aquifer recharge - and well proliferation, and cropping adjustments. Some adherence to seasonal forecasting was evident, but several shortcomings made farmers rely less on these opportunities. As a recent approach to further supporting the informed and integrated management of groundwater, citizen science focusing on the groundwater resource base across the catchment has been implemented. This has proven important in informing continued modeling as well as creating gradual coherence in the catchment with respect to joining forces on groundwater management.
\end{abstract}

\section{North - South Groundwater Partnership}

Lars Skov Andersen, ChinaRM, James Sauramba, SADC

DWF and the Southern African Development Community Groundwater Management Institute (SADC-GMI) have agreed to establish a groundwater partnership and applied for financial support from the Civil Society in Development (CISU) to develop the partnership.

GMI was established in 2008 to "strengthen the ability of national and transboundary institutions to manage groundwater, help advance research on the challenges facing groundwater, and promote infrastructure solutions".

The short-term objective is to contribute to the Sustainable Development Goal SDG 17 "Global partnerships on strengthening the means of implementation of the SDGs".

The long-term objective is to promote groundwater-based rural water supply in SADC Member States as a contribution to SDG 6 for water, specifically Target 6.1 "to achieve universal and equitable access to safe and affordable drinking water for all".

Lars Skov Andersen, China Resources Management on behalf of Danish Water Forum - chinarm@mail.dk James Sauramba, Director, SADC Groundwater Management Institute, jamess@sadc-gmi.org 


\title{
New geophysical tools applied for siting of groundwater wells in SADC member states
}

\author{
D. Grombacher, Geoscience Department, Aarhus University, Aarhus University Center for Water Technology*, $P$. \\ Maurya*, R. Kraghede*, J. Pedersen*, J. Lind*, E. Auken*,**, Geological Survey of Denmark and Greenland**
}

\begin{abstract}
Optimal well-siting requires local hydrogeological knowledge. However, it is common that one is forced to site wells with limited data, which results in great uncertainty as to the location and sustainability of local groundwater sources. This uncertainty often results in the drilling of unsuccessful boreholes. To enhance the likelihood of drilling a successful borehole in these data-poor environments we demonstrate the utility of a towed transient electromagnetic systems, called tTEM, capable of providing rapid cost-efficient characterization of local hydrogeological systems. Examples from surveys in Tanzania and South Africa are presented to illustrate the potential of such a system, and examples of successful well-siting as a result of tTEM surveys will be discussed.
\end{abstract}

Introduction: To aid in optimizing well locations non-invasive geophysical tools show great promise of providing rapid characterization of groundwater systems - capable of mapping the geometry, spatial extent, and identifying hydrological units likely or unlikely to house water. One such tool that shows great promise is tTEM, a transient electromagnetic system towed behind an ATV, capable of surveying more than 100 hectares per day. We demonstrate the utility of the tTEM system through two campaigns in Tanzania and South Africa, where the system is shown to perform well under both regolith settings (Tanzania) and hard-rock environments (in the Karoo, South Africa).

Methods and data: The tTEM system produces images of the subsurface electrical resistivity, where geological units can be delineated based on their contrasting electrical properties. The system collects data while being driven at speeds up to $25 \mathrm{~km} / \mathrm{h}$, producing a depth profile of electrical resistivity every $\sim 3$ meters. The suite of depth profiles, often thousands produced per day, can be stitched together to produce high resolution images of complex 3D geological structures. The typical depth of penetration for the system can reach up to 80-100 meters depending on the subsurface properties. The system is capable of being transported between sites using two standard pick-up trucks, or a small trailer.

Results: Two campaigns were conducted in October 2019 and February 2020, in Tanzania and South Africa, respectively. In Tanzania, surveys were performed in five host-communities and two refugee camps, in a regolith setting. The tTEM system was shown to provide rapid characterization of widespread 3-layer subsurface composed of an upper resistive laterite layer, underlain by a lower resistivity clay-rich saprolite, with an underlying weathered bedrock at the base. Several wells drilled into the weathered bedrock at the base were found to be highly productive. As a result of the campaign, a well was sited in Makere, Tanzania and was drilled in November 2020. A significant water strike was encountered at depths coinciding with the tTEM's prediction of the weathered bedrock depth. The South African survey targeted a range of geological settings, from alluvial aquifer systems in the KwaZulu-Natal province to hardrock environments in the Karoo. In total approximately $1000 \mathrm{kms}$ of data was collected during a month-long field campaign. Several challenges were identified in the Karoo, where difficult terrain in the vicinity of outcrops often limited tTEM access or reduced driving speeds and highly resistive backgrounds produced low-amplitude signals. Despite these challenges, the tTEM provided high resolution characterization of groundwater systems in the vicinity of a number of communities currently dealing with severe water issues. A successful well was sited in a tTEM characterized region in the vicinity of Sediba, South Africa, where a significant water strike was observed at a depth predicted to coincide with a layer boundary in the tTEM results. Furthermore, wells sited as a result of surveys conducted in Laingsburg, South Africa have also intercepted productive aquifer systems - where 11 out of 12 wells sited based on tTEM surveys intercepted water at depth.

Discussion and take-home message: The tTEM system is well-suited to rapid mapping of hydrogeological systems and shows great value for well-siting workflows in regions without significant knowledge of local groundwater systems. The system has been demonstrated to provide robust reliable performance in a range of geologic settings likely to be encountered throughout the SADC member states.

*denys.grombacher@geo.au.dk, C-F Møllers Alle 4, Aarhus C, Denmark. 


\title{
Testing Danish groundwater mapping methodologies in South Africa, Case Ladysmith, South Africa
}

\author{
J. Kürstein, Rambøll*, T.M Madsen**, Rambøll, P.G. Pedersen***, Miljøstyrelsen, M. S. Linneberg, Miljøstyrelsen****, \\ ${ }^{* * * * *}$ F. Fourie, DWS, $* * * * * * M$. Awodwa, DWS, N. Vermaak, University of Free State, $* * * * * * G$. Metcalf, Umgeni \\ Water
}

\begin{abstract}
Introduction: The Strategic Water Sector Cooperation (SSC) between Denmark and South Africa is a long term bilateral cooperation, which amongst others are contributing to the South African water sector by demonstrating and testing different Danish groundwater mapping methodologies in South Africa in order to add long term value to the South African work on optimizing the utilization of groundwater and to increase the resilience against drought.
\end{abstract}

One key aspect is to develop a South African groundwater mapping methodology, based on the detailed Danish methodology and South African specialized knowledge of the South African hydrogeology.

Methods and data: In this case, the SSC has contributed to the work done by Umgeni Water in The District Municipality of uThukela in the KwaZulu-Natal (KZN) province of South Africa. The District Municipality has appointed Umgeni Water as Water Supply Provider in the area around the city of Ladysmith. The methodology that has been used is integrated modelling using 3-geological models built in GeoScene3D and groundwater modelling, which was based on existing data from Umgeni Water and Department of Water and Sanitation (DWS) and t-TEM data from Aarhus University

Results: Based on the outcome of the 3-D geological voxel model the distribution of 14 different formations have been outlined and within these formations aquifers have been identified and outlined. This includes both known aquifers where the boundary has been adjusted, as well as new aquifers. Good places for drilling production boreholes have been identified, followed by groundwater modelling of sustainable abstraction rates from existing and new potential well fields. Finally, recommendations were made for new data collection and input on how to modify the Danish mapping approach for use in South Africa, taking the differences in geology and water management into consideration.

\section{Discussion and take-home message:}

The Danish methodology for groundwater mapping is adaptable to South African conditions but it requires that Danish and South African experts works close together. There are some challenges, for example the geology is dominated by fractured rock aquifers and groundwater recharge primarily taking place along dykes, challenging the modelling scale. These challenges and knowledge gained will be presented. The project has also shown that integrated 3-D geological modeling and hydrological modelling can contribute to a sustainable development of groundwater in South Africa, as well as the Danish methodology for modelling and monitoring sustainable abstraction rates.

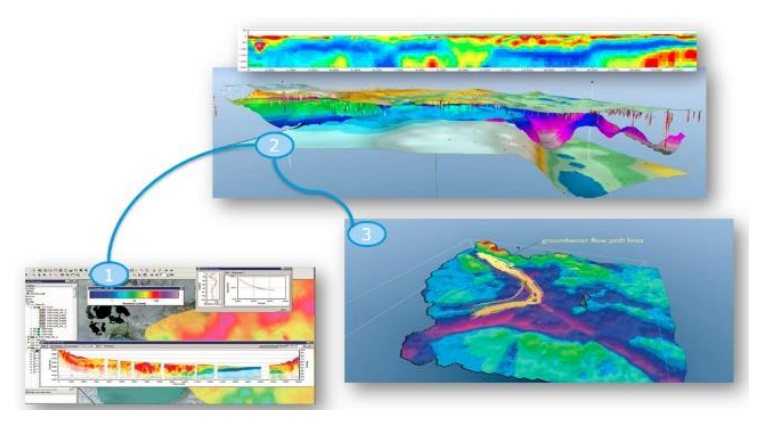

*jnku@ramboll.dk; **tlm@ramboll.dk; ***phghe@mst.dk; ****masli@mst.dk; *****FourieF@dws.gov.za; ******MagingiA@dws.gov.za; *******nokkie.vermaak@gmail.com; ******** graham.metcalf@umgeni.co.za; 


\title{
Flowing rivers and full stomachs? Socio-economic benefits of ecological infrastructure in South Africa
}

\author{
Maya Pasgaard, Niels Fold, Rasmus Skov Olesen and Laura Vang Rasmussen \\ Department of Geosciences and Natural Resource Management (IGN), University of Copenhagen
}

Introduction: Countries, cities and local communities all over the world struggle to secure sufficient clean water, while addressing a whole range of other basic human needs. This presentation addresses the question whether it is possible to promote investments that address hydrological and social challenges at the same time via investments into Ecological Infrastructure. Ecological Infrastructure (EI) constitute the underlying framework of natural ecosystems, functions and processes that supply ecosystem services, including provision of clean drinking water and river flow regulation. A healthy El complements the built - or grey - infrastructure receiving water provided by the upstream ecosystem services from the natural environment.

In South Africa, several public programs are established to restore unhealthy El and thereby improve the quality and quantity of water that supply downstream users, such as inhabitants and businesses in larger cities like Durban and Cape Town. Only a few years back, Cape Town was critically approaching so-called "day zero", where water sources would literally run dry. The public El restoration programs recruits poor people, typically from townships or rural communities, who are employed to conduct ecological restoration in important water catchments. Restoration workers receive a needed income, valuable training and environmental education, and the teams primarily conduct clearing of invasive alien plant species. These water-demanding and ecologically damaging species are infesting and drying out enormous areas, including private agricultural lands and water catchments supplying cities. The challenge is, however, to incentivize a wider range of actors to invest in these or similar programs as public funds are far from being of a sufficient magnitude. A possible way to convince private investors to join forces is to demonstrate that El interventions have positive socioeconomic benefits for those people that are employed to carry out the restoration work.

Methods: In our study we use livelihood surveys, semi-structured interviews and stakeholder discussions to investigate the socioeconomic benefits of the El employment to restorations workers. Data was collected in two separate water catchments, upstream of Cape Town and Durban respectively, and more than 300 workers were surveyed.

Results: Our results show that workers experience great livelihood improvements from their El-related income and from the training and education they receive (Figure). They mainly spend their income on basic needs, such food and medicine improving the health of the entire household, and they can pay for their children's school fees and uniforms. Many workers now proudly perceive themselves as the family's "breadwinner". Their environmental awareness and general wellbeing also increase while they work together to improve essential water sources.

Discussion and take-home message: Our results convincingly show multiple socioeconomic benefits of ecological restoration programs and that coordinated actions combining hydrological and social benefits are needed. However, one big problem overshadows the positive outcomes: Continuity in funding to keep the

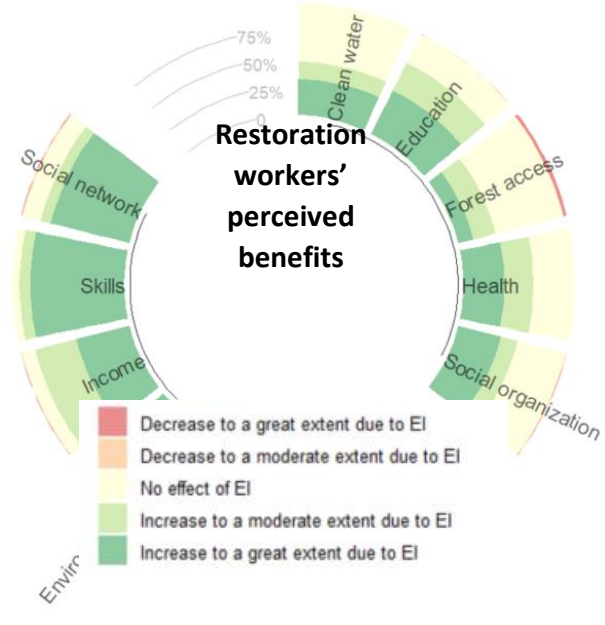
programs running. Our results can be used to promote funding from a broader portfolio of investors interested in projects ranging from social uplifting, green transition, climate mitigation, community development, and -importantlyany attractive combination hereof. 


\section{Pathways to Water Resilient South African Cities (PaWS)}

Lise Herslund, Patience Mguni and Marina Bergen Jensen, University of Copenhagen

Kirsty Carden and Neil Armitage, University of Cape Town

While the need to shift to more adaptive approaches combining centralised water networks with decentralised water sensitive nature-based options is clear, how such hybrid transformations could be realised remains unclear. This Danida supported water research project PaWS combines physical on-ground experimentation with exploration of governance aspects required for the integration of nature-based solutions into the urban water infrastructure in Cape Town and Johannesburg.

In Cape Town the focus is on repurposing existing flood control infrastructure, - detention ponds into infiltration basins through managed aquifer recharge to also improve water supply. The idea is to create multifunctional solutions so the repurposed ponds also can serve as much needed recreational spaces for the adjacent local communities.

In Johannesburg, we examine already implemented nature-based solutions that are emerging as a consequence of Stormwater By-Laws; what works, what does not work and are there missed opportunities etc. Stakeholders involved in the planning, implementation as well as the present maintenance of the solutions are followed in order to explore how such solutions are part/or not part of the urban water governance structure.

A mapping of key stakeholders and a system and actor analysis have been completed in both cities where results indicate a progressive engagement with water sensitive water management in both cities by different actors levels. However, there is a lack of coordination and capacity due to limited social networks between key stakeholders and a lack of an enabling environment for higher order learning to take place. Learning from already, implemented naturebased solutions are not taking place due to limited resources and ambiguity as to who should maintain and monitor. We also find practitioners struggle with reconciling the pursuit of visions of sustainability to be realised through nature-based urban development with the pressing water supply and sanitation deficits that persist.

The results and experiments will serve as a cornerstone in an arena process to start up in both cities where key stakeholders meet up for hands-on learning, master-classes, vision and network-building in order to co-create shared agendas for moving the two cities towards being more water resilient.

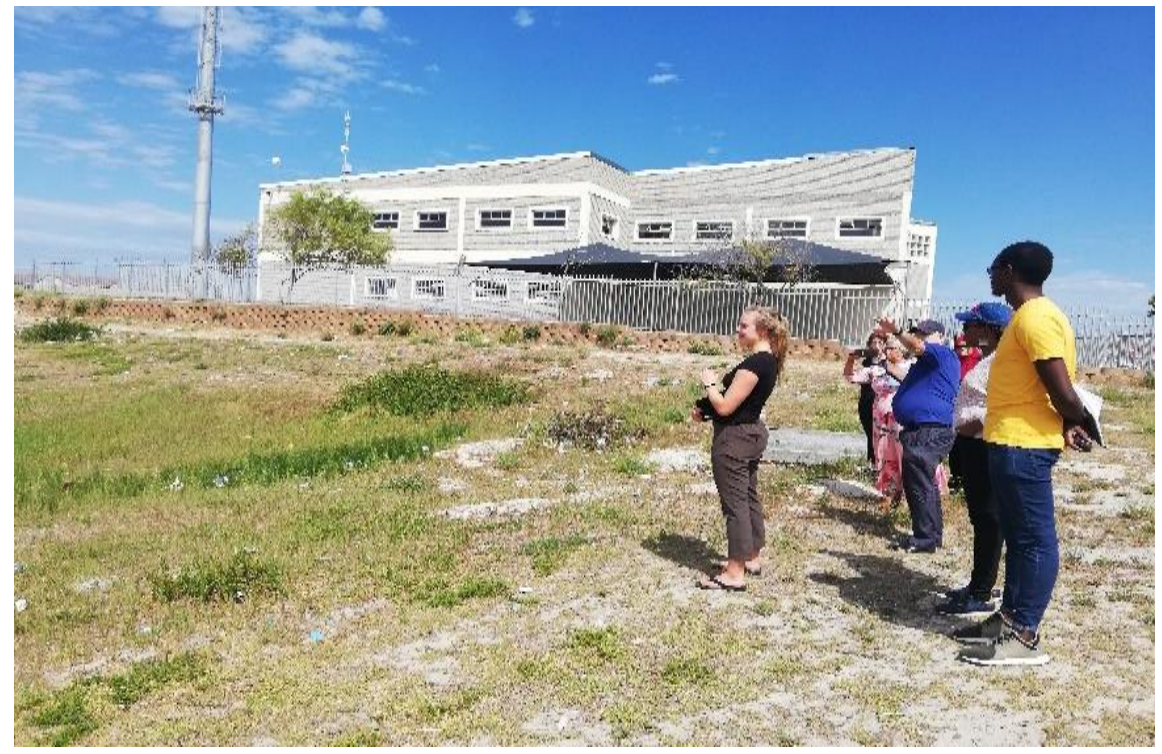

Picture - A site visit to a case detention pond where local people engage with the project members on how they would like the area to develop and how they could take part. The photo is taken by Kirsty Carden in 2020 


\section{Assessment of new sludge management strategies in the Cape Flats wastewater treatment works, South Africa}

X. Flores-Alsina, E. Ramin, K.V. Gernaey, DTU Chemical and Biochemical Engineering ${ }^{1}$ (DK); T. Harding, D. Ikumi, UCT Civil Engineering ${ }^{2}(Z A) ;$ C. Brouckaert UKZN, Chemical Engineering ${ }^{3}(Z A)$; D. J. Batstone, UQ Advanced Water Management Centre $(A U) ;$ S. Sötemann, CoCT Water and Sanitation ${ }^{5}(Z A)$

Introduction: The ERASE (Evaluation of Resource recovery Alternatives in South african water trEatment systems) project funded by the Danida Fellowship Center (DFC) is intending to show to water utilities the benefits of promoting resource recovery (energy, organics, nutrients) in Wastewater Treatment Plants (WWTP). In this particular study, we assisted the City of Cape Town (CoCT) to decide amongst potential upgrades for the Cape Flats (CF) WWTP (see Figure 1a), which together with Vissershok (North) and Zandvlie (East) will centralize sludge treatment in the Western Cape Province (see Figure $1 \mathrm{~b}$ and $\mathrm{c}$ ). The CoCT refers to those as bio-solids beneficiation facilities (BBF).

Methods and Data: A plant-wide model combining both water and sludge line was developed and adapted to the CF design / operational conditions. Flow diagram and model parameters were adjusted to reproduce the influent, effluent and process characteristics. Historical data between January 2014 and December 2019 was used to compare full-scale measurements and model predictions. Next, different process intensification / mitigation technologies were evaluated considering the extra sludge coming from nearby facilities (Athlone, Mitchells Plain and Wildevoelvlei) using multiple objectives (environmental, economic, legal) simultaneously.

Results: Simulation values for COD, TSS, VSS/TSS ratio, TN, TP, $\mathrm{NH}_{4}^{+} / \mathrm{NH}_{3}, \mathrm{H}_{x} \mathrm{PO}_{4}{ }^{3-x}, \mathrm{NO}_{x}$ alkalinity and pH fall within the interquartile ranges of measured data. The effects of the 2017 severe drought on influent variations and biological phosphorus removal are successfully reproduced for the entire period with dynamic simulations. Indeed, $80 \%$ of all dynamically simulated values are included within the plant measurement uncertainty ranges. Sludge management analysis reveals that flow diagrams with thermal hydrolysis pre-treatment (THP) result in a better energy balance in spite of having higher heat demands. The flow diagram with THP is able to i) increase biodegradability/solubility, ii) handle higher sludge loads, iii) change methanogenic microbial population, and iv) generate lower solids volumes to be disposed by improving sludge dewaterability. The study also reveals the importance of including struvite precipitation and harvesting ( $\mathrm{SPH}$ ) technology, and the effect that $\mathrm{pH}$ in the $\mathrm{AD}$ and the use of chemicals $(\mathrm{NaOH}, \mathrm{MgO})$ may have on phosphorus recovery. Model-based results indicate that the current aerobic volume in the water line (if properly aerated) would be able to handle the returns from the sludge line and the contribution of a granular partial nitritation/Anammox (PN/ANX) reactor on the overall nitrogen removal would be marginal. However, autotrophic $\mathrm{N}$ denitrification generates a much lower sludge production and therefore increases AD treatment capacity.

Discussion and take home message: The study shows for the very first time how mathematical models can be used to assess bio-solids beneficiation facilities (BBF), which in case of CF enabled larger, more capital-intensive sludge management strategies. Potential barriers included the ability to process reject streams from multiple donor plants in the host plant.

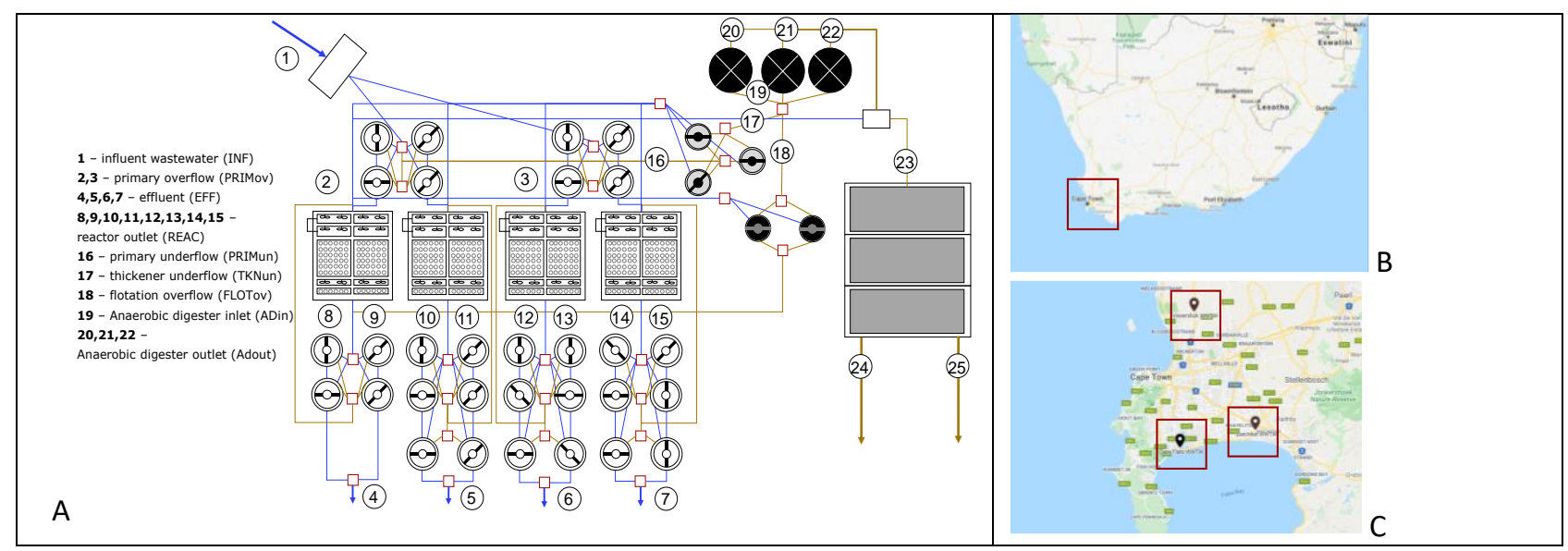

Figure 1. Schematics of Cape Flats $(A)$ and $(B, C)$ location of the future Biosolids benefitiation facilities (BFF) in Western Cape

${ }^{1}$ xfa@kt.dtu.dk, elhr@kt.dtu.dk, kvg@kt.dtu.dk: Process and Systems Engineering Center (PROSYS), Technical University of Denmark. Department of Chemical and Biochemical Engineering. Søltofts Plads Building 227 (Postal address: Building 228 A). 2800 Kgs. Lyngby, Denmark. 


\section{Session 5A: Advances in wastewater treatment technologies Part A}

\section{February 13:00 - 16:00, Teams}

\section{Chair: Hans-Martin Friis Møller, Co-chair: tbd}

13:00 Hans-Martin Friis Møller: Welcome

13:10 Jesper Dannisøe: Logistics

13:15 Ozone microbubbles/ultrasonic system for persistent organic pollutants (POPs) removal in wastewater: Xingaoyuan Xiong, Zongsu Wei

13:30 Elimination of resistant bacteria from untreated hospital wastewater - an environmentally friendly approach tested in pilot scale: Sabine Lindholst, C. Kragelund, M. Mousa, N. Mousa, C. Andersen, T. Eilkær, H.R. Andersen, R. Chhetr

13:45 Efficient biological removal of pharmaceuticals from wastewater effluent using moving bed biofilm (MBBR)/ eXeno technology: Emma S. Rasmussen, Jonas Frigaard, Kasper U. Kjeldsen, Caroline K. Rickers, Aviaja A. Hansen, Kai Tang, Henrik R. Andersen

\section{Break/discussion}

14:15 Ozonation of xenobiotic compounds from wastewater containing bromide, full scale experiences from Kalundborg Central Wastewater Treatment Plant: Sille Bendix Larsen, A. Kamper, D. Rasmussen

14:30 Regeneration of Fe(II) from Fenton-derived ferric sludge using a novel biocathode: Guan Wang, Kai Tang, Yufeng Jiang, Henrik Rasmus Andersen, Yifeng Zhang

14:45 Degradation of metoprolol in a bioelectrochemical system (BES): Xiaoyon Yang, Rusen Zou Kai Tang, Irini Angelidaki, Henrik Rasmus Andersen, Yifeng Zhang

15:00 A novel sponge filter for simultaneous removal of oil and chemical additives from produced water: Pegah Nazari, Omid Yousefi, Zongsu Wei

$15.15 \quad$ Discussion

15:30 Closing remarks 


\title{
Ozone microbubbles/ultrasonic system for persistent organic pollutants (POPs) removal in wastewater
}

\author{
Xingaoyuan Xiong*, Zongsu Wei**, Centre for Water Technology (WATEC), Department of Engineering, Aarhus
}

University

\begin{abstract}
Introduction: $\mathrm{O}_{3}$ /Ultrasonic processes, which does not require any addiction of chemical substances, have been studied to overcome the low ozone-liquid mass transfer efficiency and uncompleted oxidation of persistent organic pollutants (POPs). However, it is extremely challenging to control both ozone bubbles and cavitation bubbles in liquid phase, which directly affect the ozone-liquid mass transfer efficiency and subsequent production of hydroxyl radicals $\left({ }^{\circ} \mathrm{OH}\right)$. To this end, microbubbles, characterized by large interfacial areas, low rising velocity and high inner pressure, were introduced into the $\mathrm{O}_{3}$ /Ultrasonic process for intensifying gas mass transfer into liquid phase.

Methods and data: Using a novel ozonation reactor with a jet flow (figure below), the apparent volumetric mass transfer coefficient (KLa) was calculated by fitting observed data into $\ln \left[C_{s} /\left(C_{s}-C\right)\right]=K$ Lat, where $C_{s}$ is the equilibrium concentration of ozone in deionized water; $C$ is the dissolved ozone concentration. In this case, $C_{s}$ and $C$ were experimentally tested and measured by indigo method. Para-chlorobenzonic ( $\rho C B A)$ as a model POP was tested. The total organic carbon (TOC) of the reaction mixture was detected using a TOC-VCPH analyser.

Results: Maximum $\mathrm{K}$ a value in $\mathrm{O}_{3}$ microbubbles system was calculated to be $0.6451 \mathrm{~min}^{-1}$ while the value in ozone alone system was $0.5800 \mathrm{~min}^{-1}$. As comparison, the maximum $\mathrm{K}_{\mathrm{L}}$ a value in $\mathrm{O}_{3}$ microbubbles/ultrasonic system was $1.2894 \mathrm{~min}^{-1}$, which was at least 1.5 times enhancement compared with ozonation without ultrasonic irradiation. $\mathrm{R}_{\mathrm{ct}}$ value, a ratio of ${ }^{\circ} \mathrm{OH}$ exposure to $\mathrm{O}_{3}$ exposure $\left(\mathrm{Rct}=\left\{\int\left[{ }^{\circ} \mathrm{OH}\right] \mathrm{dt} / \int\left[\mathrm{O}_{3}\right] \mathrm{dt}\right\}\right)$, in $\mathrm{O}_{3}$ microbubbles/ultrasonic system was $1.44 \times 10^{-8}$ compared with $5.400 \times 10^{-9}$ in ozone microbubbles system. The mineralization of $\rho$ CBA was $77.54 \%$ in $\mathrm{O}_{3}$ microbubbles/ultrasonic system, while the mineralization rate reduced to $61.95 \%$ in $\mathrm{O}_{3}$ microbubbles system, and was observed almost no significant change in ultrasonic system.

Discussion and take-home message: The presence of ultrasound waves decreased saturated ozone concentration but improved KLa value, revealing that ultrasonic irradiation can promote the decomposition of ozone and generate more hydroxyl radicals. This enhancement was related to enhanced contact between ozone microbubbles and cavitation bubbles, which was verified by calculated Rct values. Results from this study indicate that ozone oxidation of POPs could be significantly improved by ultrasonic irradiation in microbubble systems.
\end{abstract}

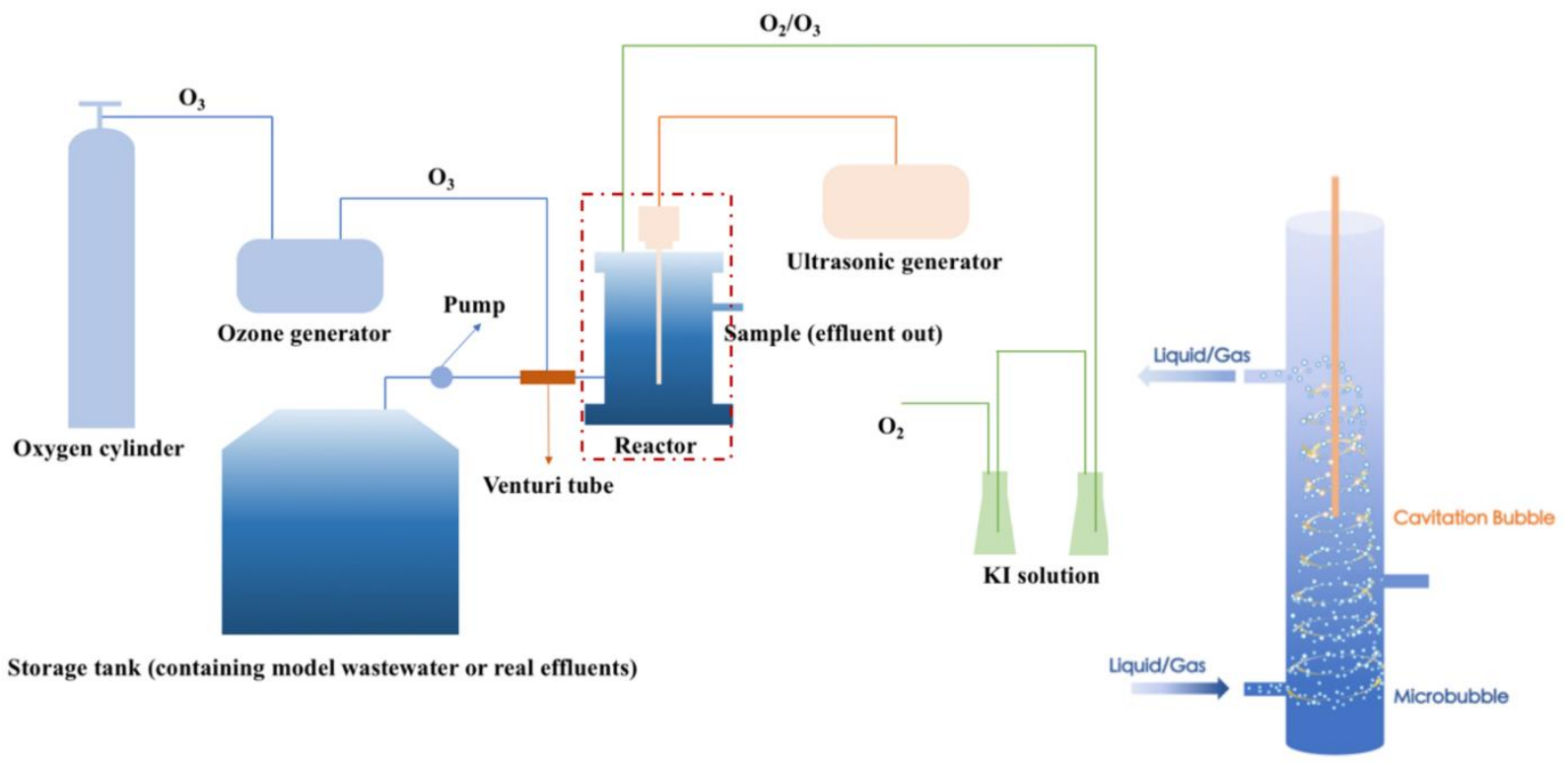

*au681899@uni.au.dk: Nørrebrogade 44, Building 18, 8000 Aarhus C, Denmark

**zwei@eng.au.dk: Nørrebrogade 44, Building 18, 8000 Aarhus C, Denmark 


\section{Elimination of resistant bacteria from untreated hospital wastewater - an environmentally friendly approach tested in pilot scale}

S. Lindholst, C. Kragelund, M. Mousa, N. Mousa, C. Andersen, Danish Technological Institute*, T. Eilkær**, Norlex Systems, H.R. Andersen, R. Chhetri, Technical University of Denmark, DTU Environment***

\section{Abstract}

Antibiotic resistant bacteria are found in hospital wastewater in great extent and constitute a health risk to sewage staff and workers at treatment plants as well as they are unwanted in the environment. This problem is addressed in the MUDP project "Desinfektion af REsistente BAkterier i HospitalsSpildevand", REBAHS, which is kindly supported by the Danish Environmental Protection Agency.

Since there are no requirements for antibiotic bacteria present in wastewater, the project aims to recommend a level of resistant bacteria accepted after disinfection of the hospital wastewater, that is based on the average concentration of resistant bacteria present at WWTPs without hospital contribution. For that purpose, a minimum of six 24-hour samples from each of 7 WWTPS spread in Danmark are analysed and the average calculated, resulting in a preliminary level of $2 \times 10^{4} \mathrm{CFU} / \mathrm{ml}$ (see the orange line in the figure below). This number can change slightly, as at the time of writing not all planned samples are received and analysed.

In a preliminary Innobooster project, the applicability of peracetic acid (PAA) as an environmentally friendly disinfectant was demonstrated in laboratory and one pilot scale test at Aarhus University Hospital. PAA showed very convincing disinfection effectivity and forms acetic acid and water as reaction products. The use of ciprofloxacin resistant bacteria worked nicely as a model organism, as it shows up in large amounts both in hospital-and municipal wastewater. All results are confirmed with tests of different other antibiotics alone and in combinations.

There are two different requirements for disinfection velocity. Hospitals, that possess their own wastewater pipeline, leading the water directly to the WWTP, can use the pipe as "reaction tank" and can do with low PAA concentrations. The wastewater of other hospitals is combined with municipal wastewater on the way to the WWTP. Here the disinfection must be finished before the junction, demanding higher PAA concentrations.

Preliminary disinfection tests with incoming wastewater in the pilot test plant at Hillerød WWTP representing long reaction times (20 to $60 \mathrm{~min}$ ) is shown in the figure below. All treatments showed very high disinfection effectivity (percentage of reduction are shown on the bars). Further steps are tests on hospital wastewater and treatments at SK Forsyning, which represents short reaction times. Data will be available on the meeting.

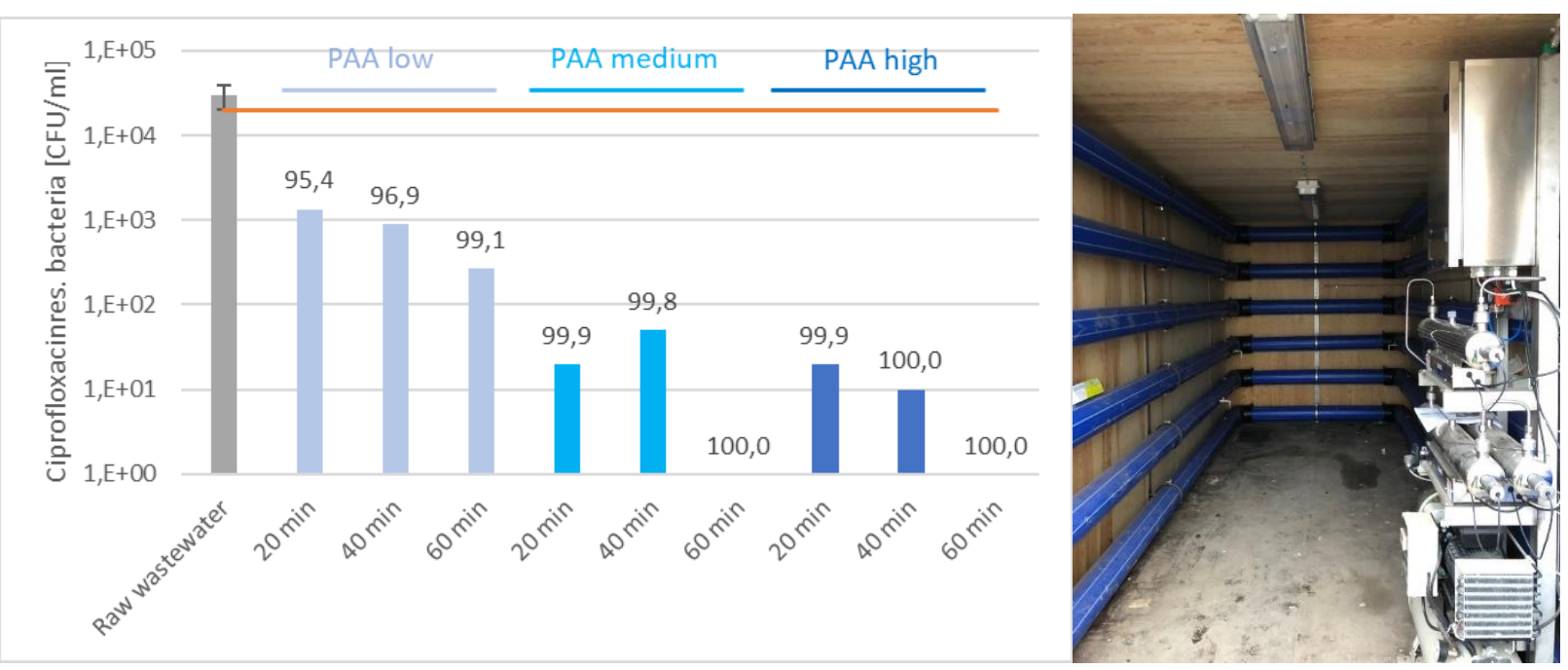

*cakr@teknologisk.dk, sbl@teknologisk.dk: Kongsvang Allé 29, DK-8000 Aarhus, Denmark

**teh@norlex.com: Bistrupvej 172, 3460 Birkerød

*** hran@env.dtu.dk : Bygningstorvet, Bygning 115, 2800 Lyngby 


\title{
Efficient biological removal of pharmaceuticals from wastewater effluent using moving bed biofilm (MBBR)/ eXeno technology
}

\author{
Emma S. Rasmussen*, Jonas Frigaard*, Kasper U. Kjeldsen*, Caroline K. Rickers**, Aviaja A. Hansen***, Kai Tang****, \\ Henrik R. Andersen****
}

\begin{abstract}
The common wastewater treatment plants (WWTPs) based on conventional activated sludge (CAS) do not efficiently decrease micropollutants below the predicted no effect concentrations (PNEC) ${ }^{1}$. Thus, bioactive pharmaceuticals are released into the recipient aquatic environments and causes damaging effects to the natural ecosystems. MBBRs have proved as a promising solution to effectively biodegrade pharmaceuticals from WWTPs at a low cost compared to other removal strategies like ozonation. Previous studies on pharmaceutical removal from effluent wastewater by MBBR, has found that intermittent feeding a small scale MBBR with raw wastewater, sustains a biomass generation that effectively biodegrade pharmaceuticals ${ }^{2}$. Also, an easy

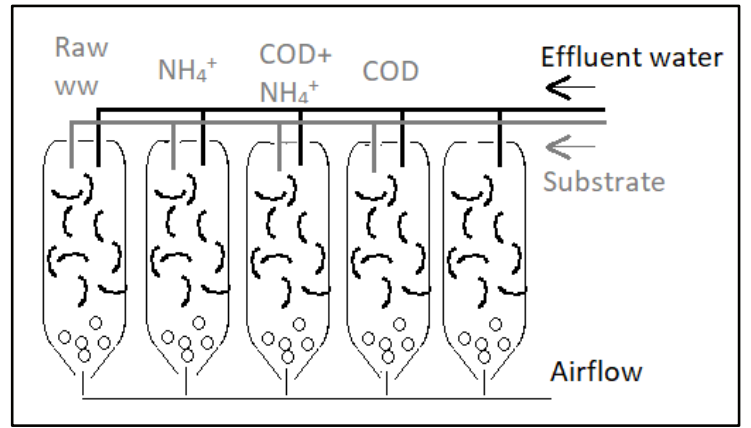

Figure 3 - MBBRs and the experimental setup of differing substrates method to assess pharmaceutical removal has been developed, as a link between nitrification and pharmaceutical removal rates has been found.

This study investigates the relative impact of organic material and nitrogen on MBBR pharmaceutical removal rates by running reactors exclusively on organic material, nitrogen in form of ammonia, and a combination of the two. A reactor was fed raw wastewater, to compare with previous identical setup and a control reactor was fed effluent water only (Fig. 1).
\end{abstract}

Early results indicate that presence of ammonia yields the highest nitrification rates and also the highest removal of pharmaceuticals, (Fig. 2).

Further work aims to identify the phylogenetic aspects of the biofilm by 16 s rRNA sequencing, to cultivate and isolate diclofenac-degrading bacteria as conducted by Bessa et al. (2017) ${ }^{3}$, and finally to link the presence of diclofenacdegrading strains with the MBBR biofilm community determined by NGS.

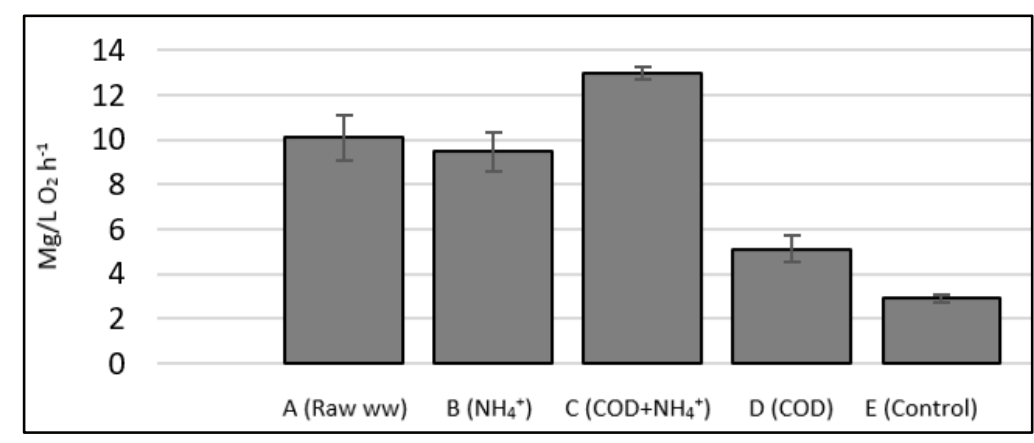

Figure 2 - Nitrification rates of the five reactors measured by oxygen consumption under use of inhibition of ammonia

\footnotetext{
*Emma.skou@bios.au.dk, jonas.frigaard@bios.au.dk: Aarhus University Department of Bioscience, Ny Munkegade 116, 8000 Aarhus.

** cakr@teknologisk.dk: Danish Technological Institute, Kongsvang allé 29, 8000 Aarhus.

***avh@kruger.dk : Krüger A/S, Haslegårdvænget 18, 8260 Aarhus.

**** Kait@env.dtu.dk, hran@env.dtu.dk: Department of Environmental Engineering, Technical University of Denmark, Miljøvej 113, 2800 Kgs. Lyngby.
}

\footnotetext{
1 https://spildevandsinfo.dk/sites/default/files/2019-06/Opdaterede\%20AMK_August_2015.pdf

2 Tang, K. et al. (2017) Bioresour. Technol. 236, 77-86 (2017).

3 Bessa V, Met al., (2017).. International Biodeterioration \& Biodegradation. 120. 135- 142. 10.1016/j.ibiod.2017.02.008.
} 


\title{
Ozonation of xenobiotic compounds from wastewater containing bromide, full scale experiences from Kalundborg Central Wastewater Treatment Plant
}

\author{
S.B. Larsen, Kalundborg Utility*, A. Kamper, $D H I^{* *}, D$. Rasmussen, $D H I^{* *}$
}

\section{Introduction:}

Xenobiotic compounds have proven to be a significant contaminant in the natural environment and the amount is increasing. A large portion of xenobiotic compounds finds its way into the water through the municipal sewer system. Conventional wastewater treatment plants are not designed for removal of xenobiotic compounds and thus they are found in the sludge as well as in the water phase excreted from the plant. Ozone has proven to be an effective and sustainable method for oxidation xenobiotic compounds. However, during the ozone treatment bromide can be oxidised to bromate. Bromide is a natural content of saltwater and is used often in the industry. Bromide is harmless, whereas as bromate is carcinogenic and harmful to aquatic organisms. In general, bromate discharged to the environment is not regulated in Denmark, however Switzerland regulates bromate with a concentration of $50 \mu \mathrm{g} / \mathrm{l}$ for water bodies ${ }^{1}$. The risk of bromate formation could eliminate ozone as relevant technology for removal of xenobiotic compounds for waste water containing bromide concentrations higher than $300 \mu \mathrm{g} / \mathrm{l}$, which would be undesirable due to the sustainability of the technology that through LCA analysis has proven to be the most environmental friendly technology for removal of xenobiotic compounds.

\section{Methods and data:}

Full scale dose response test where conducted at the Kalundborg Wastewater treatment (KCR) plant to correlate the bromate formation to the specific ozone dose. The results showed that at an influent bromide concentration of $2.5 \mathrm{mg}$ $\mathrm{Br}^{-} / \mathrm{l}$ and an ozone dose of $0.9 \mathrm{mg} \mathrm{O} / \mathrm{mg} \mathrm{DOC}$, bromate formation of $0.150 \mathrm{mg} \mathrm{BrO}_{3}^{-} / \mathrm{l}$ is seen. At this specific ozone dose, approximately 85 \% removal of Active Pharmaceutical Ingredients are removed from the water phase.

The PNEC value for bromate in marine waters was originally set to $1.1 \mu \mathrm{BrO}_{3}{ }^{-} / \mathrm{l}$, with an uncertainty factor of $1000^{2}$. A risk assessment showed that the risk from the bromate formation of the marine environment was greater than the risk from the API's in the effluent from the secondary clarifiers before the ozone treatment. Due to the high uncertainty factor for the PNEC value for bromate chronic test with Acartia tonsa was conducted. This entailed that the uncertainty factor for the PNEC values was decreased from 1000 to $100^{3}$. The risk assessment was conducted again with the new PNEC values and the showed that the risk for the marine environment was decreased during ozonation of the water due to the removal of API's. Besides the decrease of the PNEC values for bromate an extensive sampling program in the catchment aera for KCR was conducted to identify and eliminate sources for bromide in the wastewater.

\section{Results:}

The first risk assessment showed the following $\triangle R C R$ values: $\triangle R C R(A P I)=139$ and $\triangle R C R$ (bromate) $=181-455$ The second risk assessment showed the following $\triangle R C R$ values: $\triangle R C R(A P I)=139$ and $\triangle R C R$ (bromate) $=18-45$

\section{Discussion and take-home message:}

The data foundation for several of the decisions taken by authorities are often based on a narrow foundation. To create the full picture, the data baseline must be set. This is especially in relation to the fate- and toxicity of xenobiotic compounds in the environment. The fate of bromate in the environment should be investigated further to eliminate the risk from bromate formation and the use of ozone treatment as a sustainable technology for reduction of xenobiotic compounds. Bromate formation possess an ethical dilemma between removal of xenobiotic compounds versus bromate formation, a dilemma that authorities and utilities should solve proactively together.

\section{References:}

${ }^{1}$ https://www.ecotoxcentre.ch/expert-service/quality-standards/proposals-for-acute-and-chronic-qualitystandards/? ga=2.207927575.4099750.1588590425-2071363133.1575457197

\footnotetext{
${ }^{2}$ Hutchinson TH, Hutchings MJ, Moore KW., 1997. A review of the effects of bromate on aquatic organisms and toxicity of bromate to oyster (Crassostrea gigas) embryos. Ecotoxicol Environ Saf 38, 238-243.

${ }^{3}$ ECHA (2008): Guidance on information requirements and chemical safety assessment. Chapter R.10: Characterisation of dose [concentration]-response for environment
}

\section{* Sila@kalfor.dk: Dokhavnsvej 15, 4400 Kalundborg, Denmark \\ **aka@dhigroup.com: Agern Alle 5, DK-2970 Hørsholm, Denmark}




\title{
Regeneration of Fe(II) from Fenton-derived ferric sludge using a novel biocathode
}

Guan Wang, Kai Tang, Yufeng Jiang, Henrik Rasmus Andersen, Yifeng Zhang, DTU Environment*

\begin{abstract}
Fenton reactions are widely applied when degrading recalcitrant pollutants, but reusing the resulting ferric sludge remains a challenge. A novel concept for regenerating Fe(II) solution at $\mathrm{pH} 6$ based on ferric sludge from neutral Fenton was herein proposed. The microbial fuel cell (MFC) with biocathode and citric acid was used for the first time to promote the regenerated rate of Fe(II) from ferric sludge. The concentration of dissolved Fe(II) reached $120 \mathrm{mg} / \mathrm{L}$ in biocathode, which was much higher than that obtained in abiotic cathode $(<1 \mathrm{mg} / \mathrm{L})$. The main chemical cost of regenerating Fe(II) was only $3.3 \%$ of the commercial Fe(II). Subsequently, the regenerated Fe(II) solution was used to activate $\mathrm{H} 2 \mathrm{O} 2$, to remove pharmaceuticals from the municipal wastewater effluent. A wide range of pharmaceuticals was successfully removed at neutral $\mathrm{pH}$ in $60 \mathrm{~min}$, and the efficiency of the treatment was similar to when the same dosage of commercial Fe(II) was applied.
\end{abstract}

\section{Introduction:}

In this work, a novel process to regenerate $\mathrm{Fe}(\mathrm{II})$ from iron sludge is proposed through the bioaugmentation of iron reducing bacteria (IRB) in the MFC biocathode. The promotion effect of the MFC biocathode on the regeneration of $\mathrm{Fe}(\mathrm{II})$ was first investigated, following which the effects of the initial concentration of $\mathrm{Fe}(\mathrm{III})$ and the ratio of $\mathrm{Fe}(\mathrm{III})$ and citric acid were investigated. Thereafter, the regenerated Fe(II) with a biocathode was initially reused in a neutral Fenton process, to remove pharmaceuticals spiked in deionised water and municipal wastewater effluent.

\section{Methods and data:}

$\mathrm{Fe}(\mathrm{II})$ was regenerated from the ferric sludge mixture (including $200 \mathrm{mg} / \mathrm{L} \mathrm{Fe}(\mathrm{III})$ ) at two parallel MFCs with biocathodes, and it was separated with the synthetic wastewater (including $1 \mathrm{~g} / \mathrm{L}$ sodium acetate) in an anode via the cation exchange membrane. Moreover, experiments with or without citric acid $(3.6 \mathrm{mM})$ in the biocathode were used to examine its influence on the regeneration of Fe(II). Besides, to verify the importance of cathode bacteria, the other two parallel MFCs with an abiotic cathode were used for comparison with the biocathode in $\mathrm{Fe}(\mathrm{II})$ regeneration.

\section{Results:}

The regenerated concentration of dissolved Fe(II) in the novel biocathode was much higher than in systems either without citric acid or with an abiotic cathode.

Regenerated and commercial Fe(II) performed the Fenton reactions in equal measure. Diverse pharmaceuticals were successfully eliminated by the Fenton reaction, using the regenerated $\mathrm{Fe}(\mathrm{II})$ at a neutral $\mathrm{pH}$, which was comparable to the commercial $\mathrm{FeCl}_{2}$.

\section{Discussion and take-home message:}

- A neutral Fenton can be amended, to avoid Fe(II) consumption and iron sludge waste

- Wastewater, used as an electron donor, can separate from Fe(II) into two chambers

- Dissolved Fe(II) can regenerate from ferric sludge, using a biocathode at $\mathrm{pH} 6$

$\mathrm{Fe}(\mathrm{II})$ regeneration at biocathode for neutral Fenton application

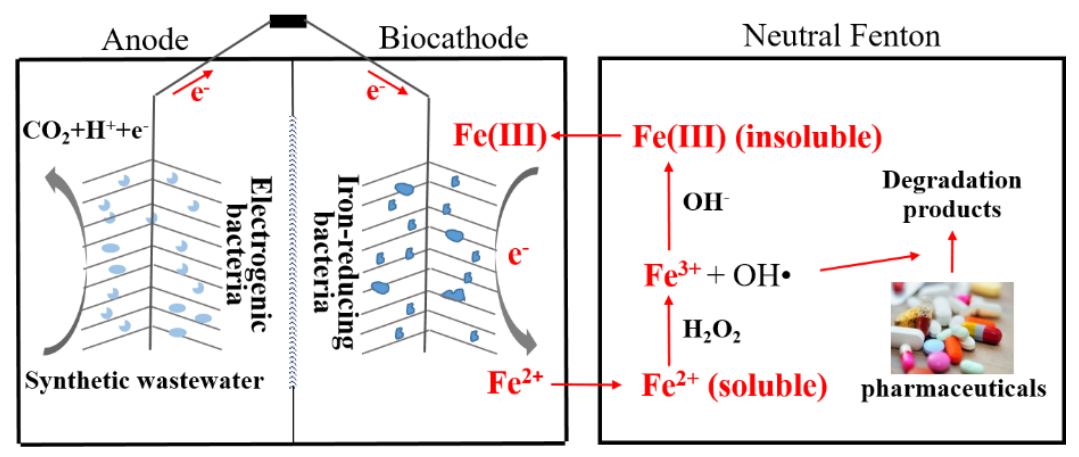

*E-mail: guwan@env.dtu.dk, kait@env.dtu.dk, yuji@env.dtu.dk, hran@env.dtu.dk, yifz@env.dtu.dk 


\section{Degradation of metoprolol in a bioelectrochemical system (BES)}

Xiaoyon Yang, Rusen Zou, Kai Tang, Irini Angelidaki, Henrik Rasmus Andersen, Yifeng Zhang* Department of Environmental Engineering, Technical University of Denmark, Kgs. Lyngby, Denmark, 2800

\section{Abstract}

Electro-Fenton (EF) process is an efficient technique to eliminate emerging pollutants; however its high energy requirement hindered its application to real wastewater treatment. Bioelectrochemical system (BES) was proved able to significantly reduce energy input by employing electroactive bacteria in a bio-anode. In the present study, the feasibility and efficiency of metoprolol removal in a BES through bioelectro-Fenton (BEF) process was examined. Applied voltage $(0 \sim 0.6 \mathrm{~V})$ and catholyte $\mathrm{pH}(2 \sim 7)$ had significant effects on the metoprolol removal while Fe dosage in the range of $0.1 \sim 1 \mathrm{mM}$ showed a minor effect on metoprolol removal. The metoprolol removal in the BES was subsequently determined at continuous flow mode. When the hydraulic retention time (HRT) was 2 hours, $77 \%$ of metoprolol was removed and the energy per order of magnitude per $\mathrm{m}^{3}$ (EE/O) was thousands times less than the energy cost in conventional EF process.

Introduction: Micropollutants (also named as emerging pollutants) are found ubiquitous in water environments and have unwanted impacts on the environment as well as human beings. Conventional wastewater treatment plants which were designed without the consideration of emerging pollutants removal have become a significant point pollution source and therefore cost-effective and sustainable advanced treatment techniques are needed. ElectroFenton (EF) process as a kind of advanced oxidation process was found has a high efficiency on micropollutants removal however requires a high energy input.

Methods and data: A lab-scale BES was set up and the removal tests were firstly examined at batch mode. The effects of applied voltage, $\mathrm{pH}$ and catalyst dosage on metoprolol removal were determined. The possible metoprolol degradation pathway was also proposed. Afterwards, the effect of HRT on metoprolol was investigated at continuous flow mode. Biotoxicity of the effluent along processing period was also tested.

Results: $66 \%$ of metoprolol (initial concentration $500 \mu \mathrm{g} / \mathrm{L}$ ) was removed in 12 hours when the BES was supplied with a voltage of $0.2 \mathrm{~V}, \mathrm{pH} 3$ and a Fe dosage of $0.2 \mathrm{mM}$. 77\% of metoprolol (initial concentration $10 \mu \mathrm{g} / \mathrm{L}$ ) was removed when the BES was operated at continuous flow mode (HRT $2 \mathrm{~h}, 0.2 \mathrm{~V}, \mathrm{pH} 3$, and Fe $0.2 \mathrm{mM}$ ). The EE/O was $5.3 \times 10^{-3}$ $\mathrm{kWh} /$ order $/ \mathrm{m}^{3}$.

Discussion and take-home message: Applied voltage, catyolyte $\mathrm{pH}$ and Fe dosage need to be optimized before real application. Multiple reactions (e.g., adsorption, electrocoagulation and advanced oxidation) were involved in the removal process.
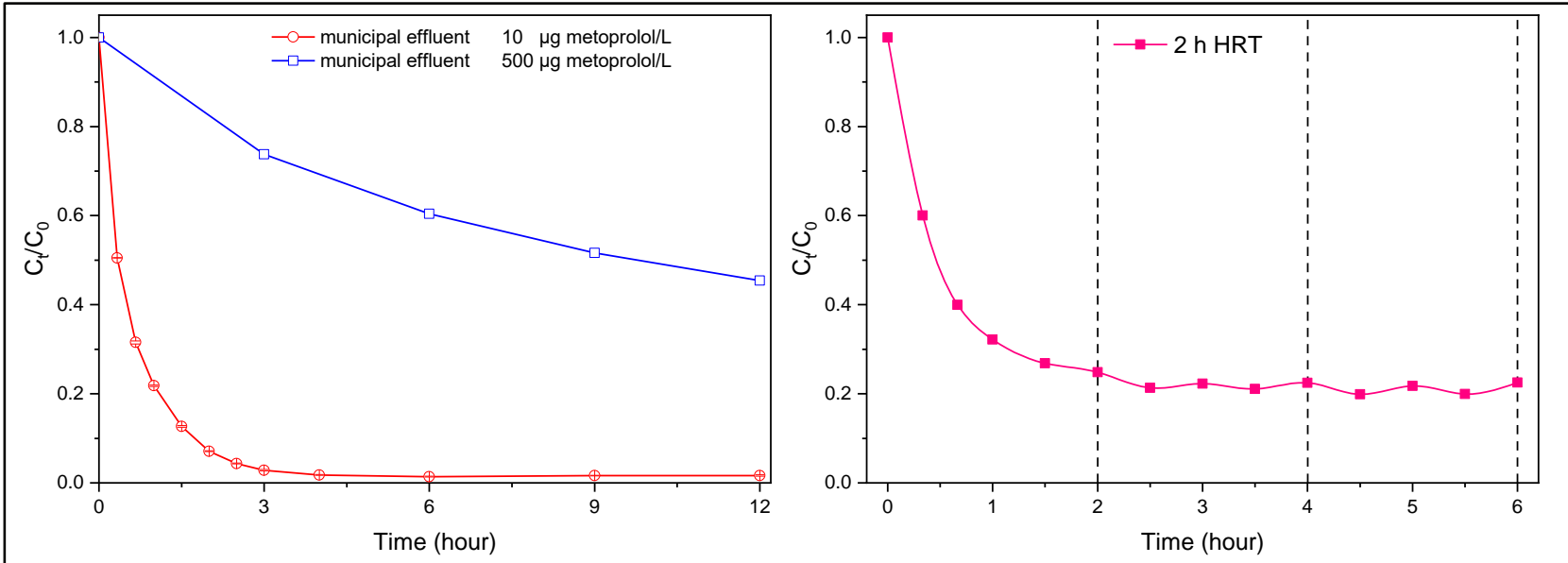

*yifz@env.dtu.dk: Anker Engelunds Vej 1, Building 115, 2800 Kgs. Lyngby 


\title{
A novel sponge filter for simultaneous removal of oil and chemical additives from produced water
}

Pegah Nazari*, Omid Yousefi**, Zongsu Wei***

Centre for Water Technology (WATEC) and Department of Engineering, Aarhus University

\begin{abstract}
Introduction: To protect marine ecosystem from the discharge of produced water (PW) containing oil residuals, OSPAR has set the discharge limit of no more than $30 \mathrm{mg} \mathrm{L}^{-1}$ during oil and gas production. Among the treatment methods, the adsorption technique is widely considered due to low-cost procedure, high efficiency, and adsorbent recoverability. Particularly, the dual (oleophilic and hydrophilic) characters of polyurethane (PU) sponge make it an outstanding choice for simultaneous removal of oil and dissolved chemicals from contaminated water. However, regeneration of the spent $\mathrm{PU}$ is quite challenging in practice. To this end, titanate nanotubes (TNT) loaded activated carbon (AC), a novel adsorptive photocatalyst, was introduced enabling to not only enhance the adsorption capacity of PU sponge but also photocatalytically degrade adsorbed compounds for regeneration. In the present work, the TNT@AC@PU sponge filter was fabricated to remove both oil and chemical additives (i.e., phenol) from mimic produced water and conveniently regenerate the spent filter under electro-photo-chemical treatments.
\end{abstract}

Methods and data: The composite TNT@AC was first prepared with a hydrothermal method. Then, polyurethane (PU) sponge blocks were impregnated by the suspension of TNT@AC in methanol. FT-IR, SEM, and energy-dispersive EDS mapping were used to characterize the sponge filters. To measure the pump/motor oil and phenol adsorption onto TNT@AC@PU, the immersion method was performed. For the flow experiment, a mixture solution containing both phenol and oil was used. The two-step method for regeneration of TNT@AC@PU filter was carried out: first, physically squeezing out the adsorbed oils; next, electro-photo-chemical treatment of the entrapped oil residual and phenol.

Results: The characterization results indicated that TNT@AC@PU sponges were synthesized successfully. TNT@AC (1:8) and TNT@AC (2:1) coated sponge had the best performance in pump and motor oils, respectively. While the salinity level has different impacts on oil adsorption, by increasing the $\mathrm{pH}$ value from acidic to basic, the phenol and pump oil adsorption was declined. By fitting adsorption models, it is revealed that the Langmuir model was the best model for describing the phenol adsorption onto the sponge depicting a monolayer and uniform adsorption of phenol in both single and binary (presence of motor/pump oil) systems. We observed that more than 300 goil $_{\text {TNT@AC }}{ }^{-1}$ and 0.36 gphenol gTNT@AC $^{-1}$ can be adsorbed by the TNT@AC@PU. Further, the adsorption capacity of sponges remains almost constant after four cycles for both pump and motor oils.

Discussion and take-home message: Results from batch and flow experiments indicate that TNT@AC@PU has excellent adsorption ability for oil and phenol, although the structural properties of oils play a significant role in the adsorption behavior. High performance of TNT@AC@PU in salty systems, along with high regeneration capacity of sponge filters after four cycles, make it a promising method for minimizing hazardous discharge offshore securing a safe marine environment.

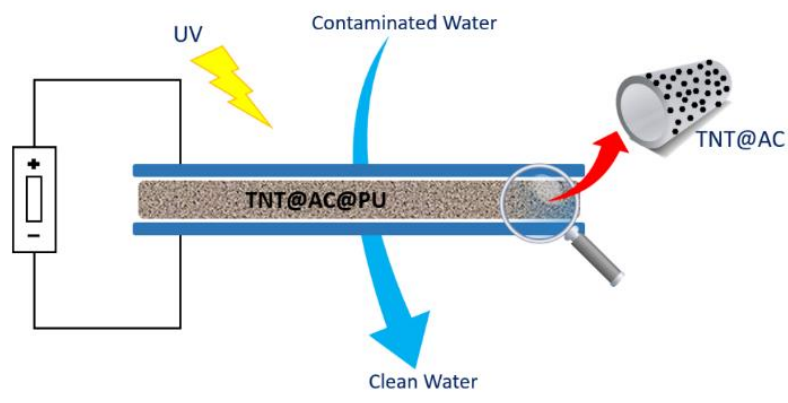

Figure 1: TNT@AC@PU sponge filter and electro-photo-chemical regeneration setup.

*nazari pegah@eng.au.dk: ** yousefipost@gmail.com: *** zwei@eng.au.dk: Nørrebrogade, Building 18, 8000 Aarhus C, Denmark 


\section{Session 5B: Advances in wastewater treatment technologies}

2. March 13:00 - 16:00, Teams

\section{Chair: Hans-Martin Friis Møller, Co-chair: tbd}

13:00 Hans-Martin Friis Møller: Welcome

13:10 Jesper Dannisøe: Logistics

13:15 Machine learning for anomaly detection in combined sewer systems: Rocco Palmitessa, A. Brink-Kjær, L. K. H. Clemmensen, M. Borup, P. S. Mikkelsen

13:30 From wastewater to industry, the potential of Constructed Wetland biomass to produce high value bio-resources: M. A. Rodriguez-Dominguez, B. E. Bonefeld, M. A. Jensen, H. Brix and C. A. Arias:

13:45 Use of struvite and PCP as phosphorus sources for microbial protein production: $\mathrm{E}$. M. Goonesekera, P. Tsapekos, I. Angelidaki, Borja Valverde-Pérez

14.00 Membrane distillation for simultaneous recovery of phosphorus and ammonia from digester centrate: Aamer Ali, M.L. Christensen

14:15 Phosphorous recovery from wastewater treatment: testing the bioavailability of $P$ bound to calcite material for maize (Zea Mays L.) growth: Solvei Mundbjerg Jensen, C. Esposito, D. Konnerup, H. Brix, C.A. Aria

14:30 Break/Discussion

14:45 Microflora Danica: Investigation of the microbiome of Denmark with focus on wastewater and wastewater treatment plants: Per Halkjær Nielsen, A. Murguz, G. Dottorini, M. Nierychlo, V.R. Jørgensen

15.00 Denitrifiers in activated sludge are particularly vulnerable to nanoplastic pollution: Thomas William Seviour, S. Mugunthan, S. Kjelleberg:

15.15 Putting MABR technology to the test at the Ejby Mølle WRRF: Nerea Uri Carreño, P.H. Nielsen, X. Flores-Alsina, Krist V. Gernaey

15.30 Vacant

15:45 Discussion/closing remarks 


\title{
Machine learning for anomaly detection in combined sewer systems
}

\author{
R. Palmitessa ${ }^{1, a}$, A. Brink-Kjær ${ }^{2, b}$, L. K. H. Clemmensen ${ }^{3, c}$, M. Borup ${ }^{1, d}$, P. S. Mikkelsen ${ }^{1, e}$
}

\begin{abstract}
The digitalization of the water sector requires the collection of large quantities of data. In urban drainage systems, this is increasingly made possible by the deployment of affordable and wireless sensors. With the increased availability of data, the need for an automatic validation of the measurements becomes paramount. This can be achieved, for example, by comparing the value measured by a sensor with the prediction of a model capable of replicating the normal behaviour of the system. This approach can detect the occurrence of anomalies, which can be either caused by a faulty sensor or a faulty system. Machine Learning (ML) can serve this purpose well, provided that the chosen technique is fine tuned to the problem at hand. Although several studies are documented in the scientific literature, there is no general consensus on which technique is best suited for urban drainage systems, and new options are continuously made available. In this study, we present an application of ML for the automatic detection of anomalies in sensor data from combined sewer systems and we outline the future research needed in this field.
\end{abstract}

Artificial Neural Networks (ANN) have the ability to learn complex, non-linear patterns in data. Long Short-Term Memory (LSTM) networks, a variant of ANN, are capable of learning temporal dependencies in the data, which makes them particularly suitable for time series prediction. We trained an LSTM network on past observations from a combined sewer overflow chamber (water depth and rainfall intensity) and used the trained model to predict the current water depth. We then compared the measured and predicted values to detect anomalies in the time series.

An LSTM network was trained on 8 months of data at 1-minute resolution. The training data included the measured water depth and the average rainfall intensity from the two rain gauges located closest to the chamber. The LSTM prediction generally matched the observed data, except for one 4-day-long event during which a large discrepancy was observed between measurement and prediction (Figure 1). Further investigation revealed that the anomaly was caused by a blockage downstream of the overflow chamber, which was not quickly detected at the time.

These preliminary results show a potential application of $\mathrm{ML}$ for anomaly detection in combined sewer systems. However, further research is needed to identify appropriate error measures and to improve the prediction accuracy, in order to avoid false alarms. Also, the setup and tuning of the ML model needs to be streamlined, in order to facilitate the deployment of the proposed methodology to a large number of sensors and locations.

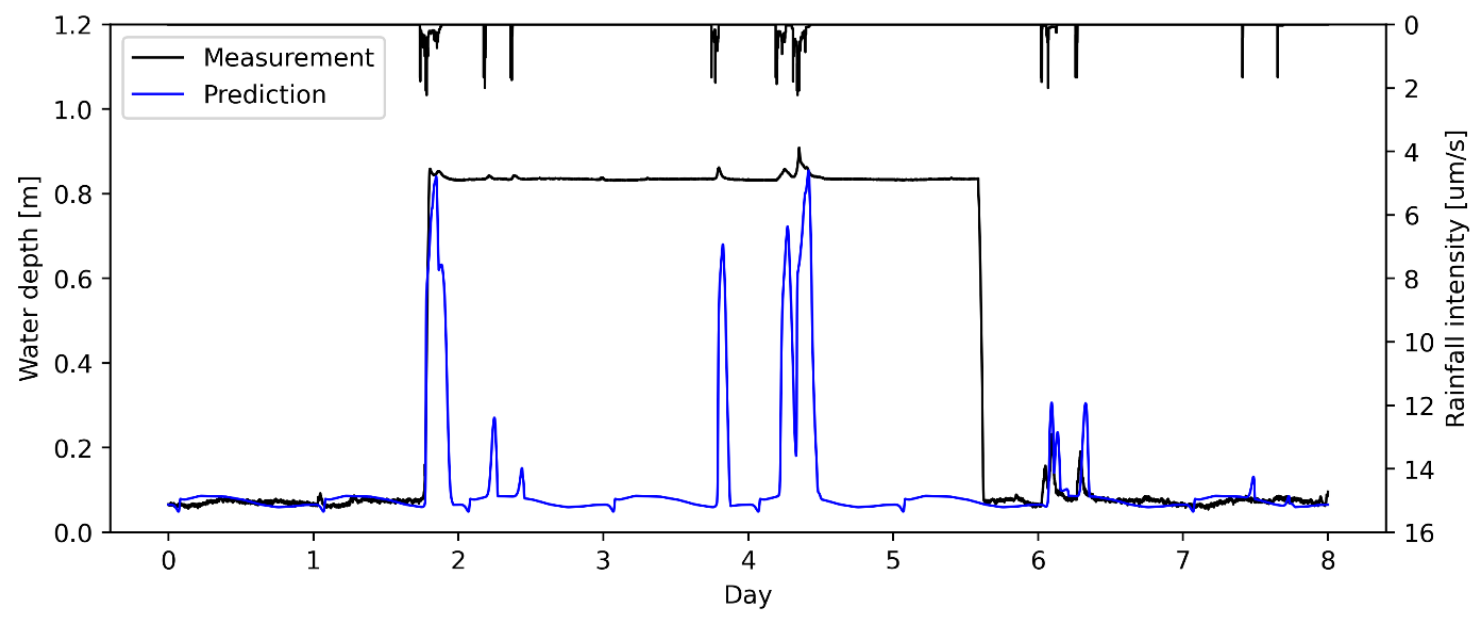

Figure 1. Primary vertical axis: Water depth at combined sewer overflow measured by hardware sensor (solid black line) and predicted with machine learning model (solid blue line). Secondary vertical axis: average rainfall intensity calculated from measurements at the two rain gauges closest to the overflow chamber.

${ }^{1}$ DTU Environment, Bygningstorvet, Building 115, DK-2800 Kgs. Lyngby

${ }^{2}$ VandCenter Syd, Vandværksvej 7, DK-5000 Odense

${ }^{3}$ DTU Compute, Richard Petersens Plads, Building 324, DK-2800 Kgs. Lyngby

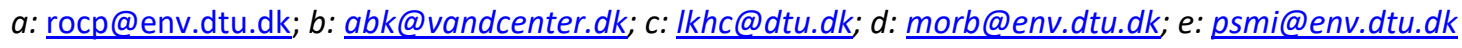




\title{
From wastewater to industry, the potential of Constructed Wetland biomass to produce high value bio-resources
}

\author{
M. A. Rodriguez-Dominguez, AU Biology/WATEC *, B. E. Bonefeld, AU Dept Eng **, M. A. Jensen AU Dept Eng **, H. \\ Brix AU Biology/WATEC *, and C. A. Arias AU Biology/WATEC *,
}

Introduction: Constructed wetlands (CW) technology is a nature-based solution, where natural processes are optimized to improve water quality. CWs are characterized by relatively low establishment costs, robustness, easily operated and maintained, and a high potential for application to treat different pollutants and climatic conditions. The performance of the technology is proven and well documented. The role of the plants have been extensively discussed, however, very seldom the studies evaluate the potential of the produced biomass in the context of circular economy. This study aims at assessing the potential of CW biomass to be transformed to a resource with high economic value. The study compared the production yields for plants growing in natural environment and those exposed to water pollutants, while ensuring no risks in the use of plants exposed to pollution.

Methods: From a local water treatment system five of the most used plants species in CW were selected to be compared to the same species that were growing under natural conditions. The analysis included, water quality parameters (APHA 2012), heavy metals in the water and the plants (ICP), Total Solids in biomass (NREL/TP-510-42621), Determination of Protein Content in Biomass (NREL/TP-510- 42625), Determination of Structural Carbohydrates and Lignin in Biomass (NREL/TP-510-42618) for cellulose content determination.

Results: Biomass obtained from CW seem suitable for cellulose and protein production. No heavy metals were found in the biomass, neither for the plants growing under natural conditions and those exposed to pollution, suggesting that the plants are safe for further applications. The results also show that crude protein content from the extracted from the plants is suitable to produce animal feeding. The content, the yields and quality of cellulose obtained from plants could be proper to be introduced in the current industrial methods for paper and textile production. Additionally, differences were found in sugar production among the plants and treatments (Fig 1). The harvested material can also be used directly as a slow released bio-fertilizer for agriculture.

Discussion and take-home message: This is the first approach to recover high value products from biomass harvested from CW. The environmental value of the plants lies on the fact that the biomass is considered a residual product and up to now, no aggregated value has been found from this low carbon foot print wastewater treatment. For the production of the plants', no extra land or nutrients are needed for growing the plants since they are part of the system. However, further studies dealing with primary production of the plants, digestibility of the produce protein, and uses of the cellulose and sugar obtained should be performed to optimize the potential and the quality of the products

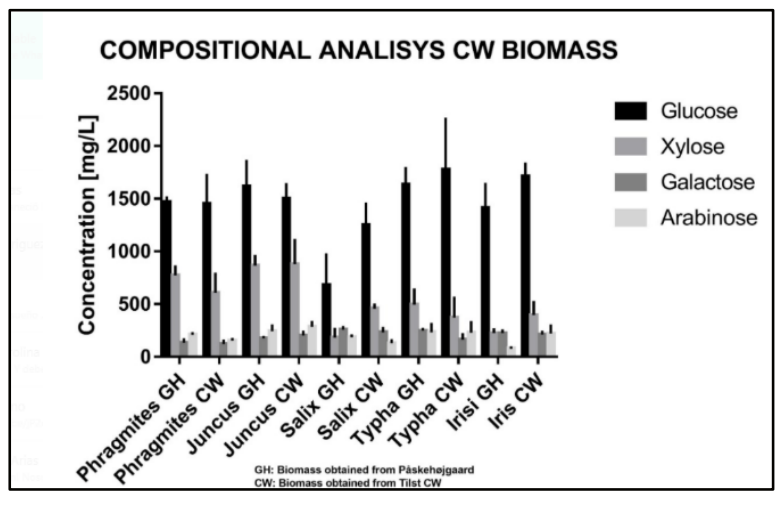

Figure 1 Sugar yield extrracted from five CW species

in the context of the circular economy. Additionally, and to increase the global impact of the study, it would be relevant to select other species used in CW, especially for systems running in the less develop countries were CW are now widely used. The approach from this particular can transform the wastewater treatment process in productive system, and simultaneously improving water quality and generating resources.

Acknowledgments The authors want to acknowledge the support from PAVITR project, a EU Horizon 2020 research and innovation programme, grant agreement No 821410 and CONACYT-CENER scholarship CVU 301254

\footnotetext{
* Department of Biology, Aarhus University Centre for Water Technology WATEC Aarhus University mard@bio.au.dk hans.brix@bio.au.dk carlos.arias@bio.au.dk
}

** Centre for Circular Bioeconomy, Department of Engineering, Aarhus University, birgit@eng.au.dk, maj@eng.au.dk 


\title{
Use of struvite and PCP as phosphorus sources for microbial protein production
}

\author{
E. M. Goonesekera, P. Tsapekos, I. Angelidaki, B. Valverde-Pérez*
}

Introduction: Microbial protein (MP) has regained popularity as an alternative to traditional protein, being methane oxidising bacteria (MOB) one option for its production. Current production processes rely on fossil fuels, although there is an increasing trend of using residual streams to obtain a more circular production model. Up to now, most research on nutrient recovery via $\mathrm{MOB}$ has focused on the nitrogen and methane sources, while little attention has been payed to phosphorus, also crucial for protein production. This study aims to understand the phosphorus requirements of methane oxidising bacteria, thus allowing an optimised use of phosphorus recovered at WWTP.

Methods and data: Batch experiments were run with different residual phosphorus sources and testing ammonia and nitrate as nitrogen sources in gas tight serum bottles. Inoculum was obtained from fermenters growing $\mathrm{MOB}$ enrichments. Optical density, $\mathrm{pH}$ and concentration of soluble $\mathrm{NH}_{4}{ }^{+}, \mathrm{NO}_{3}{ }^{-}, \mathrm{NO}_{2}{ }^{-}$and $\mathrm{PO}_{4}{ }^{3-}, \mathrm{COD}, \mathrm{TN}$ and TP were monitored in the liquid phase, while $\mathrm{O}_{2}, \mathrm{CH}_{4}$ and $\mathrm{CO}_{2}$ content was tracked in the headspace. Each experimental condition was run in duplicate. At least three consecutive runs for each condition were carried out. Microbial protein and amino acid profile were analysed at the end of the batches. Struvite was collected from Helsing $\varnothing r$ Forsyning $A / S$ (Helsingør, Denmark) and PCP was provided by EasyMining Sweden AB. Both were analysed for heavy metal content. Both struvite and PCP cannot be dissolved in water with characteristics that promote MOB growth. Thus, a preliminary screening of dissolution methods was performed, including different temperatures $\left(25\right.$ and $\left.37^{\circ} \mathrm{C}\right), \mathrm{pH}$ levels $(2$ and 5$)$ and acids $\left(\mathrm{H}_{2} \mathrm{SO}_{4}\right.$ and $\left.\mathrm{HCl}\right)$.

Results and Discussion: $\mathrm{pH}$ has a larger effect than temperature on phosphate dissolution. PCP dissolved best at $\mathrm{pH} 2$ and $25^{\circ} \mathrm{C}$, whilst struvite did at $37^{\circ} \mathrm{C}$. Recommended dissolution times are $4 \mathrm{~h}$ for struvite and $30 \mathrm{~min}$ for PCP. Using $\mathrm{H}_{2} \mathrm{SO}_{4}$ had a detrimental effect on $\mathrm{MOB}$ due to the resulting high ionic strength. Thus, $\mathrm{HCl}$ was preferred and used for the preparation of the cultivation media with PCP and struvite. Although lower, growth rates were not statistically different when supplying phosphorus from PCP or struvite (Table 1). Lowest yield was for PCP with $\mathrm{NH}_{3}$, although differences were not significant. It should be noted that the appearance of this batch was cloudy due to precipitation of $\mathrm{NH}_{4}{ }^{+}$and $\mathrm{PO}_{4}{ }^{3-}$. This could have generated cellular stress, which could lead to lower biomass yields. Indeed, for this batch the highest concentrations on soluble COD, TN and TP were detected by the end of the experiment, suggesting incomplete methane oxidation to different organic by-products, like external polymeric substances or low molecular weight organic acids ( $28.2 \pm 5.4 \%$ of the fed methane was converted into soluble organics). When using PCP as phosphorus source, the protein content was lower than in the controls. The batch where struvite was used as phosphorus and nitrogen source showed the highest protein content. Protein content higher than $70 \%$ of CDW is desirable for using microbes as feed ingredient. However, the use of residual resources from anthropogenic origin (i.e., sewage) for producing feeds and foods is currently banned. Indeed, biomass harvested from the control with $\mathrm{NO}_{3}{ }^{-}$and $\mathrm{NH}_{3}$ with struvite exceeded the limit on lead content for feeds. Biomass from $\mathrm{NH}_{3}$ with struvite also exceeded the limit for cadmium. Thus, another promising application is the hydrolysis of the protein content to produce amino acid hydroxylates, which can be used as plat bio-stimulant with a market value higher than mineral fertilizers.

Take-home messages: Key findings of our work are: 1) both PCP and struvite are good phosphorus sources for production of microbial protein via methanotrophs cultivation; 2) struvite yields highest protein content, although it has high content of cadmium and lead; 3) PCP induces microbial stress, which results in lower biomass yields and high conversion of methane into dissolved organic carbon, which needs to be treated before effluent discharge.

Table 1. Growth rates, biomass yields on methane, nitrogen and phosphorus and protein content.

\begin{tabular}{|c|c|c|c|c|c|}
\hline Condition & $\begin{array}{c}\text { Growth rate (d- } \\
\text { 1) }\end{array}$ & $\mathbf{Y}_{\text {CDW/CH4 }}$ & $\mathbf{Y}_{\text {CDW/N }}$ & $\mathbf{Y}_{\text {CDW/P }}$ & $\begin{array}{c}\text { Protein content } \\
\text { (\% CDW) }\end{array}$ \\
\hline Control $\mathrm{NH}_{3}$ & $1.11 \pm 0.00$ & $0.24 \pm 0.03$ & $14.7 \pm 1.1$ & 33.0 & $52.7 \pm 1.6$ \\
\hline Control $\mathrm{NO}_{3}{ }^{-}$ & $1.06 \pm 0.07$ & $0.26 \pm 0.02$ & $22.5 \pm 1.2$ & $93.5 \pm 3.0$ & 62.0 \\
\hline $\mathrm{PCP} \mathrm{NO}_{3}{ }^{-}$ & $0.88 \pm 0.05$ & $0.29 \pm 0.03$ & $24.3 \pm 1.1$ & $67.3 \pm 20.3$ & $48.9 \pm 1.5$ \\
\hline Struvite $\mathrm{NH}_{3}$ & $0.72 \pm 0.17$ & $0.26 \pm 0.06$ & $16.2 \pm 3.1$ & $26.8 \pm 1.3$ & $80.4 \pm 4.7$ \\
\hline $\mathrm{PCP} \mathrm{NH}$ & - & $0.21 \pm 0.06$ & $16.18 \pm 0.57$ & $22.0 \pm 0.6$ & $12.1 \pm 3.2$ \\
\hline
\end{tabular}

Acknowledgements: This work is funded by the Danish EPA - MUDP (Project FUBAF J.nr. Mst-11700508).

Corresponding author: bvape@env.dtu.dk, Technical University of Denmark 


\section{Membrane distillation for simultaneous recovery of phosphorus and ammonia from digester centrate}

\section{A. Ali *, M.L. Christensen**, AAU Chemistry and Bioscience}

\section{Abstract}

Introduction: Recovery of ammonia $\left(\mathrm{NH}_{3}\right)$ and phosphorous $(\mathrm{P})$ from municipal wastewater is important to minimize the environmental impact of their discharge and to comply with the concept of circular economy. Technologies have been established to recover $\mathrm{P}$ in form of struvite $\left(\mathrm{MgNH}_{4} \mathrm{PO}_{4} \cdot 6 \mathrm{H}_{2} \mathrm{O}\right)$ and used it as a fertilizer. It has been demonstrated in literature that recoverable amount of $\mathrm{P}$ from wastewater can be increased by increasing its concentration. $\mathrm{NH}_{3}$ is usually converted to molecular nitrogen and released to the atmosphere; however $\mathrm{NH}_{3}$ recovery in form of $\mathrm{NH}_{3} / \mathrm{H}_{2} \mathrm{O}$ mixture is relevant for numerous applications such as manufacturing of cleaning agent, sanitizers and liquid fertilizer. Thus, the objective of the current study is to apply a less-explored technology (membrane distillation) to concentrate $P$ and, at the same time, recover $\mathrm{NH}_{3}$ in form of $\mathrm{NH}_{3} / \mathrm{H}_{2} \mathrm{O}$ mixture from wastewater.

Methods and data: Membrane distillation (MD), a process driven by the partial vapor pressure across a hydrophobic membrane, has demonstrated the potential of concentrating the non-volatiles while, at the same time, removing volatiles from a solution. The current study compares the performance of direct contact and vacuum MD (VMD), which are two operating modes of $\mathrm{MD}$, for simultaneous recovery of $\mathrm{NH}_{3}$ and $\mathrm{P}$ from wastewater in form of $\mathrm{NH}_{3} / \mathrm{H}_{2} \mathrm{O}$ mixture and struvite, respectively. Experiments have been carried out by using digester centrate from Aaby wastewater treatment plant in Aarhus, Denmark.

Results: MD applied in direct contact as well as vacuum mode (represented with DCMD and VMD, respectively in figure below) was able to concentrate $\mathrm{P}$ in wastewater more than 2.5 times. Consequently, it was possible to recover more than $90 \% \mathrm{P}$ present in wastewater in form of struvite. MD also allowed recovering up to $90 \% \mathrm{NH}_{3}$ from wastewater in form of $\mathrm{NH}_{3} / \mathrm{H}_{2} \mathrm{O}$ mixture.
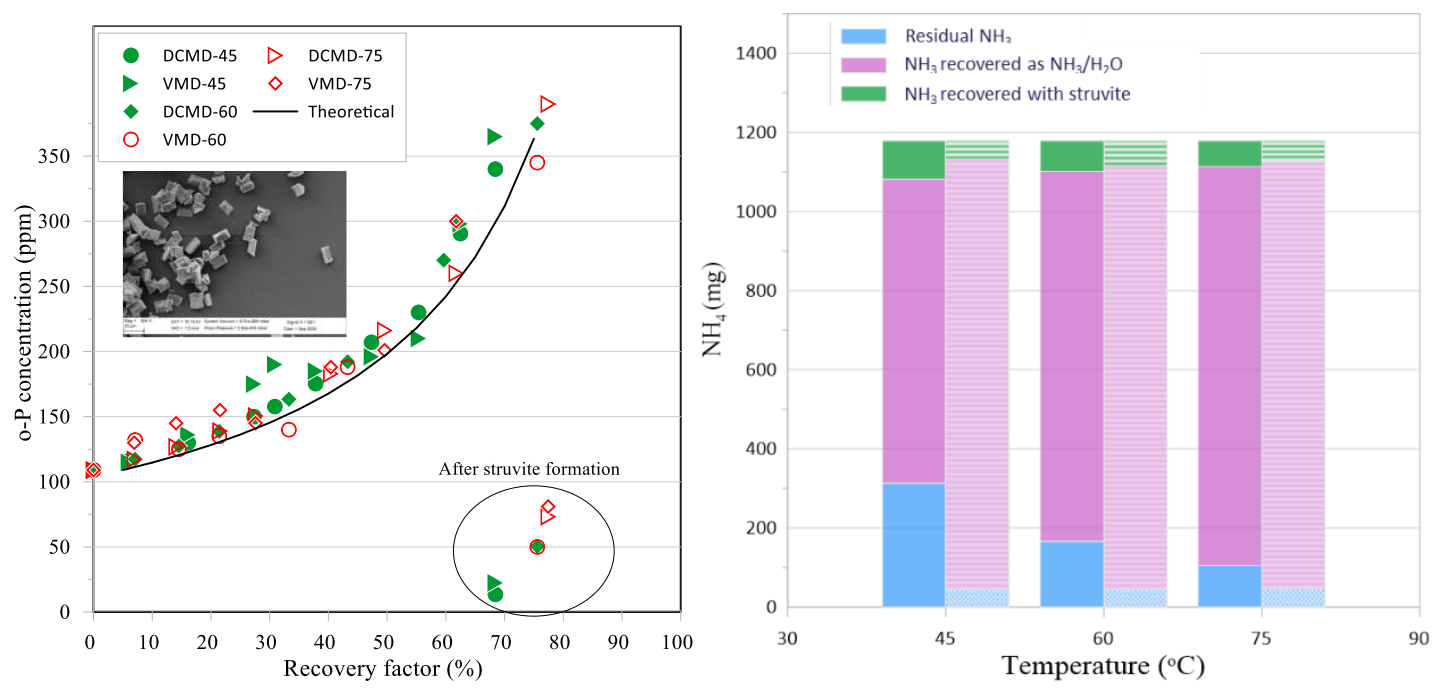

Figure. (left) Concentration of o-P in wastewater as function of water recovery factor when operating MD at 45, 60 and $75^{\circ} \mathrm{C}$. The crystals of recovered struvite have been show in inset (right) $\mathrm{NH}_{3}$ balance in wastewater treated through MD. Solid and patterned bars represent DCMD and VMD, respectively.

Discussion and take-home message: It is possible to recover more than $90 \% \mathrm{NH}_{3}$ and $\mathrm{P}$ from digester centrate of real municipal wastewater through MD without changing its $\mathrm{pH}$. Thus, MD is potentially an important tool to convert wastewater into a source of raw materials.

*aa@bio.aau.dk: Fredrik Bajers Vej 7H, 9220 Aalborg $\emptyset$ st, Denmark

** mlk@bio.aau.dk: Fredrik Bajers Vej 7H, 9220 Aalborg Øst, Denmark 


\title{
Phosphorous recovery from wastewater treatment: testing the bioavailability of $\mathbf{P}$ bound to calcite material for maize (Zea Mays L.) growth
}

\author{
S.M. Jensen, AU Biology/WATEC/SDC*, C. Esposito, AU Bioscience/WATEC**, D. Konnerup, AU Food Science***, H. \\ Brix, AU Biology/WATEC*, C.A. Arias, AU Biology/WATEC*.
}

\begin{abstract}
Phosphorous $(\mathrm{P})$ is a non-renewable resource, and it have been estimated that the reserves will be depleted in the near future. Newly engineered calcite materials could, both improve the P removal in decentralised wastewater treatment systems and enable $\mathrm{P}$ recycling into agricultural production. The effects of $\mathrm{P}$ addition with two $\mathrm{P}$-enriched materials were investigated in a mesocosm experiment with maize plants. The $P$ addition had a significant positive effect on several parameters, however, the plants grown with commercial NPK fertilizers performed significantly better in all measured parameters, suggesting that the material bound $\mathrm{P}$ were not as bioavailable as the commercial fertilizer.
\end{abstract}

Introduction: $\mathrm{P}$ is an essential macronutrient, crucial for plant growth and development. However, $\mathrm{P}$ fertilizers are mainly obtained from phosphate rock reserves, which have been estimated to be depleted within $50-100$ years. $P$ is therefore a non-renewable resource, and the management is important to secure a sustainable food production. One of several solutions would be to increase the recycling of $P$ to the agricultural production. An area with unexploited resources is decentralized wastewater treatment systems that have up to now proven ineffective in sustained $P$ removal. Work under the EU horizon 2020 INCOVER project have been performed to improve the removal with engineered materials with high removal potentials of up to $34.8 \mathrm{mg} \mathrm{P} \mathrm{g}^{-1} \mathrm{DW}$. The material could be installed onsite and improve the $\mathrm{P}$ removal, and ideally, the $\mathrm{P}$ saturated material could be directly added as a $\mathrm{P}$ source. In this experiment, we aim to evaluate the bioavailability of material bound $P$ through plant growth and photosynthetic parameters, as well as, to compare if material bound $P$ is equally as bioavailable as commercial fertilizer.

Methods: Two engineered materials (material I and II) were exposed to $\mathrm{KH}_{2} \mathrm{PO}_{4}$ solutions, preparing the $\mathrm{P}$-enriched materials. The experimental set up consisted of five replicates of 12 treatments (control, NPK fertilizer and 5 levels of the two P-enriched materials). The five material levels were supplied with 6, 12, 25, 50, $100 \mathrm{Kg} \mathrm{P}^{-1} \mathrm{yr}^{-1}$, the NPK treatment with $50 \mathrm{Kg} \mathrm{P} \mathrm{ha}^{-1} \mathrm{yr}^{-1}$, while the control treatment had no P supply. Each experimental unit was composed of a $3 \mathrm{~L}$ plastic pot containing the growth medium mixed with nutrient treatment and a one-week-old pre-germinated maize plant. The plants were grown for 8 weeks in a growth chamber. Every week the morphological parameters (e.g. height, number of leaves and chlorophyll) were measured, and during the last growth week the photosynthetic measurements were performed and the above- and belowground biomass were harvested.

Results: The main effects of the P addition and material type were analysed by two-way ANOVAs. The P addition had a significant effect on the final height and the total biomass. Contrary to our expectations, post-hoc tests revealed that plants grown in the NPK treatment were significantly taller and had a larger total biomass than the remaining treatments. The $\mathrm{P}$ addition had a significant effect on the maximum light-saturated photosynthetic rate and the respiration rate. Likewise, the post-hoc tests revealed that plants in the NPK treatment had significantly higher rates for all photosynthetic parameters compared to all other treatments.

Discussion and take-home message: The increased addition of the P-enriched material resulted both in taller plants, a larger total biomass production and higher performance in the photosynthetic parameters, however, the material bound $P$ was not as bioavailable as the $P$ added with the commercial fertilizer. Nevertheless, the materials still were able to release $P$, suggesting that slow release will occur, and therefore further long-term experiments are needed to clarify the speed and potential total $\mathrm{P}$ released of the materials to be used as $\mathrm{P}$ source and soil amendment.
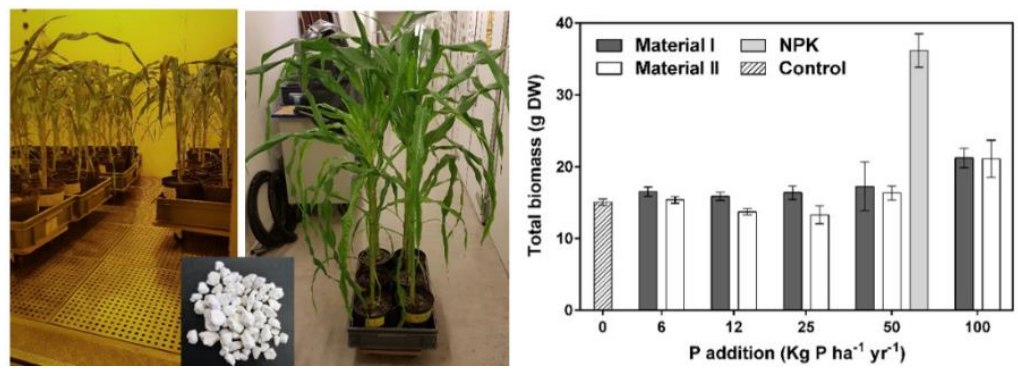

Pictures of the experiment and the material, as well as, a figure showing the effects of increasing P supply when added as P-enriched material (I or II) with five P levels $\left(6,12,25,50\right.$ and $\left.100 \mathrm{Kg} \mathrm{P} \mathrm{ha}^{-1} \mathrm{yr}^{-1}\right)$ on Zea mays total biomass.

*solvei.mundbjerg@bio.au.dk, hans.brix@bio.au.dk, carlos.arias@bio.au.dk: Ole Worms Allé 1, 8000 Aarhus C,DK.

** che@bios.au.dk: Vejlsoevej 25, 8600 Silkeborg, DK, *** dennis.konnerup@food.au.dk: Agro Food Park 48, 8200 Aarhus N, DK. 


\title{
Microflora Danica: Investigation of the microbiome of Denmark with focus on wastewater and wastewater treatment plants
}

\author{
P.H. Nielsen*, A. Murguz**, G. Dottorini***, M. Nierychlo****, V.R. Jørgensen***** \\ Center for Microbial Communities, Aalborg University, Aalborg
}

\begin{abstract}
Introduction: Microflora Danica aims to describe the microbiome of Denmark through analysis of 10,000 representative samples that cover typical Danish habitats, including various water types such as lakes, streams, drinking water and wastewater. We developed and applied novel DNA-based tools that will allow to build a reference database for all microorganisms, and we will provide the first comprehensive overview of prokaryotes and small eukaryotes across Denmark. The vast majority of microorganisms are expected to be novel and previously undescribed. The project is funded by Poul Due Jensen Foundation for the period of 2019-2023. More info can be found on the webpage (www.microfloradanica.aau.dk).
\end{abstract}

This presentation will give an overview of aim, methods, plans, and the first results, primarily from wastewater and wastewater treatment plants.

Methods and data: Together with many collaborators, an intensive sampling program has been established. It includes reproducible sampling procedures from approx. 20 biotopes types (e.g., agriculture soil, forest, coastlines, lakes, steams), collection of metadata (e.g., position, Natura 2000 habitat type), and samples storage. Novel DNA extractions and sequencing procedures, such as full 16S or 18S rRNA gene operon sequencing, have been implemented and new bioinformatic pipelines developed. Presently nearly 4,000 samples are stored (frozen), and many samples are sequenced and further processed. Among those, biomass and influent from approx. 80 wastewater treatment systems have been sampled and approx. half of them analysed.

Results: The microbial diversity in 40 wastewater treatment plants has so far been analysed and more than 3,500 different species are recorded based on their representative DNA sequence. Most of these were novel and never seen before, so their function remains unknown. The majority, however, was present only in very low abundance in the treatment plants and not assumed to be important for the treatment processes. The more abundant fraction only contains few hundred species, which is in accordance with our recent study related to MiDAS, the Field Guide to the microbes of activated sludge (www.midasfieldguide.org). Most species were found across all the treatment plants in Denmark, but some variation could be observed in community composition and structure, depending on overall process type and geographical location. The same overall pattern was found in the influent wastewater, but with a bigger variation in community compared to activated sludge. For some of the most abundant unknown species, we are applying metagenomics to obtain MAGs (metagenome assembled genomes. MAGs are the blueprint for species' function, and examples will illustrate how this can give highly valuable information about novel bacteria.

Discussion and take-home message: Microflora Danica aims to describe the microbiome of Denmark through DNAbased analysis of 10,000 representative samples that cover typical Danish soil and water biotopes. The study of Danish wastewater and activated sludge wastewater treatment plants provides a very comprehensive overview of microbial diversity present and factors affecting their presence and abundance. It addresses some key questions about microbial ecology, and it reveals a huge novelty although the number of novel abundant process-critical species is lower. These are of high priority to study more in depth, help guiding future plant operation and optimization. Furthermore, it is the first step forward toward a better understanding of microbial diversity and transportation among different part of the Danish waterways.

*phn@bio.aau.dk

**admir@murguz.dk

***gd@bio.aau.dk

****mni@bio.aau.dk

*****vrj@bio.aau.dk 


\section{Denitrifiers in activated sludge are particularly vulnerable to nanoplastic pollution}

T.W. Seviour, Aarhus University Centre for Water Technology*, S. Mugunthan** and S. Kjelleberg***, Singapore Centre for Environmental Life Sciences Engineering

Introduction: Nanoplastics (NPs), which are plastics with an equivalent spherical diameter of $<1 \mu \mathrm{m}$, can enter the environment either as primary debris through their inclusion as abrasives, or as a secondary result of weathering (Gigault et al. 2018). How "macro" plastics affect higher organisms by, e.g. asphyxiation, is well understood, however the effects of NP are not. NPs can accumulate in higher organisms. Understanding their effect on biological systems has been identified as a scientific priority (Mitrano et al. 2019). They can also disrupt microbial processes. Sun et al. (2018) demonstrated that NPs and not microplastics inhibited ammonium conversion by marine bacterium Halomonas alkaliphilia, by inducing reactive oxygen species (ROS) production. Furthermore, silver nanoparticles achieved $36 \%$ inhibition of nitrate reduction by Pseudomonas stutzeri at a concentration of $12.5 \mathrm{ppm}$, due to ROS production induced ty the NPs and not silver release (Wu et al. 2020). N-transforming microorganisms are immobilized in either floccular or granular biofilms, where the latter has a higher concentration of extracellular polymeric substances (EPS). EPS have been shown to infer tolerance to bacteria for a whole range of environmental stresses (Seviour et al. 2020). We hypothesized that EPS would provide bacteria with increased tolerance to NP stress and sought to describe the extent of inhibition of various microbial N-biotransformations by NPs in granular and floccular sludges.

\section{Methods and data:}

- Batch activity studies on laboratory and full scale granular and floccular sludges respectively, to assess effect of NPs on $\mathrm{N}$ removal rates by nitrification, denitrification, anammox and denitritation.

- NP uptake assessed by means of fluorescence microscopy

- Reactive oxygen species (ROS) production assessed by ROS sensitive fluorescence biomarkers

- ROS sensitivity assessed by addition of ROS generation agent (tert-butyl hydroxide)

- Population analysis by next generation sequencing and Fluorescence In Situ Hybridization

- NP toxicity assessed by Live-Dead staining

\section{Results:}

- $50 \%$ inhibitory concentration of NPs for nitrate reduction was ten times lower than previously reported for NPs (see Figure $A$ for inhibition curve), $10^{2}$ times higher than for anammox, and $10^{3}$ times higher than for nitrite reduction of nitrification. Inhibition of denitrification was achieved for all NP surface functionalities.

- Uptake by NPs by biomass was very specific for bacteria, with Chloroflexi in particular showing a high affinity for the NPs. See Figure B and C for NP uptake (blue) by Chloroflexi (red) in activated and granular sludges respectively).

- ROS production (red) is induced by NP exposure even in sludges that do not take up NPs (green) (Figure D)

- Bacteria in granular sludge were more likely to upon NP exposure than those in floccular sludges

- Many bacteria that take up NPs also have nitrate reductase enzyme (based on antibody binding)

Denitrification and nitrification display very similar inhibition to ROS generation agent.
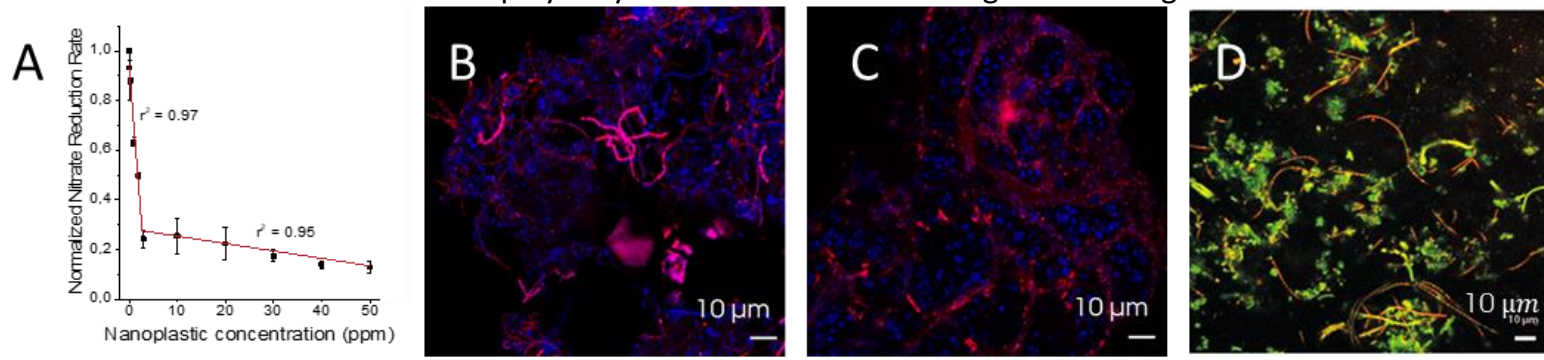

Discussion and take-home message: Denitrification in wastewater treatment plants is several orders of magnitude more sensitive to inhibition by NPs than other N-biotransformation processes, though there is not enough information regarding environmental NP concentrations to know if we should be concerned. NP exposure elicits ROS production across a range of populations, though despite literature neither this, nor cell death, appear to be responsible for NPinhibition of denitrification. The matrix does not protect cells from NP-stress.

\footnotetext{
* twseviour@eng.au.dk: Nørrebrogade 44, Building 1783 DK-8000 Hørsholm, Denmark

** mugunthan@ntu.edu.sq: SCELSE, NTU, Singapore 637551

*** laskjelleberg@ntu.edu.sg : SCELSE, NTU, Singapore 637551

References
} 
Gigault, J., Ter Halle, A., Baudrimont, M., Pascal, P.-Y., Gauffre, F., Phi, T.-L., El Hadri, H., Grassl, B. and Reynaud, S. (2018) Current opinion: What is a nanoplastic? Environmental pollution 235, 1030-1034.

Mitrano, D.M., Beltzung, A., Frehland, S., Schmiedgruber, M., Cingolani, A. and Schmidt, F. (2019) Synthesis of metaldoped nanoplastics and their utility to investigate fate and behaviour in complex environmental systems. Nature Nanotechnology 14(4), 362-368.

Seviour, T., Wong, L.L., Lu, Y., Mugunthan, S., Yang, Q., Shankari, U., Bessarab, I., Liebl, D., Williams, R.B.H., Law, Y. and Kjelleberg, S. (2020) Phase Transitions by an Abundant Protein in the Anammox Extracellular Matrix Mediate Cell-toCell Aggregation and Biofilm Formation. 11(5), e02052-02020.

Sun, X., Chen, B., Li, Q., Liu, N., Xia, B., Zhu, L. and Qu, K. (2018) Toxicities of polystyrene nano-and microplastics toward marine bacterium Halomonas alkaliphila. Science of The Total Environment 642, 1378-1385.

Wu, L., Zhu, G., Zhang, X. and Si, Y. (2020) Silver nanoparticles inhibit denitrification by altering the viability and metabolic activity of Pseudomonas stutzeri. Science of The Total Environment 706, 135711.

\title{
Putting MABR technology to the test at the Ejby Mølle WRRF
}

\author{
N. Uri Carreño, P.H. Nielsen, Vandcenter Syd *, X Flores-Alsina, Krist V. Gernaey, DTU Chemical and Biochemical \\ Engineering**
}

\section{Summary}

Utilities around the world are increasingly being challenged to "do more with less", and this is particularly true with respect to both energy efficiency and process intensification, while still achieving or improving upon effluent targets. Membrane aerated biofilm reactor (MABR) technology is recognised as a highly attractive technology that promises to achieve both goals. Since June 2018, Vandcenter Syd (VCS) Denmark has been testing four full-scale MABR units in a hybrid (IFAS type) configuration. The demonstration is equipped with several online instruments that allow for continuous data acquisition of nitrification rates and oxygen transfer rates, among others. This study has been able to demonstrate the feasibility of applying MABR technology under Danish/Nordic conditions.

\section{Methods:}

VCS Denmark, in collaboration with Jacobs and Aarhus Vand, started a full-scale demonstration of membrane aerated biofilm reactor (MABR) technology at its Ejby Mølle WWRF in 2018, with the objective of determining whether this technology could be suitable for improved energy efficiency and process intensification at full-scale. Four full-scale cassettes, two each of the SUEZ and Oxymem MABR technologies, are being operated in a hybrid (i.e. IFAS type) configuration using feed from the existing anaerobic selector ahead of the existing nitrification-denitrification reactors of the plant, as can be seen in Figure 1. The demonstration is equipped with several on-line instruments that allow for

continuous data acquisition of nitrification rates, oxygen transfer rates and $\mathrm{N}_{2} \mathrm{O}$ emissions, among others. Besides data acquisition from on-line instrumentation, grab samples are analysed twice a week to measure other parameters such as $\mathrm{PO}_{4}-\mathrm{P}, \mathrm{TSS}, \mathrm{VSS}$ and COD. The full-scale units are regularly (every 3-6 months) lifted up from the reactors to carry out visual inspections and biofilm sampling.

\section{Results:}

The demonstration study faced challenges during its first year in operation due to the low redox conditions in the feed, which caused the formation of a black coating on the membranes, probably FeS. Since September 2019, when fine bubble aeration was added to the reactor to reverse this issue, MABR has shown to be a feasible compact and energy efficient alternative to conventional activated sludge. The MABR units proved to be easy to install and operate, and debris accumulation or clogging was not a concern. Results from the pilot demonstration show the reactors were able to continuously nitrify and denitrify simultaneously within a single reactor, achieving total nitrogen effluent values lower than $0.5 \mathrm{mg} \mathrm{N} / \mathrm{L}$. Wet weather and low temperatures did not impact the performance negatively and the energy consumption was significantly lower than for conventional fine bubble diffusion. 

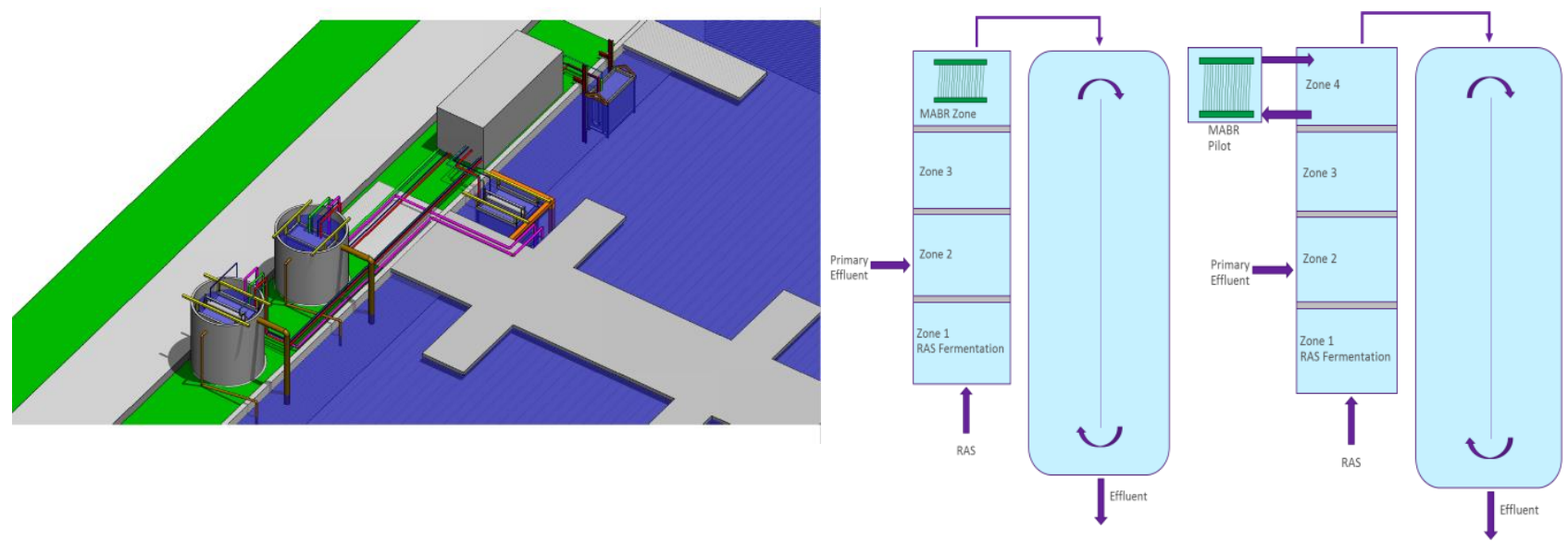

*nur@vandcenter.dk,phn@vandcenter.dk:Vandværksvej 7, Odense, 5000 Denmark

**1xfa@kt.dtu.dk, kvg@kt.dtu.dk : Process and Systems Engineering Center (PROSYS) Technical University of Denmark. Department of Chemical and Biochemical Engineering. Søltofts Plads Building 227 (Postal address: Building 228 A). DK - 2800 Kgs. Lyngby 


\section{Session 6: Taking a moment - Bridging Seniors and Young Water Professionals}

4. March 13:00 - 16:00, Teams

Organizers: Ines Breda, and moderators, Agnete Ansbæk and Eirini R. Kouzi, Young Water Professionals

This workshop will facilitate communication across generations in the water sector through a series of presentations by guest speakers and panel discussions. The workshop will include guest from the industry and the public sector. You will gain insight on the career path and ambitions of prominent seniors professionals. You will get to know their biggest mistakes and biggest accomplishment. You will get the opportunity to get advice and perspective on your own career.

Tentative program:

15 min Setting up, Intro of topic plus Hi to all studios

5 min Launching the conversation: Take a moment to see what today's challenges are and in what scale of severity and urgency.

10 min Speaker 1 on: Career how this was 30-50 years ago, which were the challenges, were you able to identify them at the time? Did you foresee the challenges of today?

10 min Panel in Studio 1. Do they agree? What do they have to add?

In the meantime, audience is making questions for either panelists or speaker.

10 min Q\&A from audience

5 min BREAK

10 min Speaker 2 on: "What advice would you give to a younger you? "

$10 \mathrm{~min} \quad$ Panel in Studio 2. Do they agree? What do they have to add? Soft Skills vs Technical Skills In the meantime, audience is making questions for either panelists or speaker.

10 min Q\&A from audience

NO ABSTRACTS: It is an online workshop 


\section{Session 7: Water Resources}

18 March 2021, 13:00 - 16:00, Teams

Chair: Esben Auken, GEUS. Co-chair: Anders Refsgaard, COWI.

13:00 Esben Auken: Welcome

13:05 Jesper Dannisøe: Logistics

13:10 Using machine learning to downscale climate change-induced changes to the shallow groundwater table: Raphael Schneider, H. J. Henriksen, J. Koch, S. Stisen

13:25 Assessing the effect of shallow hydrogeology on water table depth variation and potential nitrate reduction in subsurface drained clayey till area: Hafsa Mahmood, R.R. Frederiksen

13:40 A concept for hectare-scale nitrate retention mapping by full integration of geophysical, geological, geochemical and hydrological data: Rasmus R. Frederiksen, A.V. Christiansen, N. Claes, T.N. Vilhelmsen, H. Kim, B. Hansen, E. Auken

13:55 Test of bacterial isolates to improve nitrate removal efficiency in woodchip bioreactors at low temperature: Arnaud Jéglot, S. R. Sørensen, K. M. Schnorr, F. Plauborg, L. Elsgaard

14:10 Break

14:25 Direct Sampling - Quantifying what we know and filling in what we do not know. Niels Claes, Vilhelmsen T.N., Frederiksen R.R., Kim H., Foged N.,Christiansen A.V.

14:40 Vertical flow constructed wetlands to treat water contaminated with cyanotoxins. Pedro N Carvalho, A. Potokar, LIMNOS, C.A. Ramirez-Vargas

14:55 Electrokinetic remediation of contaminated sites: Advances from process-based simulations and machine learning: Riccardo Sprocati, M. Rolle

15:10 Vacant

15:25 Esben Auken, Anders Refsgaard: Closing remarks 


\title{
Using machine learning to downscale climate change-induced changes to the shallow groundwater table
}

\author{
R. Schneider*, H. J. Henriksen**, J. Koch***, S. Stisen****
}

Introduction: Within the establishment of the public Hydrologisk Informations- og Prognosesystem (HIP4Plus/FODS6.1 Initiativ om fælles data om terræn, klima og vand), a distributed hydrological model for all of Denmark with focus on the shallow groundwater table and surface water runoff was created. This model is based on the DK-model (www.vandmodel.dk), set up in MIKE SHE, and run both with model grid sizes of $500 \mathrm{~m}$ and $100 \mathrm{~m}$. Part of HIP is the assessment of the impact of climate change on the future shallow groundwater table across Denmark, where potential users are interested in high-resolution data (i.e. $100 \mathrm{~m}$ ). National climate change impact assessments were carried out for a large ensemble of climate models using the $500 \mathrm{~m}$ resolution hydrological model. Computational limitations linked to the hydrological model inhibited carrying out a similar approach in the desired $100 \mathrm{~m}$ resolution. To overcome this limitation, we employed machine learning-based (ML) algorithms to produce nationwide climate change signals in the shallow groundwater table in $100 \mathrm{~m}$.

Methods and data: Five selected catchment models (covering around 9\% of Denmark) were run with five selected climate models in $100 \mathrm{~m}$ resolution. Using the simulated changes in $100 \mathrm{~m}$ resolutions from those models as target, combined with a set of co-variates including the simulated changes in $500 \mathrm{~m}$ resolution, we trained ML algorithms to downscale simulated changes from $500 \mathrm{~m}$ to $100 \mathrm{~m}$.

Results: Using those ML algorithms, we created Denmark-wide maps of expected changes to the shallow groundwater table for two future periods and two greenhouse gas concentration scenarios in $100 \mathrm{~m}$. Included statistics were the change in the mean depth to the groundwater table, $1 \%$ and $99 \%$ quantiles, exceedance probabilities and return periods for groundwater level events.
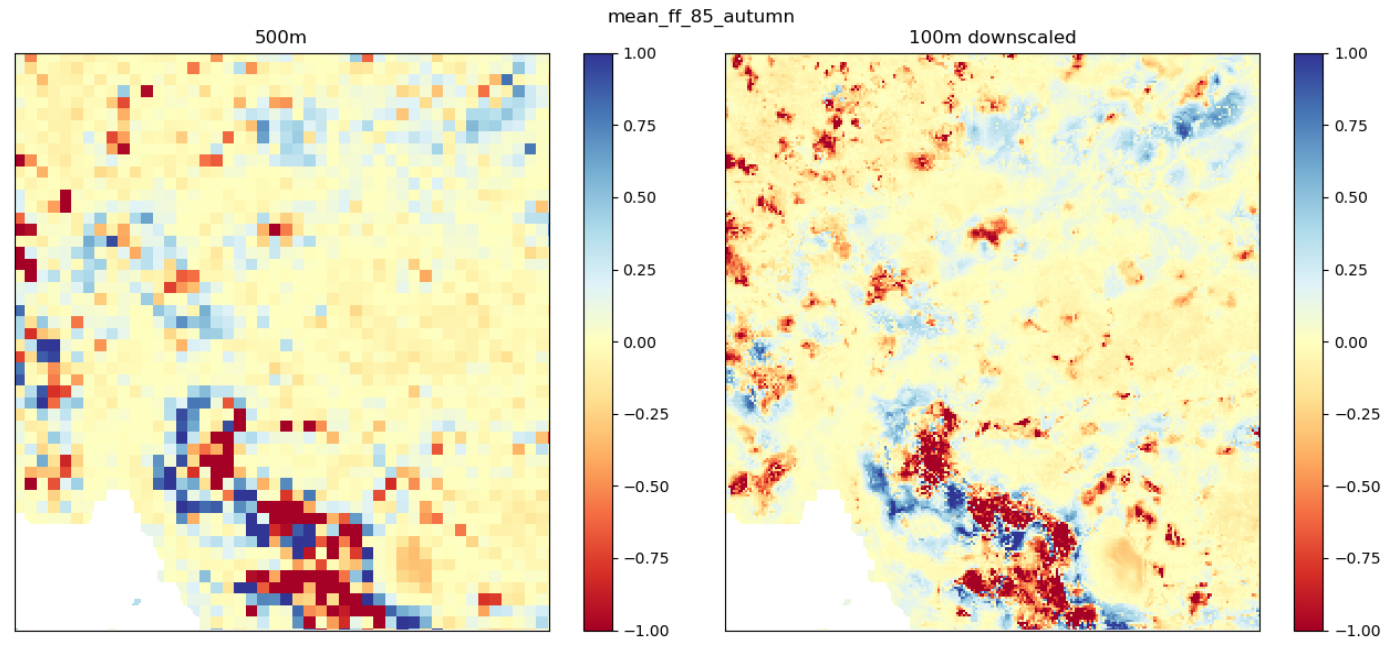

Figure 4. Change to the mean depth to the shallow groundwater table in autumn for the period $2070-2100$ and RCP8.5. Left: $500 \mathrm{~m}$ hydrological model results. Right: $100 \mathrm{~m}$ ML downscaling. Changes are given in metres, as future - reference.

Discussion and take-home message: The use of machine learning-based downscaling allowed to produce climate change predictions for the changes of the shallow groundwater table in unprecedented resolution of $100 \mathrm{~m}$. To verify the downscaling results, the machine learning algorithms were successfully cross-validated against results from actual hydrological models in $100 \mathrm{~m}$ for the five selected submodels. The experience gained also opens for various other applications of similar algorithms where computational limitations inhibit running distributed hydrological model in fine resolution.

*rs@geus.dk, ** hjh@geus.dk,***juko@geus.dk, ****sst@geus.dk

All authors: De Nationale Geologiske Undersøgelser for Danmark og Grønland (GEUS), Øster Voldgade 10, 1350 København K, Denmark 


\title{
Assessing the effect of shallow hydrogeology on water table depth variation and potential nitrate reduction in subsurface drained clayey till area
}

\author{
Hafsa. Mahmood*, R.R. Frederiksen**, Hydro Geophysics Group, Department of Geoscience, Aarhus University
}

\begin{abstract}
Loss of nutrients from agricultural fields is one of the largest challenges for a sustainable agricultural sector. The current nitrate $(\mathrm{N})$ regulation in Denmark is implemented on a scale of approx. 15 square $\mathrm{km}$ in so-called ID15 catchments. However, $\mathrm{N}$-retention varies between agricultural fields within ID15-catchments. Variation in $\mathrm{N}$-retention between fields is controlled by $\mathrm{N}$-retention in the root zone and the saturated zone, $\mathrm{N}$-retention in the riparian zone, and drain flow fraction. Yet, current mapping of N-retention on ID15 scale is not considering the N-retention in the root zone. In subsurface drained clayey areas, variation in water table depth potentially affects the variation in $\mathrm{N}$-retention in the root zone. In this presentation, we will assess the effect of shallow hydrogeology on water table depth variation for a case site.
\end{abstract}

The overall approach is to identify which hydrogeological variables (i.e. input factors) that control water table depth variation in the root zone (quantity of interest) using a groundwater flow model. We are collecting hydrological data (water table depths in piezometers and drain flow at the outlet) and geophysical data (electrical resistivity of the subsurface). The geophysical data are collected using two ground-based electromagnetic systems (DUALEM and tTEM). Areas with no geophysical data are simulated using Multi Points Statistics. The electrical resistivities are directly translated to hydraulic conductivities based on a threshold value. Hydraulic properties are assigned to each zone then. We generate a number of groundwater flow models (realizations) which have varying spatial distribution of hydraulic zones and varying hydraulic properties (input factors). The variation in input factors are related to variation in simulated water table depths and drain flow at the outlet using a one-at-a-time sensitivity analysis.

The sensitivity analysis of the model boundary conditions (recharge and water flow across the surface watershed) are under process. Furthermore, we are working on including drain flow fraction in the analysis as quantity of interest. Drain fraction is calculated as the ratio of generated drain flow within an area to the net precipitation within the same area. Data about model boundary conditions are obtained from the national hydrological model. The results of the study will provide information about key controlling factors of water table depth based on which estimation of $\mathrm{N}$-retention variation between fields can be predicted. For the presentation, we will show examples for a case site in eastern Jutland, Denmark. The focus is to explore the relationship between hydrogeological variables and water table depth. We will show preliminary results and discuss possible implications for assessing drain fraction and potential nitrate reduction.

* hm@geo.au.dk, C.F. Mollers Alle, Aarhus, 8000, Denmark

** rasmus.rumph@geo.au.dk, C.F. Mollers Alle, Aarhus, 8000, Denmark 


\title{
A concept for hectare-scale nitrate retention mapping by full integration of geophysical, geological, geochemical and hydrological data
}

R.R. Frederiksen*, A.V. Christiansen, N. Claes and T.N. Vilhelmsen, Department of Geoscience, Aarhus University H. Kim, B. Hansen and E. Auken, Geological Survey of Denmark and Greenland (GEUS)

\begin{abstract}
We present a concept integrating information from geophysical, geological, geochemical and hydrological data to predict nitrate retention in the open landscape on hectare-scale. For intensively farmed catchments, delineation of vulnerable or robust areas is an important factor for reducing the impact of agricultural nitrogen ( $N$ ) to the aquatic environments. The regulation is intended to be at the hectare scale which puts very high demands to the amounts and quality of data needed. The new concept has been developed in the rOpen and MapField projects bringing together scientists, farmers and other stakeholders. In the projects the goal is to make a data-driven and transparent tool where an essential element is the incorporation of uncertainty in both the geological, geochemical and hydrological modelling and its implications for uncertainty on the predictions of N-retention from agricultural fields to streams. In short, the concept comprises the following key elements:
\end{abstract}

1. Geophysical mapping using tTEM. tTEM is an ATV-towed system which maps the upper $70 \mathrm{~m}$ of the subsurface in high 3D resolution with data for each ten meters along driving tracks and $20 \mathrm{~m}$ between lines. On average 150 ha are mapped per day and all accessible fields are mapped.

2. Hydrostratigraphical modelling. An ensemble of realizations of the 3D hydrostratigraphy is generated using Multi-Point-Statistics (MPS). The training image used in MPS is a 3D hydrostratigraphical model based on a geostatistically combination of geological information from boreholes and geophysical resistivity models from tTEM.

3. Geochemical modelling. An ensemble of realizations of the 3D redox zones is generated using MPS. The training image is a cognitive interpretation of the $3 D$ redox conditions based on a combination of information from boreholes and geophysical resistivity models from tTEM. Moreover, the $\mathrm{N}$ reduction rate and uncertainties are assigned for each redox zone based on laboratory analysis of core samples.

4. Root zone modelling. A root zone model is sequentially coupled to the groundwater flow model to simulate Nleaching and water percolation from the root zone to the saturated zone based on agricultural practice, soil types, and climate data.

Items 1-4 are then used to create an ensemble of groundwater models, which then ideally complies with all the acquired data and generated realizations. A particle-tracking module is attached at the end of each groundwater flow simulation to simulate transport of $\mathrm{N}$, and the total amount of $\mathrm{N}$ removal via $\mathrm{N}$ reduction reactions along a pathway in the saturated zone is calculated.

All of the above inputs are integrated through a script-based modelling framework which is data-driven, flexible (in terms of data type, data format, and model setup), reproducible and cost-effective.

The presentation summarizes the central aspects of the concept with a focus on the hydrological modelling including an in-depth discussion of the uncertainties. Finally, we show an example in which the concept is used to predict $\mathrm{N}$ retention on a hectare-scale in Denmark.

* rasmus.rumph@geo.au.dk, CF Møllers Alle 4, bygn. 1120, 8000 Aarhus C 


\section{Test of bacterial isolates to improve nitrate removal efficiency in woodchip bioreactors at low temperature}

A. Jéglot, WATEC and Aarhus University Dept of Agroecology*, S. R. Sørensen, Novozymes A/S**, K. M. Schnorr, Novozymes A/S***, F. Plauborg, WATEC and Aarhus University Dept of Agroecology****, L. Elsgaard, Aarhus

University Dept of Agroecology*****

\section{Introduction}

Mitigation of nitrogen $(\mathrm{N})$ leaching from agricultural land to freshwater ecosystems is important to protect natural ecosystems from eutrophication. Woodchip bioreactors have proven their efficiency in converting nitrate- $\mathrm{N}$ in agricultural drainage water to molecular nitrogen $\left(\mathrm{N}_{2}\right)$ gas before the nitrate reaches streams and subsequent water bodies. However, the biological nitrate removal (denitrification) is sensitive to temperature changes, and has a low rate during the peak of the Danish drainage period in the winter when the water temperature drops below $10^{\circ} \mathrm{C}$. Adding specific strains of bacteria to increase nitrate removal efficiency during the colder periods is a technology known as bioaugmentation, which has been applied successfully in similar ecosystems. The present study focuses on the selection of bacterial strains with potential application for bioaugmentation of woodchip bioreactors.

\section{Methods and data}

Out of a larger collection, 11 bacterial strains isolated from soil, sediments and woodchip bioreactors, were selected for assays to determine denitrification efficiency, robustness and adaptability of the different strains. The preselection of the strains was conducted based on their genomes by validating the presence of known genes associated with dissimilatory denitrification. During the assays, the bacteria were grown in media supplemented with nitrate and different carbon sources. First, nitrate removal efficiency of the different strains was assessed under anoxic conditions; then the strains were challenged by providing various growth conditions: presence of oxygen, low and high carbon to nitrogen ratio, and diverse carbon sources. Finally, a bioaugmentation assay in batch cultures was conducted at 5 and $10^{\circ} \mathrm{C}$. The selected strains were added to an existing mixed bacterial community enriched from a woodchip bioreactor. Subsequently nitrate removal and taxonomic bacterial abundances were monitored (by $16 \mathrm{~S}$ rRNA microbiome analysis) to assess the impact of the addition of the selected bacterial strains.

\section{Results}

Three bacterial strains belonging to the genus Pseudomonas showed consistent growth and denitrification efficiency during the assays. During the bioaugmentation batch assay, the addition of these strains resulted in a significantly higher abundance of the genus Pseudomonas in the bioaugmented cultures, especially at $5^{\circ} \mathrm{C}$. Yet, since the mixed culture already showed proficient nitrate removal, no increase in nitrate removal rates was observed.

\section{Discussion and take-home message}

The results highlight the large potential of bacteria belonging to the genus Pseudomonas for biological water treatment and nitrate reduction. The three selected strains are promising candidates for bioaugmentation in woodchip bioreactors as they were able to colonize the ecosystem and denitrify at low temperature.

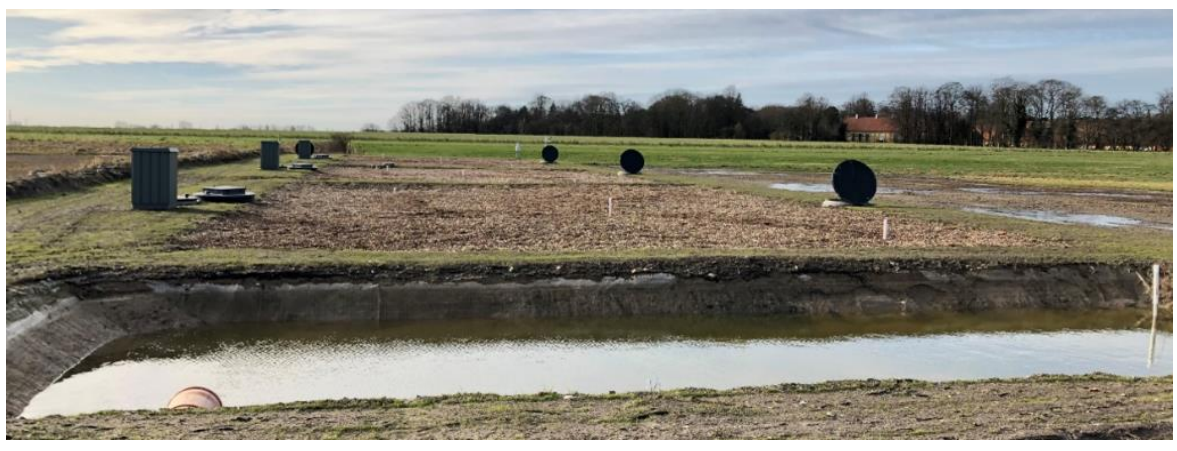

* arnaud.jeglot@agro.au.dk: Blichers Allé 20 DK-8830 Tjele

**srsq@novozymes.com: Biologiens vej 2, 2800 Kgs. Lyngby

***kksc@novozymes.com: Biologiens vej 2, 2800 Kgs. Lyngby

**** finn.plauborg@agro.au.dk: Blichers Allé 20 DK-8830 Tjele

***** lars.elsgaard@agro.au.dk: Blichers Allé 20 DK-8830 Tjele 


\title{
Direct Sampling - Quantifying what we know and filling in what we do not know
}

\author{
Claes N. ${ }^{(1)}$, Vilhelmsen T.N. ${ }^{(1)}$, Frederiksen R.R. ${ }^{(1)}$, Kim H. ${ }^{(2)}$, Foged N. ${ }^{(1)}$, \& Christiansen A.V. ${ }^{(1)}$ \\ (1) Aarhus University, Department of Geoscience, HydroGeophysics Group, Aarhus, 8000, DK \\ (2) GEUS, Groundwater and Quaternary Geology Mapping, Aarhus, 8000, DK
}

\begin{abstract}
The development of groundwater models has several challenges associated with it. One of the main challenges in groundwater modeling is the incorporation of uncertainty in the structural development of the models. Structural limits or boundaries, derived from geophysical or based on few point observations have uncertainties associated with them due to uncertainty in measurements or inversion results, or limited data availability. Another challenge is that datasets that are used to derive structural input for groundwater models often suffer from variations in spatial data density or areas without any data. Classical two-point statistical methods to remediate these data-gaps, such as kriging, have difficulties simulating complex geological patterns. Furthermore, if complex relationships between different continuous variables (e.g. resistivity) and discrete variables (e.g. hydrogeological units) exist, these should also be represented in the constructed models.
\end{abstract}

We used the Direct Sampling (DS) method to overcome these challenges in the process of creating structural input to groundwater models and their associated redox-structures for investigation of the fate of nitrate in the subsurface. With DS we co-simulate hydrogeological structures and geochemical structures (redox) and thereby maintaining the complex relation between these variables in the simulations. This method searches via a random path in a training image for an area that exhibits a similar spatial pattern as the area around the cell that is being simulated in the model. It subsequently copies this value into the simulated grid and continues to the next cell that will be simulated. This process is repeated for hundreds of simulations, following different paths, which results in an ensemble of models that represents a similar complexity as the training image(s). In other words, all the realizations will be in agreement with the input data (e.g. geophysical models, boreholes, training image) and they will be in internal agreement as they are co-simulated.

We incorporate the uncertainty in the training data through filtering between hard data and soft data based on probability distributions. The hard data are the points that are kept constant between each simulation and are used to condition the simulations. While the soft data are only present in the training data. This results in variability between simulations driven by our uncertainty and spatial availability of data.

The result of this approach is an ensemble of groundwater models and redox-structure models that is evaluated for entropy, which is a measure of variability in between the models. A higher entropy value would mean an area where the simulated models show a lot of variability between each other and might indicate uncertainty about groundwater model structure or the redox-structure. A second measure to evaluate the simulations and our conceptual understanding of the system is to analyze how well the training image is represented in the simulated set of redox structures through scoring functions. If the majority of the simulations does not follow the training image in a particular area, this might indicate that we need to collect more data or evidence to support our training image in that area, or that we need to reconsider our conceptual understanding of the system.

DS is a powerful method to incorporate uncertainty in the data used to develop models, and quantify how this affects the ensemble of constructed models afterwards. Using this in the context of groundwater and redox-structural modeling, allows for incorporation of complex relations between geological structures and redox-states, inclusion of the uncertainty associated with the input data in the simulations, and evaluation of our understanding of the system. 


\title{
Vertical flow constructed wetlands to treat water contaminated with cyanotoxins \\ P.N Carvalho, AU-ENVS \& WATEC*, A. Potokar, LIMNOS**, C.A. Ramirez-Vargas, AU-BIO***, C.A. Arias AU-BIO \& \\ WATEC****
}

\begin{abstract}
Introduction: Fresh water resources are becoming vulnerable and limited worldwide, especially with the climate change and the increasing drought periods. Thus, higher eutrophication of water bodies is occurring with the consequent increase of incidence and intensity of Cyanobacterial Harmful Algal Blooms (CyanoHABs). Under water scarcity conditions, these eutrophic bodies containing cyanobacteria and respective toxins are often the only available source. If the drinking water sector is highly controlled, the same is not true for agricultural purposes. In fact, cyanotoxins contaminated water is being used for agricultural irrigation.

Constructed wetlands, as low-cost nature-based solutions with proven capacity to clean many different types of water are potentially a solution. Studies reporting the capability of aquatic plants and microorganism sediment-communities to remove/degrade different cyanotoxins from the water are encouraging. Therefore, under the EU-project TOXICROP and danish project WETCYANO, we are studying whether constructed wetlands can be used to enable irrigation from contaminated surface water bodies.
\end{abstract}

Methods and data: We are currently developing the first laboratory-scale trials to assess whether i) cyanotoxins can be removed by CWs, and ii) what is the overall fate of the biomass and the toxins in the system. We set up a total of 18 microcosms (12 L each) mimicking vertical flow (unsaturated) systems. In triplicate, we are comparing, sand or gravel as filter media, as well as 3 vegetation options: unplanted, planted with Phragmites australis or Juncus effusus. Systems are being fed with synthetic water mimicking a eutrophic surface water body containing $10 \mu \mathrm{L} \mathrm{L}^{-1}$ of the cyanotoxins microcystin-LR and cylindrospermopsin. System we set up in the early summer 2020, acclimatized for 1month and the first exploratory tests conducted, herein reported.

Cyanotoxins concentrations have been measured by HPLC-MS/MS. Ongoing analytical work by LC-HRMS will try to understand the biotransformation pathways of the cyanotoxins. Several water quality endpoints (e.g. pH, TOC, TN) were monitored, or at least samples were collected for the respective analysis.

Results \& discussion: First results points towards a better performance of sand- than gravel-based systems. No major differences can be seen between planted or unplanted microcosms. Nevertheless, removal efficiency presented high variability within a $48 \mathrm{~h}$ period. This might be due to: 1 ) up-concentration effects due to high evapotranspiration; 2 ) mesocosms were still adapting, the missing data on the water quality endpoints should also clarify this; 3 ) the microbial community might have been disturbed by the sudden spike of cyanotoxins, a second experiment to characterize the biofilm structure and potential changes is also underway. The HRMS data is expected to confirm if biotransformation occurred and under which biodegradation pathways.

Take-home message: Preliminary results are encouraging to explore the potential of vertical flow constructed wetlands to treat water contaminated with cyanotoxins.

Acknowledgment: This research has received funding from the European Union's Horizon 2020 research and innovation programme under the Marie SkłodowskaCurie grant agreement No 823860, and the Independent Research Fund Denmark.

* pedro.carvalho@envs.au.dk; Frederiksborgsvej 399, Roskilde, 4000, Denmark

**anja@limnos.si; Podlimbarskega 31, 1000 Ljubljana, Slovenia

***c.a.ramirez@bio.au.dk; Ole Worms Alle 1, Aarhus C, 8000, Denmark

**** carlos.arias@bio.au.dk; Ole Worms Alle 1, Aarhus C, 8000, Denmark 


\title{
Electrokinetic remediation of contaminated sites: Advances from process-based simulations and machine learning
}

\author{
R. Sprocati, DTU Environment*, M. Rolle, DTU Environment**
}

\begin{abstract}
The modeling of electrokinetic remediation (EKR) is fundamental for quantitative understanding, design and upscaling of this promising in situ technology. However, it is a challenging task due to the complex interplay between solute transport, fluid flow, electrostatics and biogeochemical processes that occur in porous media during EK treatment. In this work we present a novel reactive transport software, NP-Phreeqc-EK, which can simulate a wide variety of biogeochemical processes during EKR. The capabilities of NP-Phreeqc-EK to model complex field settings, are demonstrated in a pilot-scale application of electrokinetically-enhanced bioremediation (EK-Bio) targeting chlorinated ethenes. Finally, we describe how we integrated NP-Phreeqc-EK within a machine learning workflow to reduce the computational costs of more than 3 orders of magnitude, thus allowing the possibility of real-time model evaluations.
\end{abstract}

\section{Introduction:}

Electrokinetic remediation is an in-situ technique that uses electrodes placed in boreholes to apply a direct current in subsurface porous media. The resulting electric potential field results in two transport phenomena, proportional to the electric potential gradient: (i) electromigration, consisting in the displacement of charged ions towards the electrode of opposite charge and (ii) electroosmosis, that for soils at near-neutral $\mathrm{pH}$ results in the movement of bulk water from the anode to the cathode. EKR is typically used for the remediation of low-permeability soils (e.g. silt and clay), in which hydraulic flushing is impractical and species' distribution as a result of electromigration and electroosmosis would be orders of magnitudes larger than what could be achieved by advection and/or diffusion.

To model the multiphysics interactions occurring during EKR and to be able to account for geochemical and biochemical reactions, we developed a new software: NP-Phreeqc-EK. The code has been tested in a series of benchmark problems and has been applied for the process-based modeling of a pilot application of EK-Bio, in which an electron donor (lactate) and a strain of specialized exogenous degraders (KB-1) were delivered electrokinetically in a low-permeability zone, to promote in situ biodegradation of tetrachloroethylene (PCE) to the non-toxic ethene.

\section{Methods and data:}

The pilot scale application of EK-Bio was inspired from a real implementation performed in Skuldelev (Denmark). In our work, we simulated the electrokinetic delivery of lactate and the microbial consortium KB-1 and evaluated the spatial distribution and total mass of the initial chlorinated ethenes and reaction products in the system over one year. NP-Phreeqc-EK was used to model the complex processes occurring during EKR. The software consists of a coupling between the flow and transport code COMSOL Multiphysics and the geochemical code PHREEQC. The advantages of this architecture include the flexibility of COMSOL Multiphysics in terms of physics design, customization, meshing and boundary conditions, solver efficiency and direct integration with MATLAB, which facilitated the communication with the reactive module of PHREEQC, PhreeqcRM, which is a C++ module optimized for shared-memory multiprocessing. Finally, we used a High Performance Computing (HPC) cluster to distribute several process-based models to train a surrogate model, which uses an Artificial Neural Network algorithm to relate the input variables with different performance indicators.

\section{Results:}

The process-based simulation of EK-Bio included: (i) multidimensional EK transport in saturated porous media, (ii) charge interactions, (iii) geochemical reactions, (iv) microbial populations dynamics of indigenous and specialized degraders (KB1), (v) biodegradation kinetics of the different chlorinated compounds and (vi) contaminant mass transfer between NAPL and dissolved phase. With the development of surrogate models it was then possible to evaluate the model in real-time, thus allowing exploration of model scenarios, sensitivity analysis, uncertainty analysis and probabilistic assessment of different remediation configurations, instrumental for design and optimization.

\section{Discussion and take-home message:}

NP-Phreeqc-EK was successfully benchmarked and demonstrated to be suitable to model EKR in field settings. Moreover, the development of a surrogate model within the implemented framework proved to be successful and we envision future uses in collaborative sessions between environmental engineers, public authorities and stakeholders. * risp@env.dtu.dk :, ** masro@env.dtu.dk: Bygningstorvet, Bygning 115, 2800 Lyngby 
